(Aus der Universitäts-Augenklinik in Leipzig.)

\title{
Pathologisch-anatomische Beiträge zur Kenntnis der angeborenen Colobome des Anges ${ }^{1}$.
}

\author{
Von \\ Stabsarzt Dr. R. Seefelder, \\ Privatdozent in Leipzig.
}

Mit Taf. XVI-XVII, Fig. 1-7, und 9 Figuren im Text.

Inhaltsübersicht.

1. Einleitung. 2. Makroskopische und mikroskopische Beschreibung eines Auges mit atypischem cystischem Colobom in der Gegend des hinteren Pols. Erorterung der voraussichtlich in dem Verhalten der Augenblase gelegenen Ursache. 3. Mikroskopische Beschreibung eines Iris(?)-, Ciliarkörper- und Aderhautcoloboms bei einem Katzenembryo. Rosettenbildung. Eigenartige gliöse Verbindung zwischen Netzhaut und Pigmentepithel. Vorhandensein zweier getrennter Lagen Netzhaut - äussere pervers gelagert - im Bereiche des Funduscoloboms. Histologie und Herkunft der Rosetten. Rosetten in dem normal grossen nicht colobomatösen Auge eines 7- und 8monatlichen menschlichen Fötus. 4. Typisches Iris-, Aderhaut- und Sehnervencolobom mit sog. Colobom am Sehnerveneintritt (makrosk. u. mikrosk. Beschreibung). Besprechung der Sehnervencolobome. 5. Mikrophthalmus mit Orbitalcyste (makrosk. u. mikrosk. Beschreibung). Tumorähnliche gliöse Wucherung sowohl innerhalb des Bulbus als der Cyste. 6. Besprechung des gänzlichen Sehnervenpapillenmangels in missgebildeten Augen. sowie bei der Anencephalie. 7. Perforation der Linsenkapsel in Fall IV; ibre Entstehung und Folgen. 8. Über Strangbildnng von der Linse zur Kommunikationsstelle zwischen Cyste und Bulbus. 9. Ansehauungen über die Bedentung mesodermaler Gewebseinlagerungen in der fötalen Augenspalte. 10. Theorie Elschnigs. 11. Würdigung dieser Theorie. 12. Gründe für die Bedeutung der Mesodermleisten, -Zapfen usw. als Hindernisse des Spaltenschlusses. Faltungen der Pars coeca retinae. Abnorm grosse und nach hinten verlagerte Ciliarfortsätze. Netzhautduplikaturen. 13. Erörterung der konstanten Grössenübereinstimmung zwischen Pigmentepithel- und Aderhautdefekt. Folgen des letzteren für die Netzhaut. 14. Bedeutung der durch die fötale Augenspalte verlaufenden Gefásse für die Colobomgenese. 15. Abschnürung oder Resorption des Mesoderms im Spaltenbereich? 16. Bedeutung der Theorie Elschnigs für die Erklärung atypischer Funduscolobome. 17. Über taschenförmige Einlagerwngen der Netzhaut zwischen Sklera und Aderhaut. 18. Besprechung der Iriscolobome. Tabellarische Zusammenstellung der Grössenverhältnisse des menschlichen Auges von der 6. Woche des fötalen Lebens bis zur Geburt. Die Pupille vergrössert sich kontinuierlich bis zum 8. Monat. Ein Vorwachsen der Iris auf der Linse findet nicht statt. Ablehnung der auf diese Annahme gestützen Theorien. 19. Fleisehers Milrophthalmustheorie. 20. Die anatomische Grundlage der schlauch-, strang- und zeltdachähnlichen Gebilde im Glaskörper vom Standpunkte der embryologisehen Forschung. 21. Zusammenfassung. 22. Verzeichnis der im Text citierten Literatur. 23. Erklärung der Abbildungen.

1) Habilitationsschrift. 
Wer die neuere Literatur über diesen Gegenstand verfolgt hat, wird wohl ebenso wie ich den Eindruck gewonnen haben, dass wir von einem Ziele, dem wir schon einmal ziemlich nahe gekommen. zu sein schienen, wieder etwas abgeriickt sind.

Trotz zahlreicher ausgezeichneter anatomischer Untersuchungen sind wir von einer einheitlichen Auffassung des Wesens selbst der typischen Colobome heute ebenso weit entfernt als je.

In viel höherem Grade gilt dies aber noch von den atypischen, d. b. denjenigen Colobomen, welche ibrem Sitze nach von vornherein in keinen Zusammenhang mit der fötalen Augenspalte zu bringen sind.

Ferner hat fast jeder neue anatomische Beitrag den Beweis erbracht, dass auch der morphologische Teil unserer Frage noch lange nicht erschöpfend bearbeitet ist, dass vielmehr der Mannigfaltigkeit der histologischen Bilder im colobomatösen Auge anscheinend keine Grenzen gezogen sind.

Unter diesen Umständen erscheint ein weiteres Bearbeiten dieses Gebietes nicht nur wünschenswert, sondern geradezu geboten, und es braucht der Bearbeitende nicht zu fürchten, dass er keine Früchte ernten wird.

Gewiss ist nicht jedes Feld auf diesem Gebiete gleich ertragreich und bietet gleich viel Aussicht auf Erfolg. Dies gilt bekanntlich besonders von älteren Colobomaugen, bei welchen die ursprünglichen Verhältnisse häufig stark verwischt und nur mit Mühe von den sekundären Veränderungen zu trennen sind.

Dazu bedarf es vor allen Dingen eines eingehenden Vorstudiums der Entwicklung des Auges. Ist es ja doch eine allgemein beIrannte und anerkannte Tatsache, dass nur derjenige, welcher sich genügende embryologische Kenntnisse zu eigen gemacht hat, an das Studium der Missbildungen mit Aussicht auf Erfolg herangehen kann. Und ich gehe so weit, zu behaupten, dass es gerade bei diesem Zweige der Wissenschaft noch nicht einmal mit dem Vertiefen in die Literatur, und sei es auch noch so gründlich, getan ist, sondern dass erst durch ein persönliches Bearbeiten eines grösseren embryologischen Materials eine richtige Vorstellung von manchen Dingen gewonnen werden kann.

So meine ich, um nur ein Beispiel anzuführen, dass jemand, der sich zu wiederholten Malen und bei den verschiedensten Stadien von der enormen Zartheit des embryonalen Netzhautgewebes überzeugt hat, diesem nie und nimmermehr die Fähigkeit zusprechen kann, 
Pathol.-anat. Beiträge zur Kenntnis der angeborenen Colobome d. Auges. 277

Iris und Corpus ciliare zur Zeit der Entwicklung an umschriebener Stelle nach hinten zu zerren und dadurch ein Iriscolobom zu erzeugen.

Er wird dies um so weniger tun, wenn er beobachten konnte; dass die Entwicklung dieser beiden Gebilde im menschlichen Auge verhältnismässig spät einsetzt, und dass die Verbindung der Anlage des Corpus ciliare mit der skleralen Anlage ganz gewiss von Anfang an einem stärkeren Zuge stand hält, als die Netzhaut auszuüben vermag, ohne selbst einzureissen.

Durch den Besitz und die Bearbeitung eines, wie ich wohl sagen darf, ungewöhnlich grossen und tadellos konservierten Materials menschlicher Embryonen bzw. Föten, welches ich zum grössten Teile der Güte des Herrn Geheimrat Prof. Dr. Zweifel und dem grossen Entgegenkommen seiner ehemaligen Herren Assistenten Dr. Barth, Schottelius und Thies verdanke, ist mir reichlich Gelegenheit geboten worden, den Bau des menschlichen Auges in allen Phasen seiner Entwicklung, vom Beginn des Schlusses der fötalen Augenspalte angefangen, zu studieren und dadurch im Folgenden über manche in missgebildeten Augen gefundene Veränderungen eine, wie ich hoffe, befriedigende Erklärung zu geben.

Ich war bestrebt, bei den anatomischen Beschreibungen meiner Fälle alles Nebensächliche nur so weit zu erwähnen, als es mir zum Aufbaue des Gesamtbildes unerlässlich schien. Insbesondere habe ich von einer minutiösen Schilderung aller zweifellos sekundären Veränderungen abgesehen, um nicht die Geduld und das Vorstellungsvermögen der Leser in noch stärkerem Masse in Anspruch zu nehmen, als es bei diesem Kapitel ohnehin erforderlich ist.

\section{Fall I.}

Coloboma atypicum oc. sin. Cataracta congenita oc. utr. Hierzu Taf. XVI, Fig. 1.

E. Sch., 1 Jahr 14 Tage.

Dieser Fall weist vor allem eine in bezug auf die Vererbung von Anomalien des Auges sehr bemerkenswerte Familiengeschichte auf.

Der Grossvater hat auf beiden Augen von Geburt auf grauen Star gehabt und ist blind gewesen. Die Mutter hatte ebenfalls auf beiden Augen grauen Star und hat sich erst im 15. Lebensjahre hier operieren lassen. (Derzeitiger Visus $=$ Finger in $6 \mathrm{~m} \mathrm{mit}+12,0$.) Ein Bruder der Mutter, welcher von einer andern Mutter herstammt, hat ebenfalls doppelseitigen Star. Die übrigen vier Brüder der Mutter sehen gut.

Die drei Geschwister des Falles sind hier bereits wegen angeborenon Stars operiert worden (primäre Linearextraktion). 
Bei allen hatte sich stets der gleiche Befund gezeigt: Getrübter and geschrumpfter Kern mit ganz schmaler durchsichtiger Randzone, das Bild einer geschrumpften Zonularkatarakt.

Bei unserem Falle wurde am 27. IX. 04 die primäre Linearextraktion der rechten Linse in Chloroformnarkose ansgeführt.

In der Nacht zum 28. IX. starb das Kind plötzlich unter krampfähnlichen Erscheinungen, ohne dass die Sektion einen Anbaltspunkt für die Todesursache zu ermitteln vermochte.

Das etwa 12 Stunden p. m. enucleierte und in Zenkerscher Lösung fixierte Auge wies äusserlich keine Besonderheiten auf. Seine Grösse entsprach vollkommen dem Alter des Kindes, insbesondere war an keiner Stelle eine Ektasie festzustellen.

Auch nach der Halbierung des Bulbus im Äquator trat nichts Auffalliges zutage, abgesehen von starken Faltungen der Netzhaut, welche mit Recht als kadaveröse Veränderung gedeutet wurden.

Die mikroskopische Untersuchung des in horizontale Sehnitte zerlegten vorderen Augenabschnitts ergibt einen etwas engen Schlemmschen Venenkranz, sowie ein wirkliches Ligamentum pectinatum ${ }^{1}$, insoferm im Kammerwinkelbereiche die vorderen Irisschichten, nach Art der Irisfortsätze bei verschiedenen Tieren, hakenförmig nach vorne umbiegen und am sklerocornealen Netze, jedoch hinter dem Hauptlumen des Schlemmschen Venenkranzes, inserieren.

Vom Ciliarmuskel ist nur die meridionale Portion verhältnismässig gut entwickelt, wenn auch bei ihr das intramuskuläre Bindegewebe vermehrt erscheint. Die äquatoriale Portion ist sehr verkümmert, es sind von ihr nur Spuren vorbanden. Der Muskel zeigt somit im ganzen den sog. myopischen Bau.

Uber das histologische Verhalten der Linse lassen sich leider keine Angaben machen, da sie beim Schneiden infolge teilweiser Verkalkung zerbröekelte.

Beim Schneiden des hinteren Bulbusabschnittes, von dem man sich nach dem makroskopischen Aussehen kaum etwas Interessantes erwarten konnte, fiel mir auf, dass die Sklera an einer scharf umschriebenen Stelle eine Unterbrechung zeigte. Leider habe ich es damals unterlassen, mich sofort übor die genaue Lage dieser Stelle zu orientieren, so dass ich heute über diesen wichtigen Punkt keinen ganz zuverlässigen Aufschluss geben kann.

Folgendes ist für die Lokalisation zu verwerten:

Die Schnittrichtung ist sicher horizontal, da Papille, Macula und Ansatzstelle des Musculus obliquus inférior in einer grösseren Anzahl von Schnitten gleichzeitig enthalten sind.

Von allen diesen Gebilden fehlt in den Schnitten, welche das Colobom enthalten, jede Spur. Es liegt ferner weit abseits von dem vertikalen Meridian, wahrscheinlich nasal, und jedenfalls sicherlich nicht im Bereiche der fötalen Augenspalte. Das mikroskopische Bild eines durch

1) Eine besondere Bedeutung möchte ich diesem Befunde nicht beimessen. Ich habe solche Irisfortsătze im Laufe der Zeit des ofteren auch in ganz normalen Augen angetroffen. 
Pathol.-anat. Beiträge zur Kenntnis der angeborenen Colobome d. Auges. 279

die Mitte des Coloboms verlaufenden Schnittes bestätigt ohne weiteres die makroskopische Beobachtung, dass die Sklera an einer umschriebenen Stelle vollständig unterbrochen ist.

Ihr Gewebe ist an den Rändern des Defektes in geringem Grade kolbig verdickt und zeigt hier ein wesentlich dichteres Gefüge als sonst. In der gleichen Ausdehnung finden wir an Stelle des sonst ziemlich regelmässigen lamellären Baues eine ganz atypische Anordnung des skleralen Gewebes; seine Bündel haben einen stark gewellten Verlauf oder sind stellenweise sogar in mehrfachen spiraligen Windungen aufgerollt. Unmittelbar an den Rändern des Defektes sind die Lamellen der Sklera durchwegs leicht abgerundet und weisen eine sanfte Biegung nach aussen auf.

Die Oberfläche der Sklera im Bereiche des Defektes ist in den meisten Schnitten auf der einen Seite annähernd glatt, während die andere Seite infolge von Vorsprüngen und Buchten unregelmässig gezackt aussieht. Die eine der Buchten erstreckt sich divertikelartig weit in die Substanz der Sklera hinein (vgl. Fig. 1). Die grösste Breite des skleralen Defektes beträgt $0,325 \mathrm{~mm}$.

Im Bereiche des Skleralloches befinden sich an den Rändern der Sklera grobe Klumpen und Schollen, sowie feine Körner eines braunrötlichen, stark Licht reflektierenden Pigmentes, welches deutlich Eisenreaktion gibt und auf Grund aller dieser Eigenschaften als Blutpigment anzusprechen ist.

Die Aderhaut, welche in den übrigen Teilen des Auges keinerlei Abweichungen von der Norm darbietet, reicht nur mit einem Teile ihrer Schichten bis an das Skleralloch heran; die Choriocapillaris fehlt bereits in einem grösseren Umkreise und auch der Gefässreichtum der übrigen Schichten ist in der gleichen Ausdehnung auf ein äusserst geringes Mass reduziert. Die Lamina elastica hört auf einer Seite ebenfalls schon vor dem Skleraldefekte auf, auf der andern reicht sie bis heran und zeigt in ihrem Endstück einen welligen bzw. gekräuselten Verlauf.

Mit dem Fehlen der Choriocapillaris geht ein gleich grosser Defekt des Pigmentepithels Hand in Hand.

Die Netzhaut ist grösstenteils - artifiziell - von ihrer Unterlage abgelöst bzw. im Colobombereich abgerissen. Es lässt sich nämlich ans den teilweise anhaftenden Gewebsresten mit Bestimmtheit feststellen, dass sie, wie gewöhnlich, an der Stelle des Pigmentepitheldefektes mit ihrer Unterlage verwachsen war und zwar in gleicher Weise wie im Bereiche des Skieralloches, das von ihr lückenlos ausgekleidet wird.

Die Struktur der Netzhaut ist ausserhalb des Coloboms - abgesehen von kadaverösen Veränderungen - normal.

An der Colobomgrenze verliert sie sehr rasch ihre normale Schichtung und zwar hören zuerst die äusseren und etwas später die inneren Schichten auf, bis zuletzt nur noch ein schmaler, strukturloser Streifen gliösen Gewebes, das noch einige runde, sehr chromatinreiche Kerne vom Aussehen der Zellen der äusseren Körnerschicht enthäIt, das letzte Uberbleibsel der Netzhaut darstellt.

An der Aussenseite der Sklera ist die Netzhautkuppe, welche seinerzeit äber das Nivean derselben cystenartig hervorgeragt haben muss, 
jedenfalls bei der Enucleation des Auges abgetragen worden. $\mathrm{Ob}$ die Netzbautkuppe noch von einer dünnen mesodermalen Hülle überzogen war, lässt sich aus den Präparaten nicht ersehen, ist aber mit Wahrscheinlichkeit anzunehmen.

In die erwähnte cystische Aushöhlung der Sklera dringt die Netzhaut hinein, ohne sie jedoch vollständig auszukleiden (vgl. Fig. 1).

Zu dem beschriebenen Bilde, welches uns das Wesentlichste der ganzen Veränderung zeigt, liefern folgende an andern Schnitten erhobenen Befunde noch einige Ergänzungen:

In mehreren Schnitten ist in der Sklera kein Loch, sondern nur eine anf ihre innersten Schichten beschränkte seichte Delle vorhanden, wo selbstverständlich auch die Aderhant fehlt and die Netzhant das beschriebene Verhalten zeigt. In einer Reihe von andern Selnitten ist an der inneren Seite gar kein Defekt, sondern nur eine Atrophie der Netzhaut und Aderhant mit Schwund des Pigmentenithels vorhanden, während in den äusseren Skleralschichten, scheinbar ohne Zusammenhang mit dem Bulbusinneren, ein mehr oder weniger tiefer Defekt mit retinaler Auskleidung angetroffen wird.

Diese Beobachtungen lassen darauf schliessen, dass das Skleralloch wahrscheinlich keine rein senkrechte, sondern etwas schräge Verlaufsrichtung besitzt, falls nicht eine schräge Schnittrichtung zur Ursache dieser Befunde geworden ist.

Über das Verhalten des Glaskörpers im Colobombereiche kunn ich keine bestimmten Angaben machen. Daraus, dass die vorhandenen Glaskörperreste in der Richtung nach dem Skleralloche verlaufen, ist wohl zu entnehmen, dass er sich in das Skleralloch ebenso hineinerstreckt hat, wie die Netzhaut.

Resümieren wir, so ergeben sich in einem Auge mit kongenitaler Katarakt, das im übrigen durchaus normale Verhältnisse darbietet, als wesentlichste anatomische Veränderungen in der Gegend des hinteren Augenpols inmitten einer flachen delligen Vertiefung ein scharf umschriebener lochartiger Defekt der Sklera und in der gleichen Ausdehnung und noch etwas darüber hinaus eine Atrophie der Netzhaut, Aderhaut und des Pigmentepithels, ferner eine cystische Ausstülpung der Netzhaut an der Stelle des Skleraldefektes.

Als weitere wichtige Befunde wären zu erwähnen die Verdichtung der Sklera an den Rändern des Defektes, das Ausbiegen ihrer Lamellen nach aussen, die cystische Aushöhlung im Bereiche des Loches, die Anhäufung hämatogenen Pigmentes ebendaselbst.

Was das Wesen dieses höchst eigenartigen Befundes anlangt, so darf wohl die Möglichleit einer traumatischen Entstehung, an welche vielleicht im ersten Moment gedacht werden könnte, ohne eingehende Begründung ausser acht gelassen werden. Alles spricht da- 
Pathol.-anat. Beiträge zur Kenntnis der angeborenen Colobome d. Auges. 281

für, dass wir einen angeborenen Zustand vor uns haben, den wir zwanglos in die Gruppe der Colobome einreihen können und zwar in die der colobomatôsen Cystenbildungen.

Mit an Sicherheit grenzender Wahrscheinlichkeit kann angenommen werden, dass unser Colobom nicht im Bereiche der fötalen Augenspalte gelegen hat, und somit der engeren Gruppe der atypischen Colobome anzugliedern ist.

Um so grösser sind die Schwierigkeiten, für seine Entstehungsweise eine einigermassen befriedigende Erklärung zu finden. - Die zunächstliegende Frage ist wohl die, ob das Skleralloch entstanden ist, weil sich die Netzhaut in die Sklera') bineindrängte, oder ob die Netzhaut an dieser Stelle vorquoll, weil die Sklera fehlte oder abnorm nachgiebig war, kurz, ob die primäre Ursache der Veränderung. in dem Ektoderm oder Mesoderm gelegen ist.

In dieser Frage vermag uns, wie mir scheint, das Verhalten der Skleralränder wertvolle Fingerzeige zu geben.

Wir vermissen an denselben vor allen Dingen jedes Anzeichen, welches auf vorausgegangene Versuche, einen durch ein Trauma verursachten Defekt durch Narbengewebe zu ersetzen, hinweisen würde.

Um so wichtiger ist aber die Beobachtung, dass sich das sklerale Gewebe am Lochrande in hohem Grade verdichtet hat, dass es durchgehends eine Ausbiegung nach aussen aufweist und an einigen Stellen sogar spiralig aufgerollt ist.

Alles das deutet zweifellos darauf hin, dass das Mesoderm, aus dem Sklera und Chorioidea hervorgehen, hier seinerzeit ein starkes Hindernis gefunden hat, wodurch es gezwungen war, sich zu verdichten, auszuweichen oder, wo dies nicht möglich war, zu falten und in spiralförmigen Windungen aufzurollen. Das Hindernis ist, wie leicht $\mathrm{zu}$ sehen, von der Augenblase gebildet worden, welche hier eine tiefe Aussackung aufweist. In welcher Weise diese Aussackung der Augenblase entstanden ist, lässt sich natürlich schwer entscheiden. Ich möchte mich zunächst nicht darauf einlassen, langatmige Betrachtungen darüber anzustellen, ob es sich um ein aktives Vorsprossen beider Netzhautblätter [Elschnig $(1,2)]$ oder um eine cystische Ausstülpung im wahren Sinne des Wortes oder um eine Abschnürung durch Mesoderm [Ginsberg(3)] handelt, und behalte

1) Es können hier naturgemäss inmer nur die Anlagen dieser Membranen gemeint sein. 
mir vor, auf diese Frage bei der gemeinsamen Besprechung meiner Fälle noch zurückzukommen.

So viel scheint mir jedenfalls sicher za sein, dass die primäre Ursache unsererVeränderung in einem abnormen Verhalten der Augenblase zu suchen ist, welches zu einer Veränderung geführt hat, die wir nach ihrem ganzen Verbalten als atypisches Colobom mit Cystenbildung bezeichnen müssen.

Um uns noch kurz von dem ophthalmoskopischen Verhalten Rechenschaft zu geben, das unsere Veränderung dargeboten haben müsste, so hat wohl jeder Augenarzt schon atypische Colobome beobachtet, mit welchen unser Fall einige Ähnlichkeit aufgewiesen hätte. Ich stelle mir dabei einen annähernd kreisförmigen weissen Herd in der Gegend des hinteren Pols vor mit deutlicher Refralitionsdifferenz gegenüber der Umgebung, welcher von einzelnen der atrophischen Aderhaut angehörigen Gefässen durchzogen wird und einige unregelmässig pigmentierte Stellen enthält. Der tiefe lochartige Defekt der Sklera mit seiner stark pigmentierten Wandung hätte allerdings sicherlich dem ophthalmoskopischen Bilde ein ebenso eigenartiges Gepräge verliehen, wie dies bei dem anatomischen der Fall ist.

\section{Fall II.}

Coloboma iridis(?), corporis ciliaris et chorioideae typicum.

Katzenembryo von $63 \mathrm{~mm}$ Sch.-St. Länge.

Die Präparate dieses Falles gehören meinem Kollegen Wolfrum, welchem ich für ihre Überlassung zur Publikation zu grossem Danke verpflichtet bin.

Das Objekt ist deshalb besonders wertvoll, weil es uns ein Colobom in einem frühen Stadium zeigt und durch keine sekundären Veränderungen ungünstig beeinflusst ist.

Bedauerlicherweise liegen keine Serienschnitte vor, auch ist die horizontale Schnittrichtung für die Beurteilung aller Verhältnisse nicht ausreichend. Immerhin gibt das nach Möglichkeit zu einer Serie rekonstruierte Material über wichtige Fragen genügenden Aufschluss. Klinische Notizen fehlen. Der colobomatöse Zustand des Auges trat erst während der anatomischen Untersuchung in Erscheinung.

Vorausgeschickt seien einige kurze Bemerkungen über den allgemeinen Bau bzw. Entwicklungsgrad des Auges, soweit dessen Kenntnis zum Verständnis der pathologischen Verhältnisse unerlässlich ist. 
Sagittalachse $=2,5 \mathrm{~mm} ;$ Horizontalachse $=3,5 \mathrm{~mm}$.

Im vorderen Augenabschnitte ist eine Differenzierung in Hornhaut, Irisanlage und Pupillarmembran erfolgt. Eine Vorderkammer ist keinem Schnitte nachweisbar. Linse, Pupillarmembran, Hornhant und Iris grenzen demnach hart aneinander und es ist begründeter Verdacht vorhanden, dass eine reinliche Scheidung derselben nicht in ganzer Ausdehnung erfolgt ist, sondern Adhärenzen zwischen Iris und Hornhauthinterfläche bestehen. Mit Bestimmtheit lässt sich dies jedoch wegen der dichten Aneinanderlagerung der einzelnen Gebilde nicht behaupten.

Ein Ciliarmuskel ist noch nicht deutlich differenziert. Seine Lage ist durch eine Anhäufung von langgestreckten in der Verlängerung des Descemetschen Endothels und der vorderen Wand des Kammerwinkels liegenden Zellen gekennzeichnet.

Die Processus ciliares sind als einfache Falten des retinalen Epithels,

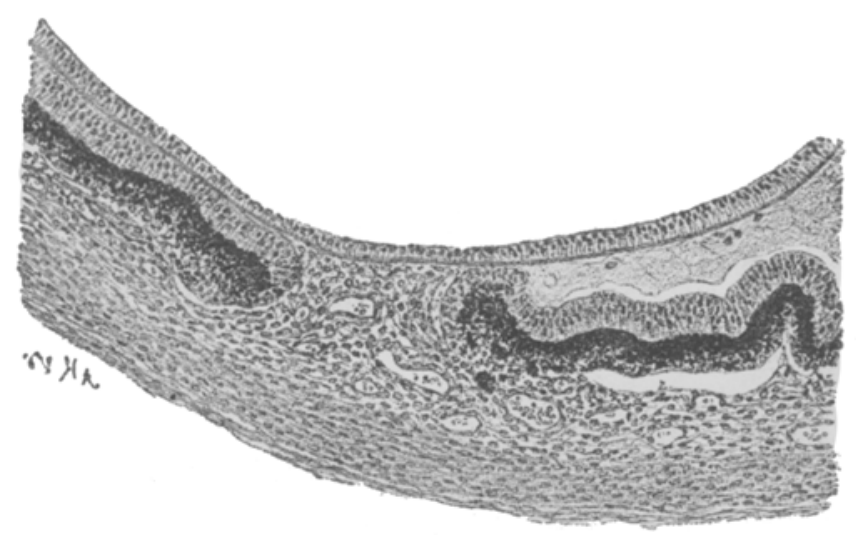

Fig. 1.

welche kapilläre Gefässe enthalten, angelegt. Das Pigmentepithel ist im ganzen vorderen Abschnitt intensiv pigmentiert, im hinteren Abschnitt, im Bereiche des Tapetums, fehlt es streckenweise ganz.

Die Linse zeigt keine Abweichungen, weder in bezug auf Grösse noch Form.

In einem Schnitte, welcher bereits so peripher - unten - liegt, dass er zwar noch Linse, aber keine Iris mehr enthält, finden wir das doppelschichtige Epithel des Ciliarkörpers durch eine ziemlich breite Schicht gefässhaltigen Mesoderms unterbrochen. Die Ränder des Epithels sind leicht gefaltet, das sonst sehr regelmässige Pigment des äusseren Blattes gelockert and ubber beide Blätter verstreut.

Das Mesoderm zwischen den Epithelrändern findet innen eine Grenze an der Linsenoberfiäche (in der Fig: 1 ist nur Linsenkapsel und -Epithel eingezeichnet) and liegt dieser innig an. $O b$ es mit ihr eine feste Verbindung eingeht, läsșt sich nicht entscheiden. Kataraktöse Veränderungen, analog denen in den Fallen v. Hippels (4), sind nicht vorhanden.

Mit dem mesodermalen Bindegewebe dringen anch Gefässe durch den 
Epithelspalt und ziehen, begleitet von einer schmalen Schicht dieses Gew webes, entlang der Linsenoberfläche bis in die Nähe des Äquators der Linse. Diese Verhältnisse sind in der Fig. 2 veranschaulicht

Diese zeigt uns ferner, dass sich die interponierte mesodermale

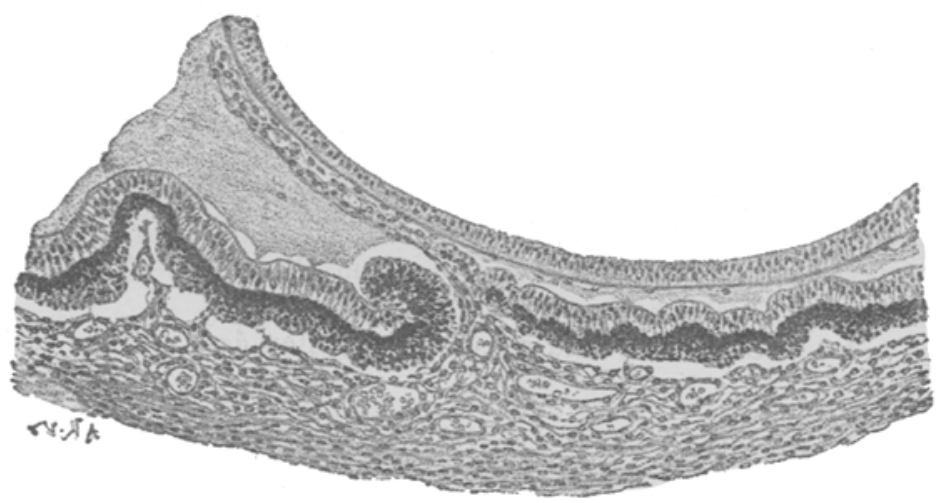

Fig. 2.

Schicht beträchtlich verschmälert hat, ein Zustand, welcher noch weiter peripher einen so hohen Grad annimmt, dass die ganze Mesodermleiste bis auf ein schmales Fädchen, welches mit Glaskörpergefässen in Verbindung steht, reduziert ist (Fig. 3). Die Breite des Coloboms nimmt

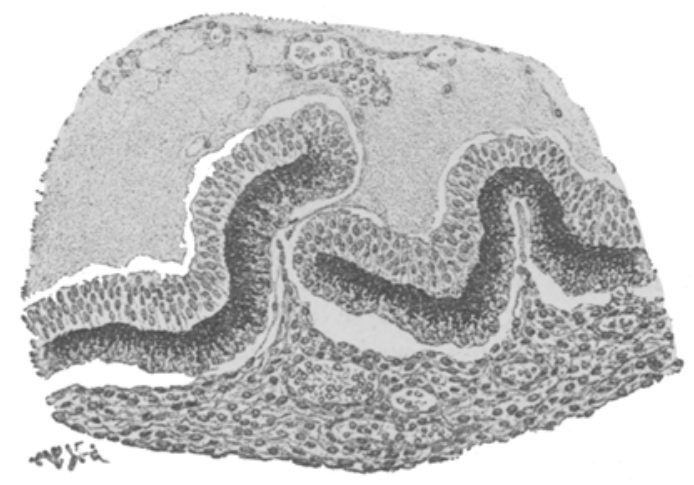

Fig. 3 . entsprechend ab. Die Epithelränder verhalten sich, wie auch die $\mathrm{Ab}$ bildungen zeigen, in verschiedener Weise.

Meist sind sie etwas eingerollt und zwar häufiger nach innen als nach aussen.

In einigen Schnitten ist der eine Epithelrand, ohne jede Faltenbildung zwischen einem schmalen Mesodermbande and der Linse eingekeilt, de* ren Oberfläche er sich eng anschmiegt (Fig. 2).

In einer kleinen Anzahl von Schnitten fehlt sogar jede Spur eines mesodermalen Gewebes innerhalb der Epithelspalte, ohne dass eine Vereinigung der fast bis zur Berührung genäherten Ränder erfolgt ist.

Alle diese Veränderungen spielen sich im Bereiche des gefalteten Teils des Ciliarkörpers ab, worauf das Vorhandensein zahlreicher Ciliarfortsätze im gleichen Schnitte schliessen lässt.

Sobald wir aus diesem herauskommen, finden wir (Fig. 4) die Meso- 
Pathol.-anat. Beiträge zur Kenntnis der angeborenen Colobome d. Auges. 285

dermleiste wieder beträchtlich verbreitert; sie hat ferner etwas an Höhe zugenommen und ragt mit ihrer Spitze, welche in allen Schnitten einen Gefässquerschnitt mittleren Kalibers trägt, in den Glaskörperraum.

Die Mesodermleiste trägt die Eigenschaften embryonalen Bindegewebes zur Schau und unterscheidet sich kaum von dem mesodermalen Boden, auf dem sie aufsitzt.

$\mathrm{Ob}$ die Ablösung der Epithelränder vor der Mesodermleiste schon in vivo bestand oder artifiziell enstanden ist, wage ich nicht $\mathrm{zu}$ entscheiden. Sicher ist, dass eine Kommunikation des subepithelialen Raumes mit dem Glaskörperraum auf keinen Fall bestanden bätte.

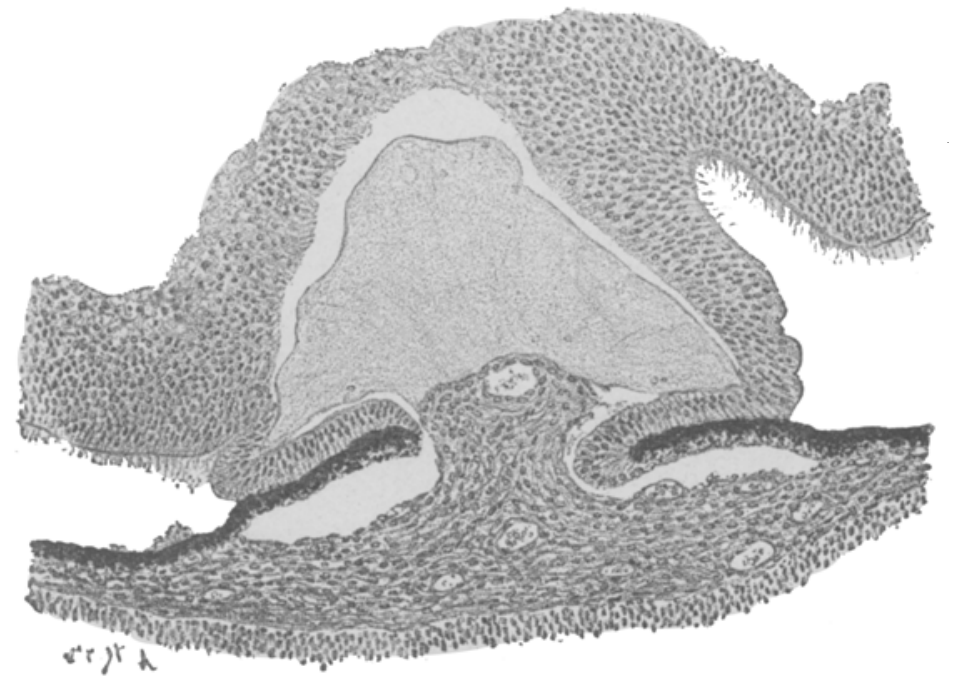

Fig. 4.

Die Netzhaut springt sogleich an ihrem Ubergange in die Pars ciliaris retinae mit steilen Falten von beiden Seiten - links ist die Falte schräg getroffen - in der Richtung des Mesodermzapfens gegen das Augeninnere vor.

In mehreren Schnitten ist zwischen den Spitzen der Falten noch ein Zwischenraum vorhanden, in den meisten aber sehen wir sie über dem Mesodermzapfen vereinigt.

Durch diese Vereinigung erscheint der Glaskörper im Schnitte in 2 Hälften - eine äussere und innere - geteilt, ein eigenartiges Bild, das leider in Fig. 4 nur unvollständig zum Ausdruck gebracht ist, da die innere Hälfte, also der eigentliche Glaskörperraum, welcher in der Abbildung natürlich nach oben von den Netzhautfalten liegen würde durch nichts gekennzeichnet ist.

Die Verhältnisse werden aber noch komplizierter, wenn wir aus dem Bereiche des Ciliarkörpers hinaus- und ganz in den der Aderhaut gelangen. 
Hier sind plötzlich die beiden Blätter der sekundären Augenblase Netzhaut und Pigmentepithel vereinigt, aber wie erstaunen wir, wenn wir die Vereinigungsbrücke des Pigmentepithels näher ins Auge fassen.

Während sie nämlich in der Nähe des Pigmentepithels erst aus einer $1-2$ fachen Lage unpigmentierter Zellen besteht, schwillt sie in einiger, in den verschiedenen Schnitten stark wechselnden Entfernung davon ziemlich plötzlich zu bedeutender Dicke an und nimmt die Eigenschaften embryonalen Netzhautgewebes an. Man unterscheidet an der äusseren - skleralen - Seite deutlich eine Grenzmembran vom Bau der Limitans internae retinae und an der entgegengesetzten Seite eine Limitans externa siv. reticularis [He ld-Krückmann $(5,6)]$, welche von Stäbchen und Zapfen in gleicher Weise durchsetzt ist, wie das innere Blatt, die eigentliche

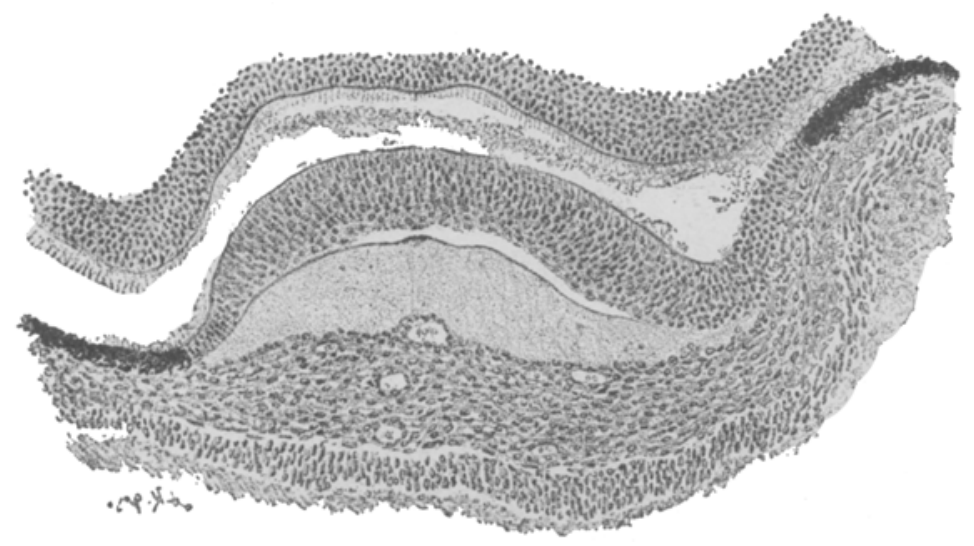

Fig. 5.

Netzhaut, welches mit der gleichartigen Schicht dem äusseren gegenuberliegt.

Und schliesslich finden wir den Raum zwischen der Verbindungs= brucke des Pigmentepithels und dem nach aussen gelegenen Mesoderm in gleicher Weise von Glaskörpergewebe eingenommen, wie dies in Fig. 4 bei dem zwischen den Netzhantfalten liegenden Glaskörperabschnitte der Fall ist.

Die Breite dieser atypischen Schicht schwankt in den verschiedenen Schnitten und beträgt an der Stelle der stärksten Ausdehnung $0,675 \mathrm{~mm}$. Wie weit sie sich nach hinten erstreckt, lässt sich nicht genau feststellen, doch geht daraus, dass sie in den sehr peripher gelegenen Schnitten nur vorne vorhanden ist, mit Bestimmtheit hervor, dass sie nicht bis zum hinteren Augenpol gereicht haben kann.

Das mesodermale Gewebe zeigt in ihrem Bereiche immer noch eine leichte Verdickung, auch ist der bereits erwähnte Gefässquerschnitt an der Stelle der stärksten Verdickung in gleicher Weise vorhanden, wie auf der Höhe der Mesodermleiste. 
Pathol.-anat. Beiträge zur Kenntnis der angeborenen Colobome d. Auges. 287

Ausser den beschriebenen, ausschliesslich auf den Colobombereich beschränlten Veränderungen weist die Netzhaut noch verschiedene Anomalien auf.

So treffen wir zunächst die als häufige Veränderung in Colobomaugen bekannten Rosettenbildungen, deren Entstehung durch Faltung und atypisches aktives Wachstum der Netzhautzellschichten auch in diesem A uge mit ausserordentlicher Klarheit beobachtet werden kann.

Eine auffälligere und mir bis jetzt unbekannte Veränderung besteht aber darin, dass an verschiedenen Stellen die Schichten der Netzhaut durch ein faseriges, ron innen nach aussen keilförmig vordringendes Gewebe ganz oder teilweise unterbrochen werden. Das gleiche Gewebe durchbricht vielfach sogar die Limitans externa siv. reticularis, breitet sich dann im subretinalen Raume aus und geht teils mit dem Pigmentepithel, teils mit einem aus benachbarten Stellen hervorgegangenen gleichartigen Gewebe feine Verbindungen (vgl. Fig. 6 ) ein. Auf Grund dieses, sowie seines tinktoriellen Verhaltens kann dieses Gewebe nichts anders als Glia sein, deren Fähigkeit, mit dem Pigmentepithel protoplasmatische Verbindungen ein-
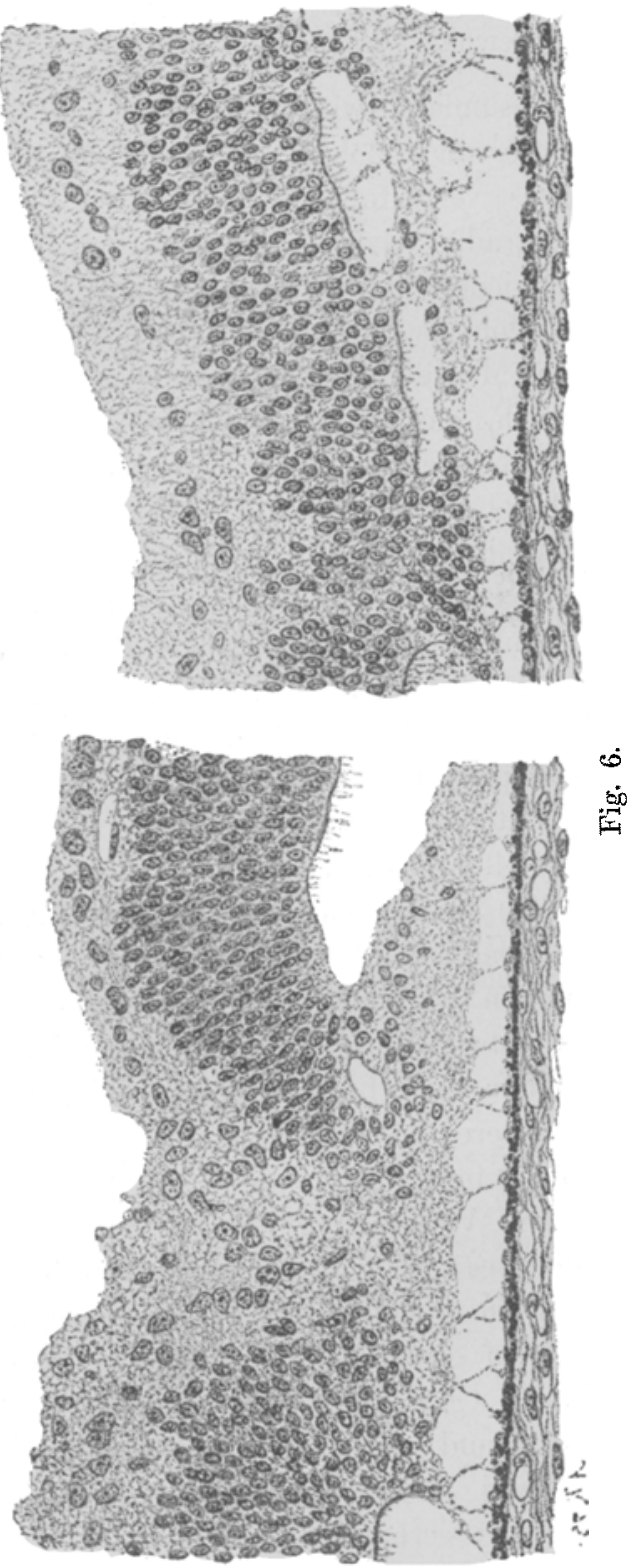
zugehen, von Krückmann $(5,6)$ auf Grund embryologischer und pathologisch-anatomischer Studien gezeigt worden ist. 
In dem andern Auge des gleichen Tieres findet sich in den vor handenen Präparaten keine Abweichung von der Norm.

Vom Optikus ist in keinem einzigen Schnitte beider Augen irgend ein Angeichen vorhanden.

Resümieren wir, so ergibt sich in dem einen Auge eines Katzenembryos ein Colobom des Ciliarkörpers, das in der Nähe des Irisansatzes verhältnismässig breit ist, sich nach der Peripherie zu höchstgradig verschmälert, aber kurz vor dem Übergang in die Aderhaut wieder beträchtlichere Dimensionen annimmt. An der Stelle des Coloboms dringen eine in ihrer Breite in gleicher Weise wechselnde Mesodermleiste, sowie Gefässe in das Augeninnere hinein. $\mathrm{Ob}$ auch, was mit Bestimmtheit anzunehmen ist, ein Colobom der Iris vorhanden war, geht aus den vorhandenen Präparaten nicht einwandsfrei hervor.

Während aber, wie besonders hervorgehoben sei, an den Augenblasen- bzw. Epithelrändern eine stärkere Duplikaturenbildung und insbesondere ein Zurückdrängen des äusseren Blattes durch das innere nicht stattgefunden hat, sehen wir in einiger Entfernung von denselben die Netzhaut von beiden Seiten in steilen Falten gegen den Glaskörperraum vorspringen und über dem Zapfen teils stark genähert, teils sogar auf der Höhe der Falten verwachsen.

Stellt dieser Befund, zu dem ich nur in dem Falle Levinsohn(7) ein Gegenstück gefunden habe, schon an und für sich eine grosse Seltenheit dar, so gilt dies noch viel mehr von den anatomischen Verhältnissen, welche wir im Bereiche des Fundus- sive Aderhautcoloboms beobachten konnten.

Hier sind beide Augenblasenblätter, und zwar das innere wit dem inneren und das äussere mit dem äusseren, vereinigt und ein Colobom im strengen Sinne des Wortes somit nicht mehr vorhanden.

Die Vereinigung ist aber nur an der Stelle des inneren Netzhautblattes durch gleichartiges Gewebe erfolgt, beim äusseren Blatte, dem Pigmentepithel, wird die Vereinigungsbrücke in der Hauptsache durch ein ganz atypisches Gewebe bewerkstelligt, das ausgesprochen retinalen Charakter zur Schau trägt. Wie ist dieses Gewebe entstanden und aus welchem Mutterboden ist es hervorgegangen?

Zwei Möglichkeiten fordern angesichts der eigenartigen anatomischen Verhältnisse zur Überlegung auf, keine lässt sich, so bedauerlich dies im Hinblicke auf die prinzipielle Bedeutung des Falles ist, beweisen, da gerade hier unausfüllbare Lücken in der Serie bestehen. 
Pathol.-anat. Beiträge zur Kenntnis der angeborenen Colobome d. Auges. 289

Der erste Gedanke, der sich jedem bei der Betrachtung der Textfigur 5 aufdrängen dürfte, ist wohl der, das Colobomgewebe von dem herzuleiten, mit dem es unmittelbar zusammenhängt, $d$. i. dem Pigmentepithel. In diesem Gedanken könnte uns die Tatsache bestärken, dass zunächst auch tatsächlich epitheliale, wenn auch pigmentlose Zellen an der Ausfüllung des Defektes beteiligt sind. Wir müssten dann aber dem bereits zum Pigmentepithel differenzierten äusseren Blatte der sekundären Augenblase notwendigerweise die Fähigkeit zuerkennen, unter gewissen Umständen in gleicher Weise Netzhautgewebe und Glaskörper zu bilden wie das innere Blatt, würden uns aber damit in einen grossen Widerspruch zu den derzeitigen modernen Ansichten der Embryologen versetzen, welche dahin gehen, dass das Material für die Augenblase bereits sehr frühzeitig differenziert ist, wahrscheinlich schon vor der Bildung der primären Augenblase, und dass später aus den dermassen differenzierten Zellen kein andersartiges Gewebe mehr hervorgehen kann. Dieser Umstand scheint von früheren Untersuchern nicht genügend gewürdigt worden zu sein.

So fand Hess(8) in einem Falle ron Orbitalcyste als Auskleidung der Cystenwand eine mächtige Schicht sehr zellreichen, bindegewebsähnlichen Gewebes, ron dem sich nach Hess auf das bestimmteste nachweisen liess, dass es aus dem Pigmentepithel hervorging, dessen unmittelbare Fortsetzung es bildete.

Von einer ganz analogen Beobachtung hat auch Ginsberg(3) berichtet und sie in gleichem Sinne gedeutet.

Die weitgehendste Übereinstimmung mit meinem Falle zeigt aber die Fig. 6 der Arbeit von Rindfleisch (10) über Mikrophthalmus usw. Es sind hier ebenfalls beide Blätter getrennt und eine Strecke des äusseren Blattes, welche auf beiden Seiten in engstem Zusammenhang mit dem Pigmentepithel steht, zu Netzhaut differenziert. Leider ist die Erklärung dieses absonderlichen Bildes ganz unzureichend. Trotz des Satzes „Ein Horizontalschnitt, welcher vorn den untersten Teil der Linse, hinten den Übergang des äusseren Blattes in das innere getroffen hat $\left.(?)^{1}\right)$, zeigt diese Verhältnisse auf das klarste $\left.{ }^{2}\right)^{\text {", }}$, in welchem eigentlich die ganze Erklärung enthalten ist, ist in diesem interessanten Falle leider noch gar manches aufklärungsbedürftig geblieben.

1) Im Original nicht gesperrt. coloboms.

2) Gemeint sind allerdings hauptsächlich die Verhăltnisse des Ciliarkörper-

v. Graefe's Archiv für Oph thalmologie. LXYII. 2. 
Die Zulässigkeit der Hessschen Auftassung wird übrigens selbst von v. Hippel(11) zugegeben, wenn dieser auch daran erinnert, dass es sich um ,rïckgebildetes, ursprünglich invers gelagertes Retinalgewebe" handeln könne. Dass das Colobomgewebe unseres Falles später auch bis auf die Stützsubstanz degenerieren könnte, ist gewiss nicht zu bestreiten; es müsste sich aber dann an ihrer Innenfläche noch normal gelagerte Netzhaut vorfinden.

Es springt aber in meinem Falle noch eine andere Veränderung in die Augen, durch welche er sich von den eben citierten noch ganz wesentlich unterscheidet, ich meine das Vorhandensein von Glaskörpergewebe und Glaskörperflüssigkeit an der Aussenseite des Colobomgewebes.

Diese Tatsache veranlasst mich, noch eine andere Entstehungsmöglichkeit in Erwägung zu ziehen, welche zunächst zwar sehr weit rom Wege ab zu liegen scheint, aber meines Erachtens dann an Existenzberechtigung gewinnt, sobald wir nicht die Fig. 5 für sich allein betrachten, sondern mit Fig. 4 vergleichen. Sicher ist, dass die beiden Schnitte, welchen die Bilder entnommen sind, ans Regionen stammen, welche nicht weit von einander entfernt sein konnten. Wir haben nun in beiden Figuren zwei scheinbar in sich abgeschlossene Glaskorperräume, von denen der eine an normaler Stelle liegt, während der andere auf einer Seite von Netzhaut, auf der andern von einer etwas verdickten Mesodermschicht begrenzt wird, welche in der Mitte einen Gefässquerschnitt mittleren Kalibers trägt. Es versteht sich von selbst, dass die beiden äusseren Glaskörperräume der Fig. 4 und 5 untereinauder in direkter Kommunikation stehen und ibrerseits wiederum nichts anderes sind, als ein durch die Verwachsung der Netzhautfalten geschaffener Ventrikel des primären Glaskörperraumes, mit dem sie naturgemäss ebenfalls direkt zusammenhängen.

Denken wir uns nunmehr die beiden an den äusseren Glaskörperraum der Fig. 4 grenzenden Netzhautschenkel von den inneren abgetrennt, miteinander vereinigt und etwas gestreckt, dann erhalten wir ein nahezu völlig gleichartiges Bild wie in Fig. 5.

Wir müssten uns also, wenn wir diese Idee weiter verfolgen, den ganzen Hergang so vorstellen, dass sich in unserem Falle in gleicher Weise wie in so vielen andern in der Literatur beschriebenen im Bereiche des mittleren Augenabschnittes Netzhautduplikaturen gebildet haben derart, dass das innere Netzhautblatt dem Mesoderm eine Strecke weit in inverser Lagerung auflag, dass die Ränder der gefalteten Netzhaut durch weiteres Wachstum sich berührten, mit- 
Pathol.-anat. Beiträge zur Kenntnis der angeborenen Colobome d. Auges. 291

einander verwuchsen und schliesslich - und das ist das punctum saliens - wie unter normalen Verhältnissen eine Trennung in ein äusseres und inneres Blatt erfahren haben.

Ich weiss wohl, dass ich mit dem letzten Gedanken, der bis jetzt noch von keiner Seite zur Diskussion gestellt worden ist, auf Widersprüche stossen werde, ich bin auch weit davon entfernt, ihn als bewiesen hinzustellen, muss aber betonen, dass er mir durch die Bilder, welche sich eben vor unseren Augen entrollt haben, sehr nahe gelegt zu sein scheint.

Bekanntlich hält v. Hippel (12) „einen solchen verspäteten Verschluss der Augenspalte bei abnorm später Rückbildung des Mesoderms nux für möglich, wenn die Ränder der Augenblase nicht umgestulpt waren". (Heidelberger Bericht 1902.) Dieser Satz ist, wenigstens in dieser allgemeinen Fassung, zurzeit sicher nicht mehr aufrecht zu halten. Fine Vereinigung von sich eng bertuhrenden Netzhautfalten ist, worauf auch Mannhardt(13) hinweist, unter allen Umständen möglich, sie wird nach meiner Ansicht sogar regelmässig erfolgen, sobald embryonales Netzhautgewebe aufeinanderstösst und kann, wie mein Fall und der citierte Fall Levinsohns(7) zeigen, sogar über dem Mesodermzapfen zu stande kommen.

Dadurch verliert aber die Frage, ob grosse Colobomflächen in ganzer Ausdehnung von retinalem Gewebe ausgekleidet sind oder nicht, ein nennenswertes Stück von der Bedeutung, welche ihr fast allgemein beigemessen wird, und zwar ganz besonders in dem Sinne, dass das Fehlen einer Lücke auf keinen Fall beweist, dass keine Störungen in dem normalen Verschlusse der fötalen Augenspalte vorgelegen haben ${ }^{1}$ ). Diese Bemerkung gilt ganz besonders für ältere Augen, in welchen das retinale Colobomgewebe auf ein schmales strukturloses Häutchen reduziert zu sein pflegt, da in diesen die Überwachsung mit Glia in noch späterer Zeit erfolgt sein kann. Und ich kann v. Hippel(11) darin nur beipflichten, dass ,derartiges Material sehr wenig geeignet ist, dem Untersucher klare und eindeutige Einblicke in die Entstehungsweise unserer Missbildungen zu gewähren".

Ich möchte noch hinzufügen, dass dies höchstens möglich ist unter engster Anlehnung an die Kenntnisse und Tatsachen, welche durch die Untersuchung jugendlicher colobomatöser Augen in einwandfreier Weise zutage gefördert worden sind.

$\left.{ }^{1}\right)$ In diesem Sinne hat sich später auch E. v. Hippel ausgesprochen, ohne jedoch von seiner citierten Voraussetzung abzugehen. 
Unser Fall bringt also trotz der ihm anhaitenden Mängel, welche zu mancherlei theoretischen Erwägungen zwangen, einesteils einige völlig neue Befunde, anderseits eine Bestätigung und Ergänzung bekannter Tatsachen, welche in den grundlegenden Arbeiten über die Colobome des Auges von Hess, Bach, E. v. Hippel, E. Bock u. A. niedergelegt sind.

Ich sehe vorläufig davon ab, auf die viel diskutierte Bedeutung der in unserem Falle so schön ausgesprochenen Mesodermleiste einzugehen, und verschiebe dies auf den Schlussteil meiner heutigen Publikation.

Es liegt nicht in meiner Absicht, mich ibber die Herkunft und Histologie der in diesem Falle mehrfach beobachteten Rosettenbild ungen eingehend zu verbreiten. Ich möchte nur meine Anschauung, die ich durch das Studium der Literatur, welche zuletzt in den Arbeiten von Pichler(17), Körber(18), Ginsberg(15,16), v.Hippel(112) und Wehrli(19) berücksichtigt ist, sowie meiner eigenen Präparate gewonnen habe, nochmals dahin präzisieren, dass an ihrem Zustandekommen sowohl Faltungen, als atypisches Wachstum vorzugsweise der äusseren Körnerschicht beteiligt sind, und dass, wenn die Faltung der letzteren sehr spät stattfindet, im Lumen ${ }^{1}$ ) der Rosetten selbstverständlich Stäbchen und Zapfen gefunden werden. Letzteres ist aber nicht immer der Fall. Ich besitze z. B. ein im übrigen normales Auge eines siebenmonatlichen menschlichen Fötus, das in den inneren Schichten des Papillenrandes mehrere Rosetten aufweist, welche aus hohen cylindrischen Zellen zusammengesetzt sind, aber keine einem Zapfenaussenglied vergleichbaren Iumenwärts gerichteten kutikularen Anhänge ${ }^{2}$ ) besitzen. Die Zellen dieser Rosetten scheinen sowohl aus der inneren als aus der äusseren Körnerschicht hervorzugehen, wenigstens stehen sie mit beiden stellenweise in direktem Zusammenhang.

Ferner habe ich in einem wohlentwickelten normalen Auge eines achtmonatlichen menschlichen Fötus nahe der Ora serrata mehrere rosettenähnliche Duplikaturen der ganz anliegenden und ausgezeichnet konservierten Netzhaut, sowie in der gleichen Netzhaut eine tumorartige schon makroskopisch sichtbare Anhäufung von Zellen der

1) Bekauntlich siad in diesem Städium die Stäbchen und Zapfen der Retina bereits wohl entwickelt and fehlen nur noch in der Maeula lutea [Chievitz (21), y. Hippel (20)].

a) Gefässe waren in meinem Falle nicht vorhanden. 
Pathol.-anat. Beiträge zur Kenntmis der angeborenen Colobome d. Auges. 293

Körnerschichten gefunden, welch letztere mit einer von Ginsberg beschriebenen Knötchenbildung in der Netzhaut eine weitgehende Übereinstimmung zeigt.

Ich. möchte diese Befunde namentlich Wehrli(19) entgegenhalten, welcher der Tatsache, dass bis jetzt in nicht missgebildeten fötalen Augen keine Rosetten gefunden wurden, eine grosse Bedeutung beizumessen scheint, beschränke mich aber darauf, sie hier zu registrieren, ohne auf die Frage nach den Beziehungen zwischen Rosetten und Gliombildung weiter einzugehen, um nicht $z u$ weit von meinem Hauptthema abzuschweifen.

\section{Fall III. \\ Colobom der Iris, Aderhaut, des Sehnerven und am \\ Sehnerveneintritt.}

Hierzu Taf. XVII, Fig. 2 a. 3.

W. Otto, 21 Jahre.

Patient suchte zum erstenmal im Jahre 1902 unsere Klinik auf. Damals wurde ein doppelseitiges Iris- und Aderhautcolobom an typischer Stelle sowie ein geringgradiger Mikrophthalmus festgestellt. Eine genaue Erörterung der hereditären Verhältnisse sowie der ophthalmoskopischen Veränderungen wurde leider unterlassen.

Das rechte Auge erlitt ein Jahr später eine perforierende Verletzung am unteren Hornhautrande, welche einen chronischen Entzündungszustand einleitete und schliesslich zur Enucleation des ererkrankten Auges führte (15. VI. 05).

Das Auge war damals hypotonisch, es bestand totale hintere Synechie, ein organisiertes Exsudat im Pupillargebiet, hochgradige Injektion, totale Erblindung usw.

Die Enucleation ergab zunächst die Unrichtigkeit der Diagnose Mikrophthalmus. Das Auge besitzt vielmehr eine ansehnliche Grösse und zeigt andeutungsweise den Bau des myopischen Auges.

Sagittalachse $=241 / 2 \mathrm{~mm} ;$ Horizontalachse $=23 \mathrm{~mm}$. Die Sklera ist in der unteren Hälfte bis zum Optikus im ganzen eine Spur stärker gewölbt als oben, eine umschriebene Ektasie ist nicht vorhanden.

Nach Abtragung einer grösseren Kalotte an der nasalen Seite zeigt sich ein breites Aderhantcolobom in dem unteren Augenabschnitt, welches in der Nähe des Äquator bulbi beginnt und hinten von allen Seiten den Optikus umgreift.

Der hintere Abschnitt scheint von den im vorderen Teile sich abspielenden Entzündungsvorgängen nicht nennenswert alteriert zu sein. 
Der Bulbus wurde in eine sagittal verlaufende Schnittserie zerlegt, um Iris- und Aderhautcolobom in eine Ebene za bekommen.

Die Erwartungen bezüglich der histologischen Ausbeute waren im Hinblick auf das Alter des Falles und den lange bestehenden Entzündungszustand des Auges ron Anfang an nicht sehr hochgeschraubt, wurden aber erfreulicherweise übertroffen.

\section{Mikroskopischor Befund.}

Die Ferhältnisse im vorderen Augenabschnitt kann ich ganz kurz zusammenfassen, da sie nur wenig Interessantes bieten.

Wir finden hier die Zeichen einer chronisehen Iridocyclitis und deren Folgen - Rundzelleninfiltration in der Iris und im Corpus ciliare, ausgedehnte Schwartenbildung usw.

Die im grossen Ganzen gut erhaltene Hornhaut wird unten in der Nähe des Limbus von einer sehr schräg verlaufenden, annähernd linearen Narbe durchsetzt, welche innen liurz yor dem Kammerwinkel endet.

Von hier ans verbreitet sich ein derbes schwartiges Gewebe im Kammerwinlkel, füllt diesen grösstenteils aus and überzieht auch die vordere und hintere Flache des kurzen Irisstumpfes, welcher im Colobomgebiet angetroffen wird.

Ein Colobom des Ciliarkörpers ist nicht nachweisbar, bei der Art der Schnitufuhrung zwar nicht ganz auszuschliessen, aber im Hinblick auf den makroskopischen Befund wahrscheinlich auch nicht vorhanden gewesen.

Corpus ciliare und das im vorderen Abschnitt vorhandene Stück Aderhaut sind auf der nasalen Seite, sowie in dem Bezirke, welcher etwa der Verlängerung des Iriscoloboms nach hinten entspricht, durch eine entzündliche bindegewebige Nenbildung, welche ibrer Innenfläche stellenweise aufgelagert ist, in grosser Ausdehnung von der hier leicht ektatisehen Sklera abgelöst. Dass sie - wie selbstverständlich - ursprünglich der Sklera angelegen haben, beweisen die den Zwischenraum durchziehenden Reste der Suprachorioidea.

In dem abgelösten Bezirke weist das retinale Epithel des Corpus ciliare, das sich auch anf die Aderhaut erstreckt, in ganzer Ausdehnung eine hochgradige Faltenbildung auf, ein Vorkommnis, auf welches in neuester Zeit Gilbert(22) aufmerisam gemacht hat, und das ich mit ibm nicht ausschliesslich auf Kosten der entzündlichen Veränderungen setzen möchte.

In dem übrigen Augenabschnitte fehlt diese Faltenbildung, Corpus ciliare und Aderhaut liegen temporal auch unten der Sklera an, und nur die Netzhaut zeigt, abgesehen von ibren Fixationsstellen an dex Colobomgrenze, eine totale fiache Ablösung.

Ungefälr in der Mitte des vorderen Aderhaut-Colobomrandes erhebt sich von der Sklera oine steil gegen den Glaskörper vorspringende, auf Querschnitten Ironisch geformte mesodermale Leiste. Vor dieser Leiste hören die Aderhaut und das hier doppelschichtige retinale Epithel mit scharfem Rande auf. Die hintere Fläche der Leiste ist zum Teil von gliös degenerierter Netzhant überzogen. 
In den Sehnitten, welche seitlich der Leiste liegen, hört die Aderhaut ebenfalls ganz unvermittelt auf, wogegen die Netzhaut zwar ihre normale Struktur verliert, aber noch als dünnes gliöses Häutchen in das Colobomgebiet übergeht. Das Pigmentepithel erstreckt sich, wenn auch in stark verändertem Zustande - es enthält nur stellenweise-Pigmentkörnchen und ist sehr unregelmässig angeordnet -, noch eine ganz kurze Strecke in das Colobomgebiet hinein. Die Netzhaut ist mit dieser Fortsetzung des Pigmentepithels in dem Colobomgebiet fest verwachsen. Die Verbindung ist ausschliesslich gliöser Natur. Die erwähnte strukturlose Schicht gliösen Gewebes überzieht im übrigen anscheinend lückenlos die ganze Innenfläche des Coloboms.

Diese Auskleidung ist aber keine glatte und regelmässige, sondern hat sich zahlreichen Nischen und Vorsprüngen anzupassen, welche hier von dem Mesoderm gebildet werden. Einen ganz besonders hohen Grad erreicht aber dieser Zustand in der Gegend des hinteren Pols, wo er sich nicht bloss auf die Oberfläche und innersten Schichten der Sklera beschränkt, sondern deren ganze Dicke betrifft. Sklera und Glia, also mesodermales and ektodermales Gewebe, liegen hier wirr durcheinander, so dass bei der Anwendung von Mehrfachfärbungen ${ }^{1}$ ) ein sehr buntes Bild entsteht.

Im allgemeinen zaberwiegt das sklerale Gewebe an Menge mit Ausnahme einer ziemlich umschriebenen Stelle in der Nähe des Sehnerveneintritts (vgl. Taf. XVII, Fig. 2), wo das gliöse Gewebe eine Art von cystischer Einstülpung in die Sklera zoigt and letztere bis anf eine schmale Schicht durchbrochen zu sein scheint. Doch sind auch hier zwischen dem gliösen Gewebe breite Züge und Inseln von mesodermalem Bindegewebe eingeschlossen. Eine ganz ähnliche Abbildung findet sich in Parsons (23), Pathology of the Eye. Vol. III, St. 891.

Von einer eigentlichen Cyste kann natürlich keine Rede sein, da es sich fast durchweg um solide Gewebsmassen handelt. Wir wissen aber, dass unter ähnlichen Umständen kleine Orbitalcysten entstehen können. An einigen Stellen sind übrigens innerhalb des gliösen Gewebes cystische Hohlräume nachzuweisen, welche von geronnenen Eiweissmassen ausgefüllt sind und ron Gliafäden durchzogen werden. Diese Veränderung, welche, wie wir beim nächsten Falle sehen und besprechen werden, innerhalb

1) Glia und mesodermales Bindegewebe sind schon bei einer einfachen Kombination von van Gieson mit irgend einer beliebigen Kernfärbung leỉcht voneinander zu unterscheiden, da erstere strohgelb, letzteres leuchtend rot erscheint. Noch deutlicher tritt der Unterschied beider Gewebsarten bei Anwendung der Heidenhainschen Färbung zutage, wobei das ektodermale Gewebe je nach der Differenzierung schwarz bis schwarzblau gefärbt ist and auch das Fasersystem des Gliagewebes deutlich in Erscheinung tritt. Die prägnantesten Bilder ergibt allerdings die Held sche Alsolhämatoxylinfärbung, welche ich nit Erlaubnis des Erfinders ebenfalls anwenden konnte. - Auf diese Verhältnisse hat bekanntlich bereits $\mathrm{Kr}$ ückmann $(5,6)$, dem wir mit Jakoby (24) den Ausbau unserer Kenntnisse der Netzhautneuroglia verdanken, in verschiedenen Arbeiten hingewiesen. 
gliöser Gewebswacherungen anscheineud des öfteren aufzutreten pflegt, ist natürlich erst sekundär entstanden und hat mit der Entstehung von Orbitalcysten nichts zu tun. In dem kurzen Zwischenraume zwischen dem Sehnerveneintritt und der sog. Orbitalcyste treffen wir ubbrigens wieder ganz analoge Verhältnisse wie vor und innerhalb der letateren, nur dass hier die Vermengung von mesodermalem and ektodermalem Gewebo auf die inneren Schichten beschränkt ist (vgl. Taf. XVII, Fig. 2 u. 3).

Die Sklora ist in ganzen Colobombereich stark verdickt und weist hier eine durchschnittliche Dicke von $2 \mathrm{~mm}$ anf.

Sehr kompliziert sind die anatomischen Verhälnisse am Sehnerven bzw. an der Sehnerveneintrittsstelle.

Wir bemerken hier vor allem, dass die zuletzt im hinteren unteren Colobomabschnitt beschriebenen Veränderungen auch nicht vor dem Sehnerven Halt machen, sondern den ganzen vordersten unteren Absehnitt desselben einnehmen. Sie erstrecken sich so tief in die Substanz des Sehnerven hinein, dass sie an dieser Stelle die Fntwicklung einer Lamina cribrosa verhindert haben. Das hier ebenfalls in starker Ausbildung vorhandene mesodermale Gewebe steht in mehrfacher Verbindung mit der verdickten Adventitia der ausschliesslich nach oben verlaufenden Zentralarterie, welche eine scharfe Grenze zwischen dem unteren pathologischen und dem oberen normalen Abschnitte des peripheren Sehnervenendes bildet. Sie verläuft jedoch zusammen mit der Zentralvene bereits unmittelbar hinter dem Auge mitten in dem Optikusstamm. Die Optikusrinne muss sich also von da ab geschlossen haben. Jedoch weisen die obere und untere Sehnervenbälfte anch hier noch tiefgreifende Unterschiede auf. Der untere Abschnitt zeigt nämlich eine schon makroskopisch deutlich wahrnehmbare Verbreiterung des Septengewebes und eine entsprechende Verminderung der nervösen Substanz, so dass er in nach van Gieson gefärbten Präparaten fast rein rot erscheint. Die mikroskopische Untersuchung ergibt zwar zwischen den Septen spärliche Reste von ektodermalem Gewebe, doch lehrt die von Gilbert (22) mit Recht warm empfohlene Markscheidenfärbung (Weigert), dass im unteren grösseren Abschnitt jede Spur yon Nervenfasern fehlt, während sie in der oberen, kleineren Hälfte eine annähernd normale Entwicklung zeigen.

Die Lamina cribrosa ist, wie Fig. 2 auf Taf. XVII zeigt, in der nasalen Sehnervenhâlfte im oberen Abschnitt ungemein kräftig entwickelt und verläuft in abnorm schräger Richtung nach hinten. Temporal kann von einer Verdickung nicht die Rede sein (Taf. XVII, Fig. 3).

Grundverschieden von den geschilderten sind die Verhaltnisse in dem klinisch ebenfalls als colobomatös erschienenen oberen Sehnervenabschnitt. Wir haben sehon erwähnt, dass die obere Sehnervenhälfte selbst keine colobomatösen Veränderungen anfweist. Hingegen besteht in der Umgebung des Sehnerven ein flacher Defekt der innersten Skleralschichten, sowie ein totaler Defekt der Aderhaut. Die Netzhaut liegt der Sklera direkt anf und zeigt hier die gleiche histologische Beschaffenheit wie im ganzen oberen Augenabschnitt. An der Colobomgrenze ist sie so stark gefaltet, dass sich die inneren Flächen berühren 
and durch gliöses Gewebe verbunden sind. Der dadurch geschaffene cystische Hohlraum ist von geronnenem Eiweiss und Zelldetritus ausgefüllt. Von der Verwachsungsstelle der Falte erstreckt sich ein dünner Faden gliösen Gewebes weit in den Glaskörper hinein.

Die Optikusscheiden sind oben in regelrechter Weise ausgebildet, unten ist jedoch kein Zwischenscheidenraum nachzuweisen.

Schliesslich findet sich temporal vom Sehnerven, und zwar an diesen unmittelbar anschliessend, zwischen Optikus und Pialscheide nochmals eine umschriebene, von Glia und Bindegewebe gebildete cystische Ausstülpung, welche in ihrem histologischen Aufbau ganz der nasal und unterhalb des Optikus befindlichen gleicht, sie aber an Tiefe ganz erheblich übertrifft. Sie erreicht annähernd die Länge des vorhandenen Sehnervenstumpfes, und auch ihre Breite kommt der des Optikus nahezu gleich. An ihrer dem Augeninneren zugewendeten Fläche besitzt sie eine ziemlich tiefe trichterförmige Excavation.

Als rein sekundäre Veränderungen, welche gewöhnlich in alten Colobomaugen gefunden werden, seien noch genannt eine Ablösung und weit vorgeschrittene Degeneration der Netzhaut des oberen Bulbusabschnittes, eine Verdickung und hyaline Degeneration ihrer Gefässwandungen, perivaskuläre Infiltration der Netzhautgefässe, diffuse and herdförmige Infiltration der Aderhaut, Sklerose der Ciliarfortsätze usw.

Auffallend ist endlich eine allgemeine mächtige Erweiterung der strotzend mit Blut gefüllten Venae vorticosae sowohl in der oberen als. in der unteren Bulbushälfte.

\section{Zusammenfassung.}

In einem ausgewachsenen Auge von normaler Grösse findet sich als anatomischer Ausdruck eines Iriscoloboms ein kurzer stummelartiger Rest von Irisgewebe (einschliesslich Pigmentepithel); an der Stelle eines klinisch festgestellten Aderhautcoloboms totales Fehlen der Aderhaut, gliöse Auskleidung der ganz unregelmässig geformten Innenfläche der Sklera und in der Gegend des hinteren Pols eine ausgedehnte, die ganze Skleraldicke betreffende diffuse Vermengung von ektodermalem (retinalem) und mesodermalem (skleralem) Gewebe.

Ausser dieser ganz diffusen Vermengung existiert noch etwas nasal und unterhalb des Sehnerven eine mehr umschriebene Einstülpung gliöser Gewebsmassen in die hochgradig verdünnte Sklera, ferner eine analoge Veränderung auf der temporalen Seite des Sehnerven zwischen diesem und der Pialscheide. An der Stelle des periphersten Abschnittes der unteren Sehnervenhälfte, welche durch die Zentralgefässe von der oberen scharf abgegreuzt ist, ist ebenfalls dieses Chaos von retinalem und skleralem Gewebe nachzuweisen. Weitere wichtigere Veränderungen sind: Totale Aplasie des ganzen 
vorhandenen unteren Sehnervenabschnittes, im vorderen A ugenabschnitte an der Grenze des Aderhautcoloboms eine breite, in das Augeninnere vorspringende Mesodermleiste.

Es hält nicht schwer bei unsern derzeitigen Kenntnissen von der Anatomie der Colobome, für diese zunächst grossenteils sehr merkwürdig erscheinenden Veränderungen eine Erklärung zu finden.

Dass sie alle in erster Linie auf eine Störung in dem Verschlusse der fötalen Augenspalte zurückzuführen sind, bedarf wohl keiner näheren. Erörterung. Welcher Art diese Störung war, lässt sich aus diesem Auge natürlich nicht mebr mit Bestimmtheit erschliessen. Ich möchte deshalb diesen Punkt vorläufig in suspenso lassen und auf die zusammenfassende Besprechung dieser Frage am Schlusse dieser: Arbeit verweisen.

Was das listologische Verhalten anlangt, so kann mit Bestimmtheit angenommen werden, dass in unserem Auge seinerzeit eine ausgedehnte Faltenbildung der Netzhaut stattgefunden hat, wobei die Falten nicht, wie so häufig, gegen das Bulbusinnere aufgestiegen sind, sondern sich nach auswärts zwischen das Mesoderm gedrängt und mit diesem innig vermengt haben. Im weiteren Verlaufe ist die Netzhaut im allgemeinen bis auf spärliche Reste ibrer Stützsubstanz zugrunde gegangen und von dem Mesoderm überwuchert worden. Nur an einigen Stellen, - unterhalb des Optikus und temporal wo es von vornherein zu einer kompakteren Masse vereinigt war, hat das Ektoderm gegenüber dem Mesoderm die Oberhand behalten.

Die Störung im Schlusse der fötalen Augenspalte hat sich auch bis in den distalen Teil des Optikus hineinerstreckt und daselbst den Schluss der Optikusrinne und die Ausbildung einer: Sehnervenpapille verhindert.

Kurz hinter dem Augapfel hat sich dann die Sehnervenrinne zwar geschlossen, es befindet sich jedoch die ganze untere Sehnervenhälfte in dem Zustande einer hochgradigen Aplasie. $\mathrm{Ob}$ diese durch eine mechanische Behinderung des Einwachsens der von der Retina stammenden Nervenfasern oder durch ein gänzliches Ausbleiben einer Entwicklung von Nervenfasern in der Retina des Colobomgebiets allein zu erklären ist, muss ich dahingestellt sein lassen.

Für mich ist die letztere Erklärung, wenigstens für meinen Fall, die wahrscheinlichere, $d a$ ich in der stark gefalteten und vielfach noch gut erhaltenen Netzhaut jüngerer Fälle ${ }^{1}$ ) von Aderhautcolobom

1) Die Präparate entstammen Fällen von $\mathrm{Bach}$ and Hess. 
ebenfalls keine Entwicklung von Nervenfasern beobachten konnte. Dass sich in meinem Falle die Optikusrinne unmittelbar an der Stelle ihrer Kommunikation mit der Augenblase nicht geschlossen liat, geht aus dem anatomischen Befunde mit Sicherheit hervor. Es ist also ein wirkliches auf den periphersten Teil des Sehnerven beschränktes Optikuscolobom vorhanden.

Es wäre dies nach Gilbert(22) erst der zweite, bzw. mitElschnigs (1) Fall, der dritte Fall eines wahren, durch Ausbleiben des Verschlusses der Optikusrinne bewirkten Coloboms, welches streng zu unterscheiden ist von den vielen andern unter dem gleichen Namen beschriebenen Veränderungen am Sehnerveneintritte, die mit dem Verschlusse der Optikusrinne in keinem Zusammenhange standen.

Die Literatur über diese Frage ist von Gilbert ${ }^{1}$ ) in seiner mehrfach citierten Arbeit auf das sorgfältigste zusammengestellt, kritisch gesichtet und eingehend berücksichtigt worden, so dass ich von einer Besprechung derselben vollkommen absehen kann. Ich stimme mit Gilbert (22) bloss darin nicht überein, dass auch Fall 2 ron Bock (25), sowie der Fall 5 von Bach(9) aus der Gruppe der wirklichen Optikuscolobome ausgeschlossen werden sollen.

Bocks(25) Fall scheint ja, nach der Beschreibung zu urteilen, mit dem meinigen nahezu identisch zu sein. Tch möchte nur einige Sätze aus derselben anfïhren, welche mir die weitgehende Ähnlichkeit unserer Fälle zur Genüge darzutun scheinen.

Auf St. 16 der Bockschen Monographie heisst es: "Die untere Hälfte der Papille ist durch eine das normale Niveau unregelmässig höckerig überragende Masse gebildet, welche aus wirr und regellos durcheinander geworfenem und verfilztem, ziemlich derbem Bindegewebe besteht. Dieses wird durch von der Sklera bzw. der Lamina cribrosa aufsteigende Balken, welche zapfenförmig in der Zahl von $1-3$ in diese Bindegewebsmasse hineinragen, in mehrere kleine Gruppen und Inseln geteilt." Diese dem Skleralgewebe gleichenden Zapfen oder Balken bilden bei dem Übergang von der Papille in die untere Hälfte der inneren Augapfelfläche einen stark hervorstehenden Buckel usw. Auch ist hier ebenso wie in meinem Falle "nur in der oberen Hälfte des Sehnerven der Austritt seiner Fasern durch die Lamina cribrosa aus der Papille zu verfolgen". Ein wesentlicher Unterschied gegenüber meinem Falle besteht darin, dass die Zentral-

1) Die während der Drucklegung meiner Arbeit erschienene ausführliche Mitteilung von George Coats (110) über den gleichen Gegenstand konnte leider nicht mehr im Texte berücksichtigt werden. 
gefässe nicht im Sehnervenstamme verlaufen, sondern ïberhaupt nicht zu finden sind.

Im Falle 5 von Bach(9) muss ausser der cystischen Ektasie unterhalb des Sehnerven auch eine ausgesprochene Störung im Verschlusse der Optikusrinne vorgelegen haben.

Die Abbildungen dieses Falles (Taf. I, Fig. 14, 15, 17 und 18), welche ich durch das liebenswürdige Entgegenkommen des Herrn Professors Bach mit den noch vorhandenen ungemein interessanten Präparaten selbst vergleichen konnte, zeigen, dass in dem unteren Abschnitte des Optikus ein bindegewebiger, gefässführender mesodermaler Zapfen verläuft, welcher offenbar dem Verschlusse des distalen Abschnittes der Optikusrinne und der angrenzenden Augenspalte ein unüberwindliches Hindernis entgegengesetzt hat. Die Folge dieses Hindernisses war, wie gewöhnlich, eine starke Faltenbildung der Netzhaut um den Zapfen herum und, wie mir scheint, sogar eine Duplikatur der Nervenfasern selbst. Ich. vermute nämlich, dass ein Teil des von Bach als Glia bezeichneten Gewebes, welches den Mesodermzapfen umgibt, aus Nervenfasern besteht und dass diese dem Zapfen entlang eine Schleife bilden. Ich schliesse dies aus dem an bestimmten Stellen sehr regelmässigen Verlauf der Fasern, deren Anordnung, wie übrigens auch in Fig. 17 ganz deutlich zu erkennen ist, streckenweise direkt an die Straktur des Sehnerven erinnert.

Da aber die mir vorliegenden Präparate nur mit Hämatoxylin oder Hämatoxylin-Eosin gefärbt sind, wobei die Nervensubstanz sich von dem übrigen Gewebe tinktoriell nur wenig unterscheidet, möchte ich dieser Vermutung nur mit grösster Vorsicht Ausdruck geben.

Für zweifellos aber halte ich die Tatsache, auf welche es hauptsäcblich ankommt, dass in diesem Falle im peripheren Ende des Sehnerven eine Verschlussstörung der fötalen. Spalte nachzuweisen ist.

Meine Annahme, dass die Vermengung des ektodermalen und mesodermalen Gewebes im Colobomgebiet durch eine Faltenbildung der Netzhaut zu erklären sei, stïtzt sich auf unsere derzeitigen Kenntnisse der pathologischen Anatomie jüngerer colobomatöser Augen, welche in den Arbeiten hauptsächlich der letzten zehn Jahre eine hervorragende Bereicherung erfahren haben. Ein Blick auf die Fig. 6, 7 und 8 in der schönen Arbeit E. v. Hippels (12) über die angeborenen typischen Spaltbildungen des Auges zeigt uns Bilder, wie sie eben von uns entworfen worden sind. Auch der Fall 2 von Bach (9) u. A. zeigt ausgedehnte Faltenbildung der Netzhaut und Dazwischenlagerung von mesodermalem Gewebe. Bach macht aus- 
Pathol-anat. Beiträge zur Kenntnis der angeborenen Colobome d. Auges. 301

drücklich darauf aufmerksam, dass „die bei dem Kaninchenfötus im Cystengebiet vorhandene Netzhaut keine Änderung ihrer Struktur, keine Atrophie zeigte". Diese Folgeerscheinungen wären aber im Laufe der Zeit sicherlich nicht ausgeblieben.

Ein irrtümlicherweise mit Coloboma nervi optici signiertes Präparat, welches ebenfalls geeignet ist, meine Ausführungen zu bestätigen, befindet sich auch in der Sammlung von Herrn Geheimrat Sattler. Es ist hier genau wie in meinem Falle unterhalb des Optikus eine umschriebene Ausstülpung von Netzhautgewebe in die Sklera und eine Vermengung der Netzhaut mit mesodermalem Gewebe rorhanden, nur dass hier die retinale Struktur noch deutlich erkenmbar ist, da es sich um ein ganz junges Individuum - neugeborenes Kind - handelt. Die Netzhaut zeigt in diesem Falle auf dem Boden der Cyste inverse Lagerung.

\section{Fall IV.}

\section{Mikrophthalmus mit Orbitopalpebralcyste links.}

Christine K., 31 Jahre.

In der Familie keine Missbildungen.

Das linke Auge ist angeblich seit der Geburt nicht zu sehen gewesen. Die Augenlider seien zuerst ganz in der Augenhöhle gelegen, dann sei das Oberlid dick geworden und später das Unterlid angeschwollen.

\section{Makroskopiseher Befund.}

Das linke Oberlid ist eingesunken, das Unterlid sowohl im Bereiche der Bindehaut als der äusseren Haut kuglig vorgewölbt. Die Cilien des Oberlids schleifen auf der Bindehant des Unterlids, welche hier ein glanzloses, xerotisches Aussehen aufweist. Im ganzen inneren (nasalen) Drittel ist die Conjunctiva tarsi beider Lider bis zum Lidwinkel verwachsen.

Die Caruncula lacrimalis, sowie die beiden Tränenpunkte sind vorhanden. Die Lidspalte ist von der gleichen Weite wie rechts, auch die beiden Orbitae zeigen die gleiche Breite und Höhe.

In der Tiefe der Orbita liegt ein Bulbusrudiment, welches grösstenteils von Bindehaut überzogen ist, so dass nur an einer kleinen, $5 \mathrm{~mm}$ breiten und $2 \mathrm{~mm}$ hohen Stelle ein als Cornea zu deutender bläulicher Saum zu sehen ist. Der Bulbus ist gut beweglich, erweist sich bei der Betastung annähernd rund und etwa so gross wie eine Haselnuss.

Die Cyste fühlt sich weich an, zeigt deutliche Fluktuation und reicht tief in die Orbita hinein.

Das rechte Auge ist äusserlich normal; es besteht ein perverser myopiseher Astigmatismus von $2 \mathrm{D}$ und eine Sehschärfe von ${ }^{6} / 30$, welche sich auf $6 / 6,6$ korrigieren lässt. 
Im Augenhintergrunde gewahrt man unterbalb der Papille zwei gelbrötliche, runde Herde.

Bei der Exstirpation der Cyste, welche ich mit Erlaubnis des Herrn Geheimrat Sattler (am 3.XI.05) vornehmen durfte, erwies sich die freigelegte Cystenwand teils sehnig weiss, teils bläulich durchscheinend, sie liess sich leicht aus ihrer Umgebung heransschälen, verlegte aber nach der Ausschälung den Eingang zar Orbita dermassen, dass eine Exstirpation im Zusammenhang mit dem Bulbusrudiment leider nicht gelang. Sie wurde deshalb für sich allein entfernt, dabei aber an einer Stelle angeschnitten, woranf sich eine zähe, gallertähuliche Flüssigkeit von gelblicher Farbe entleerte.

Bei der Enucleation des Bulbus wurde bei der Durchtrennung seiner Verbindung nach hinten das Gefühl eines knorpelharten Widerstandes ampfunden.

Durch Vernähung der Bindehantwunde usw, gelang es, einen Bindehautsack herzustellen, welcher das Tragen einer kleinen Protbese ermöglichte.

Der enucleierte Bulbus ist von annähernd kugliger Form, weist aber an seinem hinteren Pol einen Fortsatz von auffallend derber Beschaffenheit aul. Seine Masse sind folgende:

Sagittale Achse $=11,5 \mathrm{~mm}$
Horizontale $\quad "=11,5$,
Vertikale $\quad, \quad=10,1 \%$

Die Muskelinsertionen sind erkennbar.

Die Cyste ist zwar collabiert, aber vollständig vorhanden. Sie setzt sich hinten in eine zum Teil von orbitalem Fettgewebe umgebene Gewebsmasse fort, bei deren Betastung man das Gefühl von Fluktuation ompfindet, so dass in ihr eine weitere Cyste vermutet wird.

Der grösste Längsdurchmesser der collabierten Cyste beträgt im Schnitte $12 \mathrm{~mm}$, der Breitendurchmesser $4 \mathrm{~mm}$. Das Gewebe hinter der Cyste zeigt eine Ausdehnung von $12: 10 \mathrm{~mm}$.

Auch diese Masse entsprechen nicht den wirklichen Grössenverhältnissen, da das Gewebe hinten eine breite Schnittfläche aufweist, sich also jedenfalls noch wesentlich tiefer in die Orbita hineinerstreckt hat.

\section{Mikroskopische Beschreibung.}

Von dem in Zenkerscher Flüssigkeit fixierten Bulbus wurde temp. eine kleine Kalotte abgeschnitten; die Sklera erwies sich dabei ganz enorm verdickt.

Schnittrichtung horizontal.

Beim Schneiden des Bulbus stiess man sehr bald auf einen harten Körper, welcher als verkalkte Linse angesprochen und vorsichtig entfernt wurde, wobei er zerbröckelte. Das Präparat hat durch diese Manipulationen keinen Schaden erlitten.

Die Oberfläche des vorderen Augenabschnittes erweist sich auch bei der anatomischen Untersuchung von Conjunctiva überzogen, deren meist 
Pathol,-anat. Beiträge zur Kenntnis der angeborenen Colobome d. Auges. 303

regelmässiger Epithelbelag einige drüsenartige Einstülpungen zeigt. In der adenoiden Schicht reichliche Anhäufung von Rundzellen, teils in diffuser, teils in herdförmiger Anordnung.

Das Hornhantgewebe zeigt namentlich in den vordersten Schichten skleralen Charakter und ist stark vaskularisiert. In den hinteren Schichten ist es gefässlos und regelmässig angeordnet.

Eine Descemetsche Membran ist vorhanden und im Vergleiche zur Dicke der Hornhant als verdickt $\mathrm{zu}$ bezeichnen. Sie reicht in der $\mathrm{Pe}-$ ripherie nicht ganz so weit als normalerweise und hört mit zugeschärftem Rande auf.

Das Descemetsche Endothel ist nur streckenweise vorhanden. Die Iris liegt der Hornhauthinterfläche innig an und steht mit ihr in lockerer bindegewebiger Verbindung, welche von dem Irisgewebe geschaffen ist.

An verschiedenen Stellen liegt zwischen Iris und Descemetii noch eine schmale, nahezu homogene Gewebsschicht, welche die Eigenschaften des sog. kapselstarähnlichen Gewebes besitzt und endothelogener Herkunft sein dürfte.

Eine Vorderkammer ist nicht vorhanden. Die Gebilde des Kammerwinkels - sklero-corneales Netz, Skleralsporn, Sinus Schlemmii - sind aber durchweg zur Ausbildung gelangt.

Die Irisstruktur ist von ganz eigentümlicher Art. In dem stark gelichteten Stroma unterscheidet man deutlich einen zweifachen Verlauf des faserigen Gerüstes. Ein Teil desselben durchzieht die ganze Irisdicke senkrecht zur Oberfläche und setzt sich an der Hornhauthinterfläche an. Die Hauptmasse des Stromas ist aber in den Schnitten quergetroffen und muss also eine annähernd cirkuläre Verlaufsrichtung besessen haben.

Der Sphinkter ist verhältnismässig gut entwickelt, obwohl eine Pupille darchwegs fehlt. Eine Muskellage, welche dem Dilatator entspräche, ist nicht mit Sicherheit nachzuweisen.

Die Irisdicke schwankt im allgemeinen ziemlich beträchtlich. In der Gegend der Iriswurzel bzw. des Kammerwinkels ist das Stroma in grosser Ausdehnung ganz atrophiert, so dass das blosse Pigmentepithel die Hornhauthinterfläche auskleidet.

Gat ausgebildete Chromatophoren sind in der Iris nicht vorhanden, jedoch zahlreiche grössere und kleinere Pigmentanhäufungen von dem Aussehen der sog. Klumpenzellen der Iris, deren Abkunft aus dem Pigmentepithel erst von karzem von Elschnig und Lauber(26) in überzeugender Weise nachgewiesen worden ist. Das Gefässsystem der Iris ist äusserst schwach entwickelt und aus zartwandigen, kleinkalibrigen Gefässen zusammengesetzt.

Anf der Irishinterfäche 'und der Innenseite des Ciliarkörpers finden sich mehrfach Auflagerungen schwartigen Bindegewebes und deren Folgen - Destruierung der Pigmentschicht usw. - als Zeichen abgelaufener Entzündungsprozesse, über deren Bedeutungslosigkeit betreffs der Genese der Colobome heutigentages erfreulicherweise wohl allgemeine Ubereinstimmung herrseht.

Von einer eingehenden Schilderung derselben glaabe ich infolgedessen absehen zu dürfen. 
Nahe hinter der Corneo-Skleralgreaze durchsetzen ungemein starke Gefässe und Nerven die Sklera.

Die Form des verhältnismässig gut entwickelten Ciliarmuskels iš̀ ebenfalls durch sekundäre Veränderung stark beeinflusst. Es sind nur meridionale Muskelfasern vorhanden, eine cirkuläre Portion fehlt ganz.

Die Processus ciliares, welche temporal gut entwickelt, nasal aber stark verkümmert sind, sind auf der nasalen Seite so weit nach hinten gezerrt, dass ihre Basis mit der hinteren Endigung des Ciliarmuskels zusammenfallt. Auf der temporalen Seite ist diese Rückwärtszerrang lange nicht so ausgesprochen.

Sie ist durch eine schon makroskopisch festgestellte Verlagerung der Linse nach hinten bewirkt, mit welcher namentlich die Proc. ciliares der temporalen Seite durch starke Zonulafasern verbunden sind. Auf der nasalen Seite sind nur sehr spärliche Zonulafasern vorhanden, statt dessen ist hier der Raum zwischen Linse und Cilarkörper grössenteils durch ein tumorähnliches Gewebe (Glia) ausgefüllt, welches später genauer beschrieben werden soll.

Die Linse liegt, wie schon erwähnt, weit hinten und zwar, wenn wir die Augenlänge in 3 Teile teilen, ungefähr an der Grenze des hinteren und mittleren Drittels. Es sind von ihr nur die stark gefaltete und spiralig aufgerollte Kapsel, sowie dann und wann eine Spur kataraktöser Linsensubstanz, und mit Hämatoxylin tiefdunkelviolett gefärbte verkalkte - Schollen vorhanden. Im übrigen ist an ihre Stelle derbes schwartiges Gewebe getreten, das mit einem dicken, gefässhaltigen Bindegewebsstrangverbunden ist, welcher mehrfach geteilt, den ganzen hinteren Augenabschnitt durchzieht, unterhalb der Stelle, wo sich der Sehnerveneintritt befinden müsste, in die sklera einmündet und sich mit dieser teils verbindet, teils sie voll kommen durchsetzt, wobei er von dem skleralen Gewebe durch eine differente Verlaufsrichtung seiner Fasern ziemlich gut abgegrenzt zu werden vermag.

In dem nuterhalb des Stranges gelegenen Augenabschnitte ist auch von der Linse nichts mehr nachweisbar; es ist aber an der ihr entsprechenden Stelle ein dichter an den Bau eimes Angioms erinneruder Gefässknäuel anzutreffen.

Oberhalb des Stranges sehen wir die tumorartige Gewebsmasse, welche den hinteren Augenabschnitt einnimmt, durch ein aus vielfach zu Bündeln zusammengebackenen, wellig verlaufenden, sehr zarten Fibrillen gebildetes Gewebe getrennt. Die gleichen Fibrillen strahlen von einigen hinter der Linse endigenden Ästen des mesodermalen Stranges rossschweifähnlich nach allen Seiten aus. Zwischen den Fibrillen verlaufen zahlreiche engkalibrige und verhältuismässig dünnwandige Gefässe. In diesem vom hinteren Augenpol zur Linsenhinterfläche verlaufenden, von zarten Fibrillen eingenommenen Raume ist wohl unzweifelhaft der letzte Rest des ehemaligen Glaskörperxames zu erblicken, während das fibrilläre Gewebe das letzte Überbleibsel des fibrillären Glaskörpergerüstes darstellt. Das ganze Bild besitzt in bezug anf seine histologische Beschaffenheit eine grosse Ahnlichkeit mit den Veränderungen, welche man in den Glas- 
Pathol.-anat. Beiträge zur Kenntnis der angeborenen Colobome d. Auges. 305

körperrudimenten von Augen mit alten Netzhautabhebungen zu finden pflegt.

Der Raum zwischen der Hinterfläche der Iris und der nach hinten dislozierten Linse, welcher die in der nebenstehenden Skizze (Fig. 7) angegebene Form und Ausdehung besitzt, ist demgemäss natürlich nicht als Glaskörperraum anzusehen, sondern entspricht, genau genommen, der durch die Rückwärtsverlagerung der Linse stark vertieften hinteren Kammer. Er enthält auch keine Spur Glaskörpergewebes, sondern ist ausschliesslich von einem ausserordentlich dichten Fibrinnetz ausgefüllt.

Unterhalb der Linse ist der Glaskörperraum durch das gewucherte tumorartige Gewebe ganz ansgefüllt.

Ehe ich zur Beschreibung dieses Gewebes übergehe, sollen noch karz die Verbältnisse der Aderhaut und des Sehnerven geschildert werden. Die ganze Aderhaut erscheint durch ein breites schwartiges Gewebe, welches ihre Innenfläche überzieht und mit ihr in engster Verbindung steht, höchstgradig verdiekt. Eine gewisse Scheidung der beiden Schichten ist jedoch durch ein ganz unterschiedliches Verhalten derselben in bezug auf die Pigmentierung ermöglicht. Während nämlich die eigentliche Aderhaut, and insbesonders die Suprachorioidea einen ganz bedeutenden Gehalt an wohlgebildeten Chromatophoren aufweist, finden wir in der inneren Schicht ein ganz anderes in Haufen und Schläu- $h . k$. = hintere Kammer. $g l .=$ tumorchen angeordnetes Pigment, dessen $\mathrm{Ab}$ - artiges Gewebe. $l .=$ Linse. $0 .=0$ ptikus. stammung vom Pigmentepithel unverkennbar ist. Sowohl innerhalb der Aderhaut als auch in dem schwartigen Gewebe ist es stellenweise zur Knochenbildung gekommen. Im hinteren und anteren Abschnitt fehlt auf eine Strecke jede Spur einer Aderhaut.

Vom Nervus opticus ist nur ein sehr kummerliches Rudiment vorhanden, das in dem derben Gewebe in der Gegend des hinteren Augenpols eingebettet ist und erst hinter der sebr verdichteten Sklera beginnt, ohne in das Auge selbst einzudringen. Eine Papille ist unter diesen Umständen natürlich nicht nachzuweisen. Da das Präparat in Serien geschnitten und jeder Schnitt dieser Gegend gefärbt worden ist, kann auch von einem Übersehen eines derartigen Gebildes nicht die Rede sein. Der kurze, schmale Optikusstumpf hinter der Sklera besteht nur aus spärlichen Gliaresten und mesodermalem Septengewebe, welche in bezug auf ihre Anordnung einigermassen den normalen Bau eines Sehnerven nachahmen. In der Mitte dieses Rudiments verläuft ein einziges Gefüss, jedenfalls die Zentralarterie. Ein Zwischenscheidenraum findet sich nur tem. poral und oben.

Das schon mehrfach erwähnte tumorartige Gewebe, dessen Ausdehnung ebenfalls in der Fig. 7 veranschaulicht ist, zeigt alle Eigenschaften des von E.v.Hippel (27) in seiner Arbeit über das Zusammenvorkommen 
von Gliom und Mikrophthalmus beschriebenen gliosen Gewebes, das in v. Hippels Falle ebenfalls den grössten Teil des Augeninneren eingenommen bat.

Es setzt sich, wie dieses, hauptsächlich aus 2 Bestandteilen zusammen: 1. einem sehr ausgebreiteten System von Gefässen mit auffallend breiter Adrentitia und vielfach ausgesprochener Sklerose der Wandungen, 2. aus einem an Masse beträchtlich überwiegenden faserigen, gliösen Gewebe mit zahlreichen teils rundlichen (quer getroffenen), teils längsovalen Kernen. Dazwischen befinden sich ,grosse wandungslose, mit Blutkörperchen und deren Zerfallsprodukten gofülte Raume", sowie grössere und kleinere cystenartige Hohlräume, welche von Fibrin und spärlichen roten Blutkörperchen ausgefüllt sind.

Ganz übereinstimmend ist ferner auch das Verhalten des faserigen Gewebes zu den Gefässen bzw. zu dem mesodermalen Gewebe überhaupt. Es findet an keiner Stelle ein unmittelbarer Ubergang beider Gewebsarten statt, sondern es handelt sich mehr urn eine Anlagerung und Vermengung derselben, wobei das gliöse Gewebe entweder vor dem mesodermalen ausbiegt oder an einer das Ietztere umkleidenden bzw. einscheidenden Membran [Limitans Krückmann-Held (5u,6)] inseriert. Diese Beziehungen der beiden Gewebsarten lassen sich mit besonderer Deutlichkeit an den Stellen konstatieren, wo zwischen beiden durch Schrumpfung ein Spaltraum entstanden ist. (Vgl. namentlich Taf. XVI, Fig. 7.) Sie bestehen natürlich in der gleichen Weise an der Grenze zwischen dem gliösen Gewebe und der Aderhaut bzw. der sie uberziehenden Schwarte zurecht. Gerade hier äussert sich die raumausfullende Tatigkeit der Glia in der instruktivsten Weise. Sie füllt jede Lücke und Vertiefung der Oberfläche der Schwarte aus und bildet hernienartige (Krückmann) Fortsătze und Ausstülpungen.

Der Ursprung und Abfluss des weit verzweigten Gefässsystems ist in meinem Falle ebensowenig mit Sicherheit zu bestimmen, wie in dem Falle E. v. Hippels (27). Es existieren zahlreiche Verbindungen sowohl mit den Gefassen der Aderhautschwarte, als mit denen des mesodermalen Gewebsstranges, als anch mit einem sehr reichentwickelten Gefüsssystem, welches an einer umschriebenen Stelle des hinteren Pols nahe dem Stranggewebe zusammen mit dem gliösen Gewebe die Sklera durchsetzt.

In dem vorderen Abschnitte des gliösen Gewebes, sowio neben der Linse sind ebenso wie in dem Falle E. v. Hippels Züge und schlauchartige Gebilde von kubischen unpigmentierten epithelialen Zellen rorhanden, welche durch ihren Zasammenhang mit Zellen der Pars ciliaris retinae ihre Abstammnng in unzweideutiger Weise zu erkennen geben. -

Zeigt somit mein. Fall bis jetzt die denkbar grösste Ähnlichkeit mit dem E. F. Hippels (27), so ist es jetzt unsere Aufgabe, zur Schilderung der abweichenden Verbältnisse überzugehen.

Wir haben schon kurz erwähnt, dass die Aderhaut in der Gegend des hinteren Pols eine Strecke weit ganz fehlt, es ist also ein Colobom der Aderhaut vorhanden, das bekanntlich in v. Hippels Falle nicht nachzuweisen war. 
Wir haben ferner kurz angedeutet, dass die Sklera nasal hinten unten eine Unterbrechung zeigt, und dass diese Lücke durch ein Gemenge von Gefässen und gliösem Gewebe ausgefüllt ist. (Vgl. Taf. XVI, Fig. 4.) Diese Stelle befindet sich in der Nähe des Punktes, wo der zur hinteren Linsenfläche zichende Strang die Sklera durchsetzt. Neben dem Strange treffen wir nun streckenweise die gleichen Verhältnisse und zwar derart, dass der Strang in vielen Schnitten mitten in dieses Gemenge von Glia and Gefässen, das nach aussen in die Orbita quillt, eingebettet ist. Zwar ist die Verbindung mit dem orbitalen Gewebe bei der Exstirpation der Cyste bedauerlicherweise durchtrennt worden, doch tut dies der Beurteilung der Verhältnisse keinen weiteren Abbruch. Lässt sich doch mit Bestimmtheit nachweisen, dass and wo die Cyste und der Bulbus in Verbindung gestanden haben.

Das bei der makroskopischen Beschreibung erwähnte Gewebe hinter der Cyste besitzt nämlich genau die gleichen histologischen Eigenschaften, wie die gefä̀ssreiche gliöse Masse, welche den grössten Teil des Bulbus ausfullt. Es steht somit ausser Zweifel, dass es mit ihm verbunden war and einen gemeinsamen Mutterboden hat. Es ist durchwegs - mit Ausnahme seiner hinteren Fläche, wo es durchschnitten ist - von einer ziemlich dicken bindegewebigen Hülle umgeben (vgl. Taf. XVI, Fig. 5), welche sich unmittelbar in die Cystenwandung fortsetzt. Ein Teil der hinteren Cystenwand wird jedoch ron der an das Cystenlumen grenzenden vorderen Fläche des gliösen Gewebes selbst gebildet.

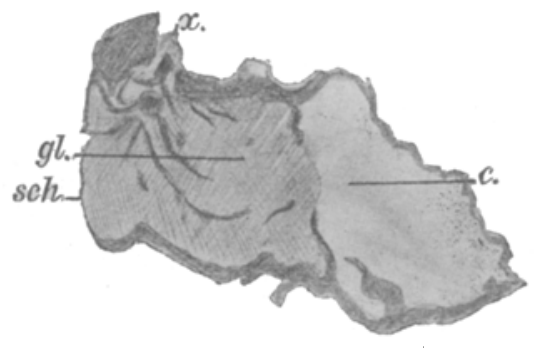

Fig. 8.

$g t_{*}=$ Glia. $c .=$ Cyste. $x .=$ Verbindungsstelle mit den Bulbus. sche = Schnittfäche (hiaten).

Der Bau des gliösen Gewebes, sowie seine Beziehnngen zu der bindegewebigen Hülle und den in ihm enthaltenen Gefässen, lassen sich, wie ich glaube, aus den Fig. 5-7, auf Taf. XVI, welche aus dem orbitalen Gliagewebe stammen, so klar ersehen, dass sich eine eingehende Beschreibung erübrigen dürfte.

Ich möchte nur darauf aufmerksam machen, dass die Verdickung der Gefässadventitia, sowie der Verengerung der Gefässlumina fast durchgehends einen aussergewöhnlich hohen Grad erreicht hat, was in den Fig. 5 u. 6 am schönsten beobachtet werden kann. So zeigte das Gefäss in der Mitte der Fig. 5 eine vollständige Obliteration seines Lumens. Interessant ist auch das Verhalten der Gefässe, was den Gehalt an elastischen Fasern anlangt. Viele weisen trotz der höchstgradigen Wandverdickung keine Spur von elastischen Fasern auf, in andern erscheinen diese cher vermehrt. Eine gewisse Gesetzmässigkeit habe ich dabei nicht herausfinden könneu.

Sehr viel Zeit und Mühe kostete das Auffinden der Stelle der Cyste, welche als die unmittelbare Fortsetzung des Bulbus angesprochen werden kann. Sie befindet sich, wie erwartet, - ich habe deswegen die Cyste in Vertikalschnitte zerlegt - im oberen Teile der orbitalen Glia und zwar 
ganz nahe ihrer hinteren Fläche (vgl. Fig. 8). Es ist hier die bindegewebige Hülle des Gliagewebes ebenso durch ein Gemenge von Gefässen und Glia unterbrochen, wie die Sklera nasal hinten unten, und es strahlen von dieser Stelle - und zwar von ihr allein - nach allen Seiten zahlreiche Gefässe fächerförmig in die orbitale Glia hinein.

Die Stelle demonstriert mit aller Deutlichkeit, dass so ziemlich das ganze reichliche Gewebe mesodermaler Herkunft, welches die orbitale Glia durchzieht, ausschliesslich aus den an dieser Stelle eingedrungenen Gefässen hervorgegangen ist.

Was endlich die Auskleidung des Cysteninneren anlangt, so ist bereits ausgesprochen worden, dass sie hinten zum Teil durch das gliöse Gewebe selbst gebildet wird. Bemerkenswert ist, dass an dieser Stelle nicht das geringste Anzeichen einer epithelialen Anordnung von Gliazellen zu betrachten ist. Aber auch in der weiteren Circumferenz der Cystenwand sehen wir noch vielfach reines gliöses faseriges Gewebe unmittelbar an das Cystenlumen grenzen oder sogar innerhalb der bindegewebigen Cystenwand inselförmig eingeschlossen. Der grösste Teil der Cystenauskleidung wird allerdings von einer in bezug anf ihre Dicke sehr wechselnden Schicht epithelialer Zellen gebildet, welche bald eine flache, bald eine hohe cylindrische Form besitzen, und stellenweise wie die Glia schlauchartige Fortsätze in die Tiefe der Cystenwandung senden oder innerhalb derselben als isolierte Haufen gefunden werden. Epithelzellen und Glia gehen dort, wo sie aneinander grenzen, ohne scharfe Grenze ineinander über. Eine abnliche Beschreibung der Cystenauskleidung haben Kundrat (28), Ginsberg(3), Natanson (29), Becker (54) u. A. geliefert.

Die Cystenwand ist nicht glatt, sondern weist zahlreiche böckerige Vorsprünge und buchtige Vertiefungen auf, welche sicherlich nicht ausschliesslich auf Kosten der artifiziellen Faltenbildungen zu setzen sind. Ihre durchschnittliche Dicke beträgt $0,35 \mathrm{~mm}$.

Ganz auffullig ist endlich der enorme Gehalt der Cystenwand an elastischen Fasern, welcher den an kollagenem Gewebe stellenweise übertrifft und bei Anwendung der Weigertschen Elastinfärbung schon mit blossem Auge durch die intensive dunkelblawe Färbung dex Cystenwand erkennbar ist.

\section{Zusammenfassung.}

In einem ausgesprochen mikrophthalmischen Auge, in welchen sämtliche Gebilde der sekundären Augenblase in mehr oder weniger veränderter Form nachzuweisen sind, verläuft durch den Glaskörperraum ein starker gefässhaltiger Bindegewebsstrang, welcher die Sklera unterhalb des Sehnerven durchsetzt, zur hinteren Linsenfläche zieht und sich mit dieser fest verbindet. Die Linse ist dadurch stark nach hinten und etwas nach unten disloziert und liegt an der Grenze des hinteren und mittleren Augenabschnittes. Sie ist mit Ausnahme ihrer vorderen Fläche von einem tumorartig gewucherten Gliagewebe 
Pathol.-anat. Beiträge zur Kenntnis der angeborenen Colobome d. Auges. 309

umgeben, welches den grössten Teil des Bulbusinnern ausfüllt, und seine Abkunft ron der Retina durch sein histologisches und tinktorielles Verhalten einwandsfrei bekundet. Dieses Gewebe durchsetzt in der Gegend des hinteren Augenpols unterhalb des Optikus za beiden Seiten des mesodermalen Gewebsstranges sowie unterhalb desm selben die Sklera und dringt hinaus in die Orbita, wo es zu einer sehr bedeutenden Mächtigkeit gelangt ist. Es ist durchweg von einer mesodermalen Hülle umgeben, welche als die unmittelbare Fortsetzung der Sklera anzusehen ist und auch den grössten Teil der Cystenwandung bildet ${ }^{1}$ ).

Die Deutung des gewucherten Gewebes als Glia, dessen Beurteilung ron v. Hippel(27) in seinem. Falle noch als sehr schwierig bezeichnet worden ist, bereitet heutzutage, nachdem unsere Kenntnisse von der Netzhautneuroglia durch die grundlegenden Arbeiten Krückmanns $(5,6)$ eine gesicherte Basis erhalten haben, keine Schwierigkeit.

Ich darf es wohl aussprechen, dass ich, ohne v. Hippels Arbeit gelesen zu haben, die Natur des Gewebes sofort beim ersten Schnitte, den ich färbte (Heidenhain, van Gieson), feststellen konnte, ja schon bei makroskopischer Betrachtung richtig vermutete. Die Heidenhainsche Färbung gestattet eben eine so scharfe Unterscheidung zwischen mesodermalem (rot-) und ektodermalem (fast schwarz gefärbtem) Gewebe, dass sie in den meisten Fällen jede spezifische Färbung überflüssig macht.

Die Gutartigkeit der gliösen Wucherung dürte durch nichts besser zum Ausdruck gebracht werden, als durch die Tatsache, dass sie sich stets an die Grenzen hält, welche ihr durch die mesodermalen Hüllen gezogen sind. (Vgl.Taf. XVI, Fig. 5.) Durch das Vorhandensein dieses tumorartigen gliösen Gewebes in der Orbita bildet

1) Es ist möglich, dass in einem von Dor(31) beschriebenen und von Chandeloux untersuchten Falle eine ganz analoge gliöse Wucherung das Cystenlumen ausfüllte. Dor erwăhnt von ihm, dass er ,a demontré la présence d'un sarcome fasciculaire au milieu du tissu cellulaire".

Ich kann mir ganz gut vorstellen, dass derartige Bilder, wie sie meinen hentigen Ausführungen beigegeben sind, zu der damaligen Zeit ebenso gut den Gedanken an ein Sarkom aufkommen lassen konnten, als beispielsweise an ein Gliom, was bekanntlich $\mathrm{Helfreich}(32)$ passiert ist.

In dem Falle von Bernheimer (92) drang ebenfalls tumorartiges retinales Gewebe an der Stelle des Sehnerven in die Orbita. Doch war hier die Zusammensetzung des tumorähnlichen Gewebes aus Netzhautfalten noch erkennbar. 
mein Fall geradezu ein Unicum ${ }^{x}$ in der Histopathologie des Anges, während die Tatsache der grossen Wucherungsfähigkeit der Neuroglia an und für sich durchaus kein histologisches Novum darstellt. Ich verweise in dieser Hinsicht wiederum auf die Publikationen Krückmanns über die Neuroglia des Auges spez. auf das Citat aus Nissls Vortrag auf S. 505-506 im LX. Bande des Archirs für Ophthalmologie.

Die grösste histologische Ähnlichkeit von den mir in der Literatur bekannt gewordenen Fällen scheint - abgesehen von den verschiedenartigen topographischen Verhältnissen - der jüngst von Dr. Charles May und Ward A. Holden(30) im LVIII. Bande des Archivs für Augenheilunde beschriebene Fall von Oberlidcyste mit Mikrophthalmus aufzuweisen.

Holden fand den oben innen! nahe dem Äquator entspringenden Stiel sowie den mit ihm verbundenen Oberlidtumor aus Netzhautfalten zusammengesetzt, welche „einfach aus einem Maschenwerk von Gliafasern mit zerstreuten Kernen, welches zahlreiche grosse sowie kleine Ganglienzellen einschloss", bestanden. Leider gestatten die beigegebenen Abbildungen nicht, sich ein bestimmtes eigenes Urteil über das genaue histologische Verhalten des Falles zu bilden. Mir erweckt nämlich z. B. die Fig. 4 weniger den Anschein von gefalteter Netzhaut, als den einer diffusen Wucherung undifferenzierten Netzhautgewebes. Im Interesse einer völligen Klarstellung dieses Falles wäre es auch wünschenswert gewesen, dass das ganze Präparat einschliesslich Auge zur Untersuchung kam, da wir so über die Art des Zusammenhangs der Cyste mit dem Bulbus nur auf vage Vermutungen angewiesen sind. Wenn es richtig ist, dass der Stiel der Cyste oben innen entsprang, so wäre dies wiederum ein Beispiel von atypischer Colobomcystenbildung, und der Fall vielleicht meinem heutigen Falle 1 zur Seite zu stellen.

Eine kurze Besprechung erheischen die zablreichen sowohl innerhalb des gliösen Gewebes im Bulbus wie in der Orbita gefundenen cystischen von Fibrin, Blutfarbstoff und zum Teil auch roten Blutkörperchen erfültten Hohlräume, welche namentlich in der Orbita stellenweise eine ganz respektable Ausdehnung zeigen.

Die Anwesenheit von Blutfarbstoff und roten Blutkörperchen gibt uns, glaube ich, einen deutlichen Hinweis, sie als Folgezustände von grösseren und kleineren Blutungen und somit als ein Analogon zu den kavernösen Hohlräumen anzusehen, welche nach Hämorrha-

5) Anm. w. d. Korr. Inzwischen hat $\mathrm{Natans}$ on ahnliche Fälle beschrieben 
Pathol-anat. Beiträge zur Kenntnis der angeborenen Colobome d. Auges. 311 gien in der Substanz des Zentralnerrensystems entstehen und von Schnaudigl (33), Deutschmann (34) u. A, im Anschlusse an Blutungen auch im Sehnerven gefunden wurden.

Darüber, dass in meinem Falle die Cystenbildung erst nach ${ }^{1}$ ) der Einstülpung der primären Augenblase zur sekundären eingetreten ist, besteht für mich kein Zweifel. Es sind ja sämtliche Gebilde der sekundären Augenblase vorhanden und es ist auch eine vollständige und regelrechte Differenzierung des äusseren Blattes zu Pigmentepithel erfolgt. Das gliöse Gewebe muss demnach aus dem inneren Blatte, von dem ja auch keine normalen Bestandteile vorhanden sind, hervorgegangen sein. Die fötale Augenspalte hat sich in unserem Falle in ihrem hintersten, unmittelbar unterhalb des Optikus gelegenen $\mathrm{Ab}$ schnitte nicht in normaler Weise geschlossen, die Netzhaut drang in Falten neben dem mesodermalen Gewebsstrang nach aussen und erfuhr im weiteren Verlaufe die beschriebene eigentümliche Umwandlung.

Es lässt sich zurzeit nicht mehr entscheiden, ob sie je eine gewisse Entwicklungsstufe im Sinne einer normalen Entwicklung erreicht hat, wobei die Neuroblasten einer totalen Degeneration anheimfallen mussten, oder ob von vornherein jede Entwicklung von Neuroblasten ausgeblieben ist und dafür die Spongioblasten zu um so kräftigerer Entwicklung gelangten. Dass die Netzhaut keine weitgehende Differenzierung erfahren hat, geht meines Erachtens vor allem aus dem Fehlen einer Papille hervor, was doch darauf schliessen lässt, dass eine normale Entwicklung von Nervenfasern unterblieben ist. Da diese ungefähr in der siebenten bis achten Woche einsetzt

1) Leo Natan s on (104) unterscheidet in seiner nach Abschluss meiner heutigen Mitteilung erschienenen sehr sorgfältigen Arbeit „Über Mikrophthalmus und Anophthalmus congenitus mit serösen Orbitopalpebralcysten (Arch.f. Ophth. Bd.LXVII, 2) scharf zwischen den Fällen, welche sich im Stadium der sekundären Augenblaseentwickeln und deren Entstehungan den ausgebliebenen Verschluss der fötalen Augenspalte gebunden ist (T. Gruppe), und denjenigen, welche im Stadium der primären Augenblase zur Entwicklung gelangen (II. Gruppe). Es versteht sich, wie gesagt, von selbst, dass mein Fall der I. Gruppe Natansons zuzurechnen ist.

Auf die Pathogenese und den Entstehungsmechanismus der Orbitopalpebralcysten im besonderen einzugehen, liegt nicht im Rahmen meiner heutigen Arbeit, was ich auch schon durch ihren Titel zum Ausdruck bringen wollte.

Mir kommt es heute nur darauf an, die Beziehungen der Orbitalcysten zu den Colobomen des Augapfels mit besonderer Berücksichtigung der beiden gemeinsamen Colobompathogenese zu besprechen, weshalb ich auch von eîner strengen Trennung der ektatischen (cystischen) Colobome und der Colobome mit Orbitopalpebralcysten abgesehen habe. 
und in der neunten Woche bereits soweit fortgeschritten ist, dass der Optikus zu dieser Zeit schon zu einem soliden Stiel geworden ist, so muss der Stillstand in der Entwicklung der Netzhaut recht zeitig eingetreten sein.

Dass trotz des Ausbleibens einer Nervenfaserbildung der im Zustand einer höchstgradigen Aplasie befindliche Optikusrest gewisse Anklänge an eine normale Optikusstruktur verrät (vgl. namentlich Fig. 9), braucht uns nicht sonderlich wunder zu nehmen, da ja

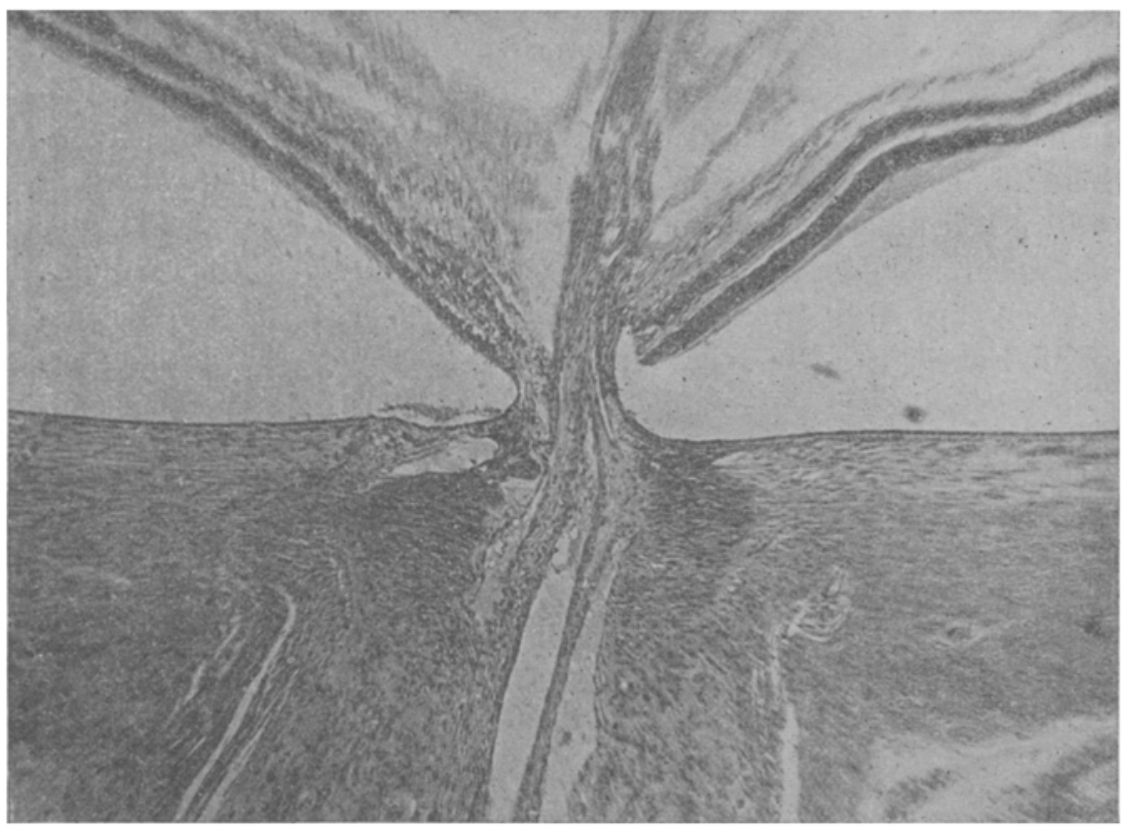

Fig. 9.

die Fähigkeit dazu den Zellen des Optikusstiels, welche bekanntlich auch normalerweise die Stützsubstanz des Sehnerven bilden, ohne weiteres zuzuerkennen ist. Die ektodermalen Bestandteile dieser Optikusrudimente können natürlich nur gliöser Natur sein. Es ist demnach, wie van Duyse $(35,36)$ bei der Besprechung eines Falles von totalem Fehlen eines Optikusstieles innerhalb der Orbita sehr richtig bemerkt, in der Tat das Ausbleiben jeglicher Entwicklung einer primären Augenblase und ihres Optikusstieles leichter zu begreifen, als die komplette Entwicklung der ersteren und das Verschwinden des letzteren.

In dem angeführten Falle van Duyses(35) fehlte ebenfalls 
Pathol.-anat. Beiträge zur Kenntnis der angeborenen Colobome d. Auges. 313

jedes Anzeichen einer Papille, jedoch waren innerhalb der Sklera rudimentäre Reste einer Optikusanlage nachweisbar, welche aber keine Zentralarterie enthielten. Diese fand sich vielmehr in dem Glaskörper unterhalb der Stelle, wo der Sitz der Papille zu vermuten war. Das Pigmentepithel zeigte an keiner Stelle eine Unterbrechung, ebensowenig die Netzhaut. "Zwar sind sie - die Pigmentepithelien - mehr oder weniger pigmentiert, einige sind auch verlagert und atrophiert infolge einer Einschaltung mesodermalen Gewebes, welches zwischen dem äussersten peripheren Ende des Optikusstiels und äusserem Pigmentblatt eine bindegewebige und gefässhaltige Schicht schuf." Das innere Blatt der Augenblase, und darauf kommt es $\mathrm{m}$. E. hauptsächlich an, ist aber nicht verändert und es ist hier nicht mit dem äusseren Blatte verbunden.

Über einen gleichen Befund berichtet Doetsch $\left.(37)^{1}\right)$ bei der Beschreibung eines Falles von Mikrophthalmus: „Es fehlt jede Andeutung einer Papille, auch im Pigmentepithel und in der Chorioidea findet sich nirgends eine Lücke, die dem Durchtritt von Nervenfasern oder Gefässen entsprechen würde."

Noch häufiger ist bekanntlich das gänzliche Fehlen einer Papille bei den hirnlosen Missgeburten beobachtet worden [Manz(38) u. A.]. Und es ist eine bekannte fast von allen Forschern [Rosenbaum(39), Sachsalber(40), Mayou(97), Golovine (98), Parsons (23), van Duyse (41) und vielen Andern] bestätigte Tatsache, dass die Netzhaut und der Sehnerv dieser Augen gewöhnlich²) jeglicher Nervenfaserbildung entbehren. In einer in dem gleichen Bande enthaltenen Arbeit über Cyklopie konnte ich zu den bisherigen Fällen einen weiteren von ganz einwandsfrei festgestelltem Fehlen jeder Papillenbildung hinzufügen, welcher mit dem Falle von van Duyse (36) auch, was das Verhalten des Sehnerven betrifft, manches gemeinsame aufweist. Es fehlt aber in meinem Falle sogar jede Veränderung seitens des Pigmentepithels, jede Lockerung seines Gefüges, jegliche Anomalie in der Pigmentierung usw. Das gleiche ist an dem korrespondierenden Netzhautabschnitte der Fall. Zur Erklärung seines Falles nimmt van Duyse (36) an, dass der Sehnerv nicht zur Rinne eingestülpt worden sei, und dass die Àrteria hyaloidea aus diesem Grunde nicht in den Sehnervenstamm eindringen konnte, sondern im

1) Auch Best (111) hat bei der anatomischen Untersuchung der beiden mikrophthalmischen Augen einer mensehlichen Missgeburt das Fehlen beider Optici beobachtet. Fine genauere Beschreibung liegt noch nicht vor.

2) Über einen Ausnahmefall habe ich in dem gleichen Hefte berichtet. 
Glaskörperraume verblieb, eine Auffassung, welcher ich nicht beipflichten kann. Es ist meines Erachtens von vornherein ganz unwahrscheinlich, dass in einer gemeinsamen Augenanlage die Einstülpung eines Teiles - der primären Augenblase - erfolgen, dagegen die eines andern Teiles - des Augenblasenstiels - ausbleiben solle.

Es ist ferner zurzeit mit Bestimmtheit anzunehmen, dass diese Einstülpung ein sowohl von der Linsenentwicklung als rom Mesoderm bis zu einem gewissen Grade unabhängiger Vorgang ist ${ }^{1}$ ). Ersteres ist erst in der allerneuesten Zeit wiederum durch die Fälle von v. Hippel(42) und Hanke(31), in welchen eine sekundäre Augenblase, aber keine Linse entwickelt war, in klarer Weise vor Augen gefibrt worden. So schreibt v. Hippel (42) wörtlich: "Wir erhalten durch unsern Befund eine neue Bestätigung der schon bekannten Tatsache, dass eine Einstülpung der Augenblase von vornherein auch ohne Mitwirkung der Linse zu stande kommen kann."

Eine sehr zutreffende Schilderung dieser Verhältnisse, soweit sie sich ausschliesslich auf die besprochene Frage bezieht, ist auch in der Arbeit Pichlers(17) enthalten.

Und Hugo Fuchs (44), dem wir eine ausgezeichnete Darstellung der Entwicklung der Augengefässe des Kaninchens verdanken, äussert sich folgendermassen: „Die Vorstellung, dass eine Gefässschlinge an der kaudalen Wand der Augenanlage gegen den Glaskörperraum vorwächst und die kaudale Wand der Augenanlage nach innen einstülpt, ist sicher nicht richtig." Der gleiche Autor erbringt auch den Nachweis, dass sich die Verbindung der primären aus der Ringarterie entspringenden Glaskörperarterie nach hinten, also die spätere Arteria centralis retinae, erst sekundär entwickelt, nachdem sich der Angenblasenstiel bereits zur Rinne eingestülpt hat. Da wir allen Grund haben, beim Menschen einen gleichen Entwicklungsgang anzunehmen, so kann demnach die Einstiulpung der Sehnervenanlage nicht von der Ausbildung dieser Gefässverbindung abhängig sein, was $\mathrm{van}$ Duyse (36), nach folgenden Worten zu urteilen, anzunehmen scheint: „Die Arterie, welche später der Zentralarterie der Netzhaut entspräche, bildet sich in dem Teile des mesoblastischen Gewebes,

1) Sehr bestimmt spricht sich darüber namentlieh Keibel(101) aus. Nach ihm „ist die Umbildung der primären Augenblase in den Augenbecher durchaus unabhängig von der Linse. Wenn man experimentell die Bildung der Linse verhindert, so bildet sich die primäre Augenblase dennoch zum Augenbecher um. Der Finstiulpungsvorgang beruht auf Wachstumsdifferenzen innerhalb der Wand der primären Augenblase' ${ }^{\circ}$. Man vgl. hiermit auch die Ausführungen A. v. Szilys (89). 
welche den Sehnerven in einer bestimmten Ausdehnung einstülpt." Meines Erachtens fordert die Betrachtung der Fälle von van Du yse (36), Doetsch(37), sowie meines nur ganz kurz angeführten Falles von Cyklopie zu folgender Überlegung auf. $\mathrm{Da}$ an der Stelle des Sehnerveneintritts, welche durch das Vorhandensein eines Optikusrudimentes innerhalb der Sklera genau bestimmt werden kann, weder das Pigmentepithel noch die Netzhaut eine Lücke aufweisen, müssen sich dort die beiden Blätter der sekundären Augenblase in der gleichen glatten Weise vereinigt haben wie im Bereiche der fötalen Augenspalte.

Um diese Tatsache kommen wir auf keinen Fall herum, so merkwürdig sie auch erscheinen mag. Eine solche abnorme Verwachsung kann natürlich nur in sehr früher Zeit erfolgen und wird höchstwahrscheinlich Hand in Hand gehen mit dem physiologischen Schliessungsprozesse der fötalen Augenspalte. Sie könnte sicherlich micht mehr stattfinden, nachdem die Entwicklung der von der Netzhaut auswachsenden Nervenfasern eine gewisse Stufe erreicht und somit die Ausbildung einer Papille begonnen hat. Über diesen Zeitpunkt besitzen wir, wenigstens vom Menschen, leider nur ganz dürftige Angaben; nach His, welcher bei menschlichen Embryonen von etwa fünf Wochen (13 mm Länge) die ersten Optikusfasern beobachtet hat, ginge er dem vollständigen Verschlusse der Augenspalte unmittelbar voraus.

Infolgedessen erscheint mir die Tatsache für das Verständnis der besprochenen Anomalie von grösster Wichtigkeit, dass letztere bis jetzt nur in Augen gefunden worden ist, in welchen keine Sehnervenfasern zur Entwicklung gelangt sind. Dies ist, wie wir wissen, regelmässig der Fall in den Augen der Anencephalen und ist auch in den Beschreibungen der Fälle von Doetsch (37) und van Duyse (35) ausdrücklich erwähnt. Dazu gesellen sich mein Fall IV, ferner mein kurz angeführter Fall von Cyklopie, in welchem ebenfalls keine Anzeichen von Nervenfaserentwicklung nachweisbar sind.

Eine gänzliche Verwachsung der beiden Augenblätter an der Stelle des Sehnerveneintrittes kann aber selbstverständlich auch dann nicht stattfinden, wenn die sekundäre Verbindung zwischen der primitiven Arteria hyaloidea und der Choriocapillaris, die spätere Arteria centralis retinae, bereits gebildet ist. Diese Tatsache könnte durch nichts besser veranschaulicht werden, als durch die Fig. 9, welche ebenfalls dem Auge einer hirnlosen cyklopischen Missgeburt (Fall IV meiner im gleichen Hefte enthaltenen Arbeit über Cyklopie) ent- 
stammt und in überzeugendster Weise zeigt, dass nur das Vorhandensein. der Zentralgefässe und ihrer Fortsetzung, der übermächtig entwickelten Arteria hyaloidea, die vollständige Vereinigung der auf das stärkste genäherten beiden Blätter der sekundären Augenblase verhindert hat.

$\mathrm{Zu}$ diesem rein anatomischen Befunde bildet folgende hochinteressante Beobachtung von Brière (105), welche übrigens beweist, dass ein gänzlicher Mangel von Nervenfasern in der Netzhaut und im Sehnerven auch bei einem anscheinend durchaus normalen Individuum vorkommen kann, eine wertvolle Ergänzung: Bei einem siebenjährigen Kinde fand sich auf beiden Augen bei der ophthalmoskopischen Untersuchung als einzige Abweichung von der Norm ein totaler Defekt der Papille. An der Stelle, wo die Papille zu vermuten war, war weiter nichts als der Eintritt der Netzhautgefässe, welche eine normale Verteilung aufwiesen, wahrzunehmen. Die Pupillen beider Augen waren weit und erfuhren nur bei Anwendung starker Lichtreize eine schwache Verengerung ${ }^{1}$ ). Es bestand totale Amaurose.

Die gleiche Beobachtung hatte Brière bereits in einem andern Falle gemacht.

Ich glaube, aus dem Gesagten ergibt sich die Schlussfolgerung hinsichtlich der Pathogenese der in Rede stehenden Veränderung von selbst:

Infolge des Ausbleibens einer Entwicklnng von Nervenfasern erfolgt an derStelle, wo das Einwachsen der Nervenfasern in den Augenblasenstiel stattfinden soll, eine abnorme Annäherung der beiden Blätter der sekundären Augenblase, welche in den besprochenen sowie andern Fällen $z u$ einer glatten Vereinigung derselben geführt hat.

So zeigen auch die Abbildungen von Sehnerveneintrittsstellen menschlicher Anencephalen, welche den Arbeiten Sachsalbers (40) und Rosenbaums (39) beigegeben sind, eine derartige Verkleinerung der Sehnerveneintrittsstelle und eine so starke Annäherung der Augenblasenränder, dass nur wenig gefehlt hätte, um sie zur Vereinigung zu bringen, was auch aus folgenden Worten Sachsalbers hervorgeht: „Die Netzhaut ${ }^{2}$ ) ragt von allen Seiten soweit über die Papille herein, dass nur etwa $0,3 \mathrm{~mm}$ im Zentrum unbedeckt bleiben."

1) Vgli Hertel (106, 107), Experimentelles über die Verengerung der Pupille auf Lichtreize, 33. Heidelberger Bericht 1906. Arch. f. Ophth. Bd. LXV. 1906.

2) In der Abbildung auch das Pigmentepithel (d. Vorf). 
Pathol.-anat. Beiträge zur Kenntnis der angeborenen Colobome d. Auges. 317

Die Perforation der Linsenkapsel, für welche im Falle E. v. Hippels(27) keine ausreichende Erklärung zu finden war, dürfte in meinem Falle vielleicht auf den Zug des an der hinteren Linsenfläche befestigten Stranges zurückzuführen sein. Spielen doch ähnliche Verhältnisse in der Pathogenese des Lenticonus posterior, bei welchem fast stets eine Zerreissung der hinteren Linsenkapsel gefunden wurde, eine grosse Rolle, wobei der Annahme nichts im Wege steht, dass eine derartige Ruptur ein anderes Mal eine vollständige Resorption der Linsensubstanz zur Folge haben kann, ja stets haben wird, sobald nicht der Kapselriss auf irgend eine Weise geschlossen wird. So hält z. B. auch Bach $(9,45)$ in seinen Fällen für wahrscheinlich, „dass die Ruptur der Linsenkapsel und die Lenticonusbildung durch Zugwirkung von seiten des durch die Mitte des Glaskörpers ziehenden, aus der Embryonalzeit persistierenden Bindegewebsstranges verursacht sei, eine Ansicht, die bereits vorher von Hess (8, 47), später, auch von Salffner (46) ausgesprochen worden ist. Auch Rogman (68) führt in seinem Falle von Mikrophthalmus mit Orbitalcyste die Ruptur der Iinsenkapsel auf eine Zugwirkung durch den an der Linsenhinterfläche befestigten und zur Cystenöffnung ziehenden Strang zurück.

Durch den Nachweis eines vom hinteren unteren Augenabschnitte zur Linse ziehenden Mesodermstranges tritt unser Fall in enge Beziehungen zu einer Reihe von andern Fällen, welche in der Literatur beschrieben worden sind.

So liess sich in dem überaus klar beschriebenen Falle von Hess (8) ein feiner bindegewebiger Strang von der hinteren Linsenfläche in den Verbindungskanal zwischen Bulbus und Cyste verfolgen.

In vier von den fünf Fällen Kitamuras (48), ,zieht ein bindegewebiger Strang durch das Colobom von unten in den Glaskörperraum, wobei er mit der noch vorhandenen bindegewebigen Linsenkapsel in innige Verbindung tritt".

In einem Falle Natansons (29) zog von der Linse ein gefässhaltiger Bindegewebsstrang zur unterhalb des Optikus gelegenen Cystenpforte hin.

Das gleiche war der Fall in den Fällen von Cruise (49), Treacher Collins (50) und Bednarski (69).

In einem andern Falle von Hess(52) zog ebenfalls von dem unteren Rande der Optikusfasern ein ungefähr $1 \mathrm{~mm}$ dicker bindegewebiger Strang nach vorwärts zur hinteren und unteren Linsenfläche. Der Strang durchsetzt hinten die Sklera und es „wuchs 
dann hier zu beiden Seiten des Stranges das Retinagewebe durch den Spalt nach aussen".

In einem weiteren Fall von Orbitalcyste, der von Hess(51) beschrieben worden ist, verlief ebenfalls durch die Mitte der Kommunikationsöffnung zwischen Cyste und Bulbus ein kleiner runder Strang von $1 \mathrm{~mm}$ Durchmesser, von welchem zahlreiche, ziemlich starke Fasern in geradlinigem Verlaufe leicht divergierend zur Linse zogen.

Dazu kommen endlich die Fälle II u. $V$ von Bach (9) mit cystischen Elktasien der Sklera und Ausstülpung der Netzhaut in die Orbita, in welcher ebenfalls vom unteren Rande des Optikus bindegewebige Stränge zur Linse verlaufen.

Diese Fälle mit Strangbildung ${ }^{1}$ ) unterhalb des Sehnerven sind wiederum mit allen den Fällen von Colobom und Mikrophthalmus mit und ohne Cystenbildung prinzipiell auf eine Stufe zu stellen, bei welchen an einer Stelle, wo normalerweise der Schluss der fötalen Augenspalte erfolgen sollte, mesodermale Einlagerungen gefunden wurden. Hat sich doch immer mehr die zweifellos richtige Anschauung Bahn gebrochen, dass es sich bei allen diesen Zuständen nur um verschiedene Modifikationen eines colobomatösen Prozesses handelt, ebenso, wie es im Prinzip völlig gleichgültig ist, an welcher Stelle der Augenspalte dieser mesodermale Strang, Zapfen oder die Leiste gefunden wird. Meiner Ansicht nach ist auch die Frage, ob diese Gebilde als Folgezustände mangelhafter Rïckbildung des normalerweise zu einer gewissen Zeit im Fötalspalt vorhandenen mesodermalen Bildungsgewebes angesehen werden, oder ob den durch die Augenspalte ein- bzw. austretenden Gefässen die Hauptrolle zugeschrieben wird (Manz 53), von nebensächlicher Bedeutung im Vergleiche zu der wichtigen Kontroverse, welche sich über die Bedeutung dieses mesodermalen Gewebes in letzter Zeit zwischen Elschnig $(1,2)$ und v. Hippel(11) entsponnen hat.

Bekanntlich ist v. Hippel, dem es zum erstenmale gelungen ist, die Entwicklung der typischen Colobome an Kaninchenembryonen von Stufe zu Stufe zu verfolgen, ein überzeugter Anhänger der schon von Manz (53) aufgestellten und durch zahlreiche Forscher, ich nenne nur Hess, Bach, Becker $(54,55)$, Bock (25), Salffner (46), ver-

1) Die Falle mit Strangbildung von der Papille zur Linse ohne Colobomoder Cystenbildung unterhalb des Sehnerven von Bach, Hess, Vossius (93) u. A. sind oben absichtlich nicht mit aufgeführt worden. Im Falle Rogman (68) lag die Offnung der Sklera und die Eintrittsstelle des Stranges oberhalb des Sehnerven. 
Pathol.-anat. Beitrüge zur Kenntnis der angeborenen Colobome d. Auges. 319 tretenen Theorie, dass die Mesodermleiste, welche er in allen seinen Fällen gefunden hat, unbedenklich als die Ursache der Colobombildung anzusprechen sei.

„Die Ränder der Augenblase werden durch einen ganz schmalen, nur aus wenigen Zellen bestehenden, Gefässe führenden mesodermalen Gewebsstrang an ihrer Vereinigung gehindert, obwohl sie fast bis zur Berührung einander entgegengewachsen sind."

"Eis entsteht eine Duplikatur der Retina, nicht weil sie das Bestreben hat, in die Umgebung hinaus zu wuchern, sondern einfach, weil sie einem Hindernisse Platz machen muss."

Die Anschauungen anderer Autoren, welche die primäre Ursache in einem vorübergehenden Stillstande des Wachstums der sekundären Augenblase erblicken [Leber(56), Pichler (17)1 $)^{2}$ )], wodurch das Mesoderm Zeit und Gelegenheit fände, in die fötale Augenspalte einzudringen und $\mathrm{zu}$ wuchern, betrachtet er durch seine Befunde als widerlegt.

Eine gewichtige Stütze für seine Stellungnahme erblickt v. Hippel(11) darin, dass die zelligen Elemente der Augenblase, speziell ihrer Ränder, in allen seinen Fällen absolut normale Verhältnisse zeigten: "Die Kernteilungsfiguren sind hier ebenso zahlreich und regelmässig wie an andern Stellen, es fehlt also jeder Anhaltspunkt für die Annahme, dass das Wachstum der Augenblase durch Schädigung ihrer Zellen beeinträchtigt ist."

Gegen die Leber-(58) Pichlersche (17) Anschaung, von der

1) Hier wäre vielleicht auch noch der Äusserung Ginsbergs (15) zu gedenken gewesen, dass in den Fällen von Mesodermbildung im Augenínnern erst nachzuweisen sei, ob das durch einen Netzhautdefekt in den Glaskörper eingedrungene Mesoderm nicht erst sekundär eingewuchert sei.

2) Bekanntlich lassen Pichler und van Duyse auch noch eine mechanisehe Behinderung des Spaltenschlusses durch Druck des Amnions auf die Augenblase gelten, eine Ansicht, welche mir gegenüber S chapringer betr. der Pathogenese der Mikrophthalmen mit Cystenbildung brieflich ausgesprochen hat. - Die Unzulässigkeit, die an einem Gummiaugenblasenmodell erhaltenen Resultate Pichlers auf das sulzige embryonale Gewebe zu übertragen, ist bereits von v. Hippel in gebührender Weise betont worden. Ich möchte noch hinzufügen, dass nach meiner Ansicht ein länger währender Druck des Amnions - denn um einen solchen müsste es sich doch handeln - in einer so frühen embryonalen Lebensperiode auch noch zu andern sichtbaren Folgen, z. B. Lidcolobomen [vgl. Fälle von E.v. Hippel (57), Hoppe (58)], Dermoiden [G. Stanculeano u. Costin (102), yan Duyse (59), Bernheimer (60), Matys (91), Marchand (99) usw.] - führen müsste, welche bekanntlich bei Colobomenaugen auch nicht häufiger beachtet werden als bei andern Augen. 
sich die Theorie van Duyse(41) nur wenig unterscheidet, hatte schon vorher Hess (51) ganz entschieden Front gemacht. Überhaupt gehört Hess von Anfang an zu den energischsten Vertretern der Theorie, welche die Mesodermleiste als das Hindernis der vorwachsenden Augenblasenränder ansieht, was auch aus folgender Äusserung in seiner letzten Arbeit über diese Frage in unzweideutiger Weise hervorgeht: „Das besondere Interesse der letztheschriebenen Fälle liegt darin, dass sie in sehr reiner und typischer Weise die Folgen der mechanischen Behinderung eines völligen Verschlusses im vorderen Abschnitte zeigen."

Diese von der überwiegenden Mehrzahl der Colobomforscher anerkannte Bedeutung des Mesodermzapfens ist nun in neuerer Zeit besonders von Elschnig $(1,2)$ bestritten worden. Elschnig behauptet, dass sie nur dann Geltung beanspruchen dürfe, falls sich der Mesodermzapfen im Colobombereiche durch eine besondere histologische Beschaffenheit, z. B. abnorme Derbheit, Vaskularisation usw., von dem auch normalerweise im Spaltbereiche vorhandenen Mesoderm unterscheide. Sei dies nicht der Fall, "dann haben wir nicht die Berechtigung, denselben als die Ursache des Offenbleibens der Fötalspalte anzusehen, so wenig, wie das normalerweise immer ursprünglich die Fötalspalte füllende Mesodermgewebe den normalen Verschluss verhindert".

Durch den Vortrag E. v. Hippels (12) in Heidelberg, in welchem dieser die Ergebnisse seiner embryonalen Forschungen in Kürze bekannt gab, hält Elschnig diesen Beweis noch nicht für erbracht. Er hält infolgedessen an seiner schon früher geäusserten Ansicht fest, „dass primär ein Sprossen der Augenblasenränder in abnormer Richtung die Ursache der Bildungsanomalie sei".

Auf einen Teil der Einwände Elschnigs $(1,2)$ ist E. v. Hippel (11) bereits gelegentlich der ausfübrlichen Publikation seiner Forschungsergebnisse eingegangen. $Z \mathbf{u}$ den letzten $\ddot{A}$ usserungen Elschnigs hat er meines Wissens nicht eingehend Stellung genommen. Es dürfte deshalb in Anbetracht ihrer Wichtigkeit nicht unangebracht sein, ihre Berechtigung an der Hand des bis heute vorliegenden Missbildungsmaterials unter Berïcksichtigung der normalen embryologischen Verhältnisse nochmals zu prüfen.

Was zunächst Elschnigs (2) Forderung, dass das Mesoderm eine besondere Derbheit aufweisen müsse, anbelangt, so ist sie wohl nicht ganz wörtlich zu nehmen, da in der frühen embryonalen Periode, in welcher sich der Schliessungsprozess der fötalen Augenspalte voll- 
zieht, von einer abnormen Derbheit irgend einer Gewebsgattung überhaupt nicht gesprochen werden kann. Das Mesoderm zwischen den Augenblasenrändern ist naturgemäss zu dieser Zeit fast rein cellulär wie das die Augenblase einhüllende Mesoderm, aus welchem die Sklera und die Chorioidea - die Choriocapillaris ist schon angelegt hervorgehen. Es könnte sich wohl nur darum handeln, ob die zwischen den Augenblasenrändern vorhandenen Mesodermzellen in Colobomaugen vielleicht eine dichtere Anordnung zeigen als unter normalen Verhältnissen, doch dürfte sich darüber nicht so leicht eine Entscheidung treffen lassen. A us den Abbildungen, welche v. Hippel $(11,12)$ seiner Arbeit beigegeben hat, lässt es sich jedenfalls nicht entnehmen, und in Fig. 1, welche einem 13 Tage alten Kaninchen entstammt, ist es ganz gewiss nicht der Fall. Dieses Bild unterscheidet sich überhaupt so wenig von dem einer unmittelbar vor dem Schlusse stehenden Augenspalte, dass mir nicht ganz ausgemacht $\mathrm{zu}$ sein scheint, ob hier nicht am Ende doch noch ein normaler Schluss zu stande gekommen wäre. Wenn man bedenkt, dass sich diese Vorgänge in den Augen von Tieren mit einer so kurzen embryonalen Lebenszeit mit einer geradezu verblüffenden Geschwindigkeit abspielen, so dass sicher ein halber Tag eine wesentliche Änderung der Verhältnisse bewirkt, dann wird man die Berechtigung meiner Bedenken anerkennen. Von v. Hippel(11) wird übrigens diese Frage selbst zur Diskussion gestellt. Er entscheidet sich für die Annahme eines Coloboms.

Die Beschaffenheit der Mesodermleiste in älteren Colobomaugen erlaubt natürlich keine bindenden Rückschlüsse auf ihren Zustand zur Zeit der Entstehung des Coloboms. Sie wird meist als sehr derb, skleraähnlich beschrieben, zuweilen enthält sie knorplige Einschlüsse [Hess (52), Dötsch(37), v. Hippel(112) Pichler(77)] und in vereinzelten Fällen [Wiegels (61), Lange(62)] dringt typisches Fettgewebe in den Glaskörperraum.

Auch die jüngsten menschlichen Augen, welche zur Untersuchung gelangt sind, können zur Entscheidung dieser Frage nicht mehr herangezogen werden. Von den Fällen Hess (Arch. f. Augenheilk. Bd. XLI, 1. Fall) und Bach (Arch. f. Ophth. Bd. XLV, 1. Fall) habe ich selbst Präparate gesehen und kann zu dem ersteren bemerken, dass die Mesodermleiste nur aus dicht gelagerten Mesodermzellen mit sehr zarter fibrillärer $Z$ wischensubstanz besteht, während im Falle Bach(9) die Struktur des Zapfens mit der Sklera übereinstimmt; welcher er aufsitzt. In meinem Falle 2 - einem Katzen- 
embryo - besteht die Leiste ebenfalls aus dicht gelagerten Mesodermzellen mit spärlicher Bindegewebsentwicklung und zeigt die Eigenschaften embryonalen Bindegewebes in gleicher Weise, wie die äusseren Augenhäute. Auch in einem andern Falle von Hess (Arch. f. Ophth. Bd. XXXIV, Fall 2), einem anscheinend nicht ausgetragenen Kinde ${ }^{1}$ ), ist der durch die Sklera ziehende Strang noch sehr zellreich und arm an fibrillärer Zwischensubstanz.

Gehen wir zur Erörterung der 2. Forderung Elschnigs(2) über, dass sich die Strangbildung durch abnorme Vaskularisation auszeichnen müsse, so finden wir diese schon eher erfullt. Und hier sind auch die älteren Fälle mit grösserem Rechte mit zu verwerten, da wir die Gefässentwicklung innerhalb der Mesodermleiste nicht in dem Masse als eine sekundäre Erscheinung anzusehen brauchen, wie die Verdichtnng ihres Gewebes. Man kann sagen, dass innerhalb des Stranges oder der Leiste, oder von diesen ausgehende Gefässe in den meisten Fällen gefunden wurden. Sehr schön ist dies auch in meinen drei Fällen von typischer Colobombildung zu sehen, ferner in dem schon oben erwähnten Falle von $\mathrm{Bach}(9)$, wo ausser einigen ganz feinen Gefässen auch ein stärkerer Ast in den Glaskörper eindringt und in der Richtung nach der hinteren linsenfläche verläuft. Auch in dem einen Falle von Hess (Arch. f. Augenheilk. Bd. XLT, Fall 2), von dem ich ein Präparat einsehen konnte, ist der Mesodermzapfen geradezu bespickt mit einer ganzen Anzahl von nach allen Seiten ausstrahlenden feinen Gefässen. Gefässe fanden sich ferner in den Fällen von v. Hippel $(11,112)$, Hoeltzke (95), Becker $(54)$, Bach (9) (Fall 2 und 5), Doetsch (67), Hess (63) (Arch. f. Ophth. Bd. XXXIV, Fall 1, 2, 3, Arch. f. Ophth. Bd. XXXVIII, Fall 1), Pichler (17), v. Duyse (41) (Encyklop.), Rindfleisch (10), Bock (25) u. A. So schreibt z. B. Bock, der eine sehr grosse Anzahl von Colobomen aller Art anatomisch untersucht hat, folgendermassen: „In allen Fällen sind diese medianen Bindegewebszüge reich an Blutgefässen, von denen manche am Kamme der Leiste dieser parallel verlaufen usw." -

Ganz besonders interessant gestalten sich diese Verhältnisse in dem schon mehrfach erwähnten Falle 1 von $B$ ach, welchen ich mit der bereitwilligst erteilten Erlaubnis von Hern Professor Bach hier noch näher schildern darf. Es findet sich nämlich in diesem Auge

1) Nach den Grössenverhältnissen des Augapfels hätte die Frucht, falls nicht das Auge mikrophthalmisch war, etwa im Anfange des 7. fötalen. Monates gestanden. 
Pathol.-anat. Beiträge zur Kenntnis der angeborenen Colobome d. Auges. 323

ausser dem erwähnten Mesodermzapfen in dex Nähe des Ciliarkörpers weiter rückwärts ziemlich dicht hinter dem Äquator bulbi nochmals eine Stelle, wo jede Spur von Netzhaut und Pigmentepithel fehlt und das Mesoderm unmittelbar an den Glaskörper grenzt. Hier sind aber von einer Zapfen- oder Leistenbildung keine Anzeichen zu sehen, wohl aber zahlreiche (7-8) ganz kurze Gefässstümpfchen, welche sämtlich glaskörperwärts verlaufen, ferner dann und wann ein Gefäassquerschnitt innerhalb des Glaskörperraums aber stets nur in unmittelbarer Nähe der Sklera. Erst hinter dieser Stelle erscheint dann die in vielfache Falten gelegte und nach aussen umgeschlagene Netzhaut. Der Raum zwischen den beiden Colobomstellen ist durch eine Brücke - Brückencolobom - von Pigmentepithel und pigmentlosen Epithelien ausgefullt, welche zahlreiche teils niedrige, teils höhere Falten, letztere mit Gefässen, aufweisen, so dass in dem Bereiche des $\ddot{A} q u a t o r s$ Bulbi processus ciliares zur Entwicklung gekommen sind. Was aber unser Interesse in erster Linie erweckt, das ist die Tatsache, dass die Faltenbildung der Netzhaut bzw. des retinalen Epithels nicht nur um den Mesodermzapfen herum stattgefunden hat, sondern auch vor dem zuletzt beschriebenen Bezirk, wo nur Gefässe in das Augeninnere eindringen. Dabei erweckt nichts den Eindruck, als ob hier je eine abnorme Entwicklung bindegewebigen Mesoderms, das später der Resorption anheimfiel, stattgefunden hätte.

Kann demnach die Forderung Elschnigs (2), dass im Colobombereiche abnorme Gefässverhältnisse nachweisbar sein müssten, bis zu einem gewissen Grade als erfüllt angesehen werden, so wäre des weiteren noch die Frage zu erörtern, ob nicht noch andere Veränderungen gefunden worden sind, welche den persistierenden Gefässen oder Strängen den Stempel eines Hindernisses für den Schluss der fötalen Augenspalte aufprägen.

In dieser Hinsicht ist vor allem die zuerst von Hess und später von v. Hippel auf das nachdruicklichste betonte Faltenbildung der Netzhaut hervorzuheben. Sie findet sich in mehr oder weniger hohem Grade fast in allen nicht zu degenerierten Colobomaugen, manchmal auch, ohne dass eine Mesodermleiste nachgewiesen worden ist $[z . B$. in Haabs (64) Fall], Es wiederholt sich immer wieder ein im Prinzip gleiches Bild, das alle möglichen Variationen aufweist, welche durch die Lage, Form und Ausdehnung der Mesodermleiste geschaffen werden.

So äussert sich naturgemäss die Faltenbildung im Bereiche des Ciliarkörpers in andrer Weise als im hinteren Augenabschnitte. 
Sind doch die von Bock (25) u. A. fast in jedem Falle von Ciliarkörpercolobom neben der Mesodermleiste gefundenen abnorm grossen Ciliarfortsätze, die cystischen Wucherungen und Faltenbildungen der Pars ciliaris retinae, sicherlich nichts anderes als ein Analogon zu den starken Faltenbildungen der Netzhaut. Und es ist interessant, dass diese Veränderung auch schon gelegentlich früberer Untersuchungen, so in den Fällen von Pause(14) und Haab(64), als der anatomische Ausdruck einer makroskopisch festgestellten Leiste konstatiert worden sind. Könnte nicht bei solchen Untersuchungen auf Grund einer nicht ganz zweckmässigen Schnittrichtung eine ganz schmale wirkliche (Mesoderm) Leiste entgangen sein?

Mit den Faltenbildungen der Netzhaut sind ferner identisch die vielfachen Fältelungen des sonst flachen Teils des Ciliarkörpers, auf welche in neuester Zeit Gilbert(22) die Aufmerksamkeit gelenkt hat und welche von ihm als Folge einer örtlichen Hyperplasie der Epithelzellen gedeutet werden. Sie finden sich in besonders reiner Form in dem schon von Gilbert angeführten Falle 3 von Hess (Arch. f. Ophth. Bd. XXXVI, 1, Taf. VII, Fig. 9 u. 10), ferner in dem Fall 1 von Bach (9), in welchem aus den höheren Falten durch das Einsprossen von Gefässen Ciliarfortsätze geworden sind. Ciliartortsätze in der Gegend des Äquators Bulbi sind auch von Bock (25) beschrieben worden. In dem Falle von Bach (9) treffen wir ferner im Bereiche des Ciliarkörpers einen sehr grossen Ciliarfortsatz, und an der Spitze desselben eine ganz monströse, auf die Zellschicht der Pars ciliaris retinae allein beschränkte Faltenbildung, welche mit einer von Bock (25) (Fall 11) beschriebenen Cystenbildung dieser Zellschicht eine weitgehende Übereinstimmung zeigt.

Und wir dürfen über diesen Details auch nicht das fast in allen Fällen übereinstimmende makroskopische Aussehen des colobomatösen Ciliarkörpers vergessen, welches gewiss jedem Beschauer den gleichen Eindruck erwecken wird, wie ihn Hess(51) sehr zutreffend mit folgenden Worten schildert:

„Es hat den Anschein, als ob die Ciliarfortsätze an ihrer Vereinigung durch eine feine Scheidewand gehindert wären und sich längs dieser nach rückwärts entwickelt hätten.6" Mit dieser Auffassung kommen wir sicher der Wirklichkeit und dem wahren Wesen der Dinge näher als mit der Annahme einer Rückwärtszerrung durch die hinten fixierte Netzhaut [Mannhardt $(66,13)]$, auf deren Unhaltbarkeit ich schon in der Einleitung hingewiesen habe. Auf den offenkundigen Widerspruch zwischen dieser auch mit unserem embryo- 
Pathol.-anat. Beiträge zux Kenntnis der angeborenen Colobome d. Auges. 325

logischen Empfinden unvereinbaren Theorie und den tatsächlichen anatomischen Befunden hat in jüngster Zeit auch Gilbert(22) in dankenswerter Weise aufmerksam gemacht.

Wenden wir uns nunmehr der Besprechung der Faltenbildung der Netzhaut selbst zu, welche sich in der ausgesprochensten Weise in der unmittelbaren Nähe der Mesodermleiste zu finden pflegt, so würde wohl sicher keine Erklärung grösseren Schwierigkeiten begegnen als die, dass die Netzhantfalten auf ein mangelhaftes Wachstum der Augenblase zurückzuführen seien.

Wir müssten dann schon auf eine weitere Hypothese zurückgreifen, dass dieser Wachstumsstillstand nur zu einer gewissen Zeit stattgefunden hat, welche genügte, um die Mesodermleiste erstarken zu lassen, und dass nachher ein um so lebhafteres Wachstum der Augenblase stattgefunden hat. Fïr eine solche Annahme fehlen aber doch alle positiven Grundlagen, wogegen an der Hand einer Reihe von einwandsfrei untersuchten Fällen feststeht, dass das Netzhautwachstum eher ein das normale Mass iberschreitendes als ungentigendes genannt werden muss. So hebt besonders Levinsohn (7) ausdrücklich hervor, dass in seinem Falle - einem Auge von normaler Grösse - die Ausdehnung der Duplikaturen einen viel grösseren Raum beanspruchen wärde, als es dem vorhandenen Netzhautdefekte entspräche, und er geht so weit, ,die grössere Entfaltung der Netzhaut mit einer erhöhten Wachstumstendenz der letzteren zu erklären".

Wenn ich auch in diesem Punkte der Auffassung ${ }^{1}$ ) Levinsohns (7) nicht ganz zu folgen vermag, so ist doch wenigstens das, worauf es hauptsächlich ankommt, sichergestellt, nämlich, dass die Wachstumstendenz nicht hinter der Norm zurïckgeblieben ist.

Von Bedeutung sind endlich auch die Lagebeziehungen $z$ wischen den Netzhautfalten und der mesodermalen Leiste. Ich kann mich mit Rücksicht auf die sehr eingehende Erörterung dieser Frage dnrch E. v. Hippel(11) sehr kurz fassen und möchte mich nur dahin aussprechen, dass sie meines Erachtens fast stets so beschaffen sind, dass ein unbefangener Beschauer den Eindruck gewinnen muss, dass die Netzhaut an dem Mesoderm ein Hindernis

1) Dadurch, dass der Schluss der fötalen Augenspalte ausbleibt, kommen meines Erachtens verschiedene Momente, welche auf das Wachstum der Augenblase regulierend einwirken, und deren wichtigstes die Vereinigung der Augenblasenränder selbst sein dürfte, in Fortfall, so dass ein bis zu einem gewissen Grade planloses Wachstum der Augenblasenränder resultiert, das über das Ziel bedeutend hinausschiessen kann. 
gefunden hat, vor dem sie auswich, an dem sie emporkletterte, neben dem sie nach aussen wuchs usw.

So wüsste ich mir namentlich auch die vielfach hochgradige Umkrempelung der Augenblasenränder nicht ungezwungener zu erklären.

Bei dieser Gelegenheit möchte ich auf eine Tatsache aufmerksam machen, welche mir beim Studium der Literatur des öfteren aufgefallen ist. In recht vielen Fällen ist ein sehr grosses Colobom vorhanden, wogegen eine Mesodermleiste nur an einer ziemlich umschriebenen Stelle nachweisbar ist. Eine sehr schöne Erklärung für dieses Phänomen hat uns bekanntlich bereits E. r. Hippel(11) geliefert. Während aber v. Hippels Erklärung mehr die Ursache für die hochgradige Verbreiterung der Colobome nach den Seiten aufdeckt, möchte ich die gleiche Erklärung in manchen Fällen auch auf die vor und hinter einem mesodermalen Strange gelegenen Bezirke angewendet wissen, welche in die Störung mit einbezogen werden und dadurch eine weitere Ursache für die unverhältnismässig grosse Ausdehnung der Colobome abgeben können.

So finde ich in dem Falle 1 von Bach(9) eine sehr starke Faltenbildung der Netzhaut auch hinter der Stelle, wo die Gefässe in den Glaskörper eindringen. Die Netzhaut ist nach aussen umgeschlagen und das äussere Blatt auch dort, wo es zu einer einzelligen Schicht geworden ist, noch in grösserer Ausdehnung unpigmentiert.

Ich stimme v. Hippel(11) darin vollkommen bei, dass es sehr schwer sein kann, zwischen den Zellen des inneren und denen des im Colobombereich nicht selten unpigmentierten äusseren Blattes eine scharfe Grenze zu ziehen. An den mir vorliegenden Präparaten habe ich folgendes beobachten können: Die unpigmentierten Zellen, welche an das Pigmentepithel grenzen, zeigen durchweg die verhältnismässig niedrige kubische Form der letzteren, wogegen die an die invertierte Netzhaut grenzenden eine hohe cylindrische Form besitzen und ganz mit den Zellen der Pars ciliaris retinae im Bereiche der Pars coeca retinae übereinstimmen, welch letztere bekanntlich von Falchi (67) mit Recht für undifferenzierte Netzhautzellen erklärt worden sind. Die Schlussfolgerung, wo die Grenze zwischen innerem und äusserem Blatte zu ziehen sei, ergibt sich daraus von selbst, doch gebe ich zu, dass man nicht immer ganz genau entscheiden kann, wo die cylindrischen Zellen aufhören und die kubischen beginnen.

Ich kann auch die Beobachtung v. Hippels bestätigen, dass die Chorioidea im allgemeinen stets genau so weit reicht, wie das Pigment- 
Pathol.-anat. Beiträge zur Kenntnis der angeborenen Colobome d. Anges. 327

epithel ${ }^{1}$ ); selbst bei den breitesten Colobomen, wie z. B. in meinem heutigen Falle 3, hört sie an der Grenze des Pigmentepithels meist wie scharf abgeschnitten auf.

Die Erklärung, welche E. v. Hippel(11) für diese Tatsache gibt, kann mich aber nicht ganz befriedigen. Wenn v. Hippel sagt, „das in der Gegend der Fötalspalte vorhandene Mesoderm wird deshalb nicht Chorioidea, weil es für einen andern $Z$ weck, nämlich zur Bildung der Mesodermleiste verbraucht wird", so bleibt er uns die Erklärung dafür, dass die Aderhaut auch bei den breitesten Colobomen in ganzer Ausdehnung fehlt, schuldig, da doch nicht anzunehmen ist, dass die paar Mesodermzellen und Gefässe, aus welchen die Mesodermleiste hervorgegangen ist, einen ausgerechnet genau so grossen Bezirk von Aderhaut hätten bilden sollen.

Mir scheint folgender Gedankengang der Wirklichkeit näher zu kommen:

Bekanntlich ist die Choriocapillaris schon angelegt, bevor der Schliessungsprozess der Augenspalte beginnt. Sie überzieht zu dieser Zeit bereits als ein lockeres Netzwerk die ganze Augenblase und wartet nur auf den Moment der Schliessung des Augenspaltes, um auch diesen Teil der Augenblase in der sonstigen regelmässigen Weise zu umgarnen. Bleibt aber der normale Schluss der Augenspalte aus, dann erfolgt auch keine normale Anbildung der Chorioidea und zwar, was sehr merkwürdig ist, genau in der Ausdehnung; in welcher sich diese Störung in dem ektodermalen Anteil der Augenanlage geltend macht.

Meine Ansicht unterscheidet sich also von der v. Hippels dadurch, dass sie das Primäre in dem Verhalten des Ektoderms erblickt und das Ausbleiben der Entwicklung der Aderhaut als einen sekundären Vorgang auffasst.

Ich glaube, dass auf diese Weise namentlich die konstante genaue Übereinstimmung des Pigmentepithel- und Aderhautdefektes in befriedigender Weise erklärt wird. Die Breite des klinisch wegen des Fehlens der Aderhaut als Colobom imponierenden Bezirks

1) Es sind zwar mehrere Fälle von Bach(9), Rindfleisch und Mannhardt beschrieben worden, in welchen selbst ektatische Colobome angeblich in ganzer Ausdehnung von Pigmentepithel ausgekleidet waren. Das Pigmentepithel war aber in den Fällen von Rindfleisch (10) und Mannhardt $(13,66)$ stark verändert, nicht oder nur stellenweise pigmentiert. Zum Falle $\mathrm{Bach}$ ist keine nähere Beschreibung vorhanden. Mit Recht äussert deshalb v. Hippel den Verdacht, dass es sich in solchen Fällen wohl ebenso gut am invertierte Netzhaut handeln konnte. 
wird doch, wie uns $v$. Hippel selbst in so einleuchtender Weise gelehrt hat, durch die Ausdehnung der Netzhautduplikatur bestimmt. Nur dieser Umstand macht es verständlich, dass "ein ganz schmaler Zapfen von Mesodermgewebe im Fötalspalt Ursache der breitesten Colobome werden kann". Das ist eigentlich mit andern Worten dasselbe, was ich soeben behauptet habe, nämlich dass die Entwicklung der Aderhaut durch das Verhalten der Augenblase in gebieterischer Weise beeinflusst wird. Die Tatsache, dass in diesem Falle das Elktoderm der bestimmende Faktor sein dürfte, wird übrigens auch noch durch eine andere Beobachtung, welche ich im Vorausgehenden verzeichnet habe, nahe gelegt. Haben wir doch gesehen, dass sich selbst in der Gegend des $\ddot{A} q u a t o r s$ Bulbi und noch weiter rückwärts Ciliarfortsätze entwickeln können, sobald sich nur das Ektoderm - hier das retinale Epithel - in Falten legt. Auch hier ist die Gefässeinsprossung ein sekundärer Vorgang, sie erfolgt anscheinend überall, gleichgültig, wo sich die Falten befinden. In gleicher Weise geht bekanntlich auch die normale Entwicklung der Ciliarfortsätze vor sich.

Das Fehlen der Aderhaut bleibt aber selbstrerständlich auf die Dauer nicht ohne Folgen für die Netzhaut, welche zu ersterer in bezug auf ihre Ernährung in einem so wichtigen Abhängigkeitsverhältnis steht. Dieser Einfluss scheint sich aber im embryonalen Leben noch nicht in dem Masse geltend zu machen, als in späterer Zeit. So finden wir in jüngeren Augen die Netzhaut auch im Colobomgebiet meist verhältnismässig gut erhalten und zu einer gewissen Differenzierung gelangt. [Fälle von $\mathrm{Haab}(64)$, Becker (54), Bach (9), Hess $(51,52,53)$, v. Hippel(11), mein Fall 2, Rindfleisch(10).] Selbst die ausgestülpte Netzhaut behält offenbar noch eine gewisse Zeit ihre histologischen Eigenschaften bei. [Bach (9), v. Hippel(11), Hess (52), Rindfleisch(10), Mayou(97), Bernheimer(92).] In älteren Augen ist dies aber nicht mehr der Fall. Die Netzhaut fällt im Laufe der Zeit einer hochgradigen Degeneration anheim, und es bleibt von ihr nur das meist auf ein dünnes Häutchen reduzierte, manchmal aber auch erhebliche Wucherungsprozesse eingehende Stützgewebe, die Glia, übrig, welches kaum noch vermuten lässt, was dereinst an seiner Stelle gewesen ist.

Ich kann deshalb vom anatomischen Standpunkte aus den vereinzelten Angaben gegenüber [v. Haab (64), Schmidt-Rimpler (87) u. A.], dass im Colobombereich Lichtempfindung vorhanden war, meine Bedenken nicht unterdrücken und halte es für höchst unwahrschein- 
Pathol.-anat. Beiträge zur Kenntnis der angeborenen Colobome d. Auges. 329

lich, dass sich innerhalb der grossen flächenhaften, klinisch als weisse Herde erscheinenden Colobome, wo die Aderhaut in ganzer Ausdehnung fehlt, lichtperzipierende Netzhautelemente auf die Daner funktionstüchtig erhalten können. Es muss überhaupt als sehr zweifelhaft bezeichnet werden, $o b$ in den vielfach gefaiteten und durcheinander geworfenen Netzhautpartien des Colobombereichs jemals eine regelrechte Ausbildung von Nervenfasern erfolgt. Ich wenigstens babe in den mir zugänglichen Präparaten keine finden können.

Nachdem wir uns dafür entschieden haben, mit der Mehrzahl der Autoren als erste Ursache der Colobombildung Störungen im Verschlusse der fötalen Augenspalte durch dazwischen gelagertes Mesoderm anzusehen, erübrigt noch, zu einer Frage zweiter Ordnung Stellung zu nehmen, nämlich der nach der Art der den normalen Verschluss störenden mesodermalen Bestandteile.

E. v. Hippel(11) hat uns gezeigt, dass im embryonalen Kaninchenauge sowohl Gefässe als zelliges Mesoderm innerhalb der Augenspalte angetroffen werden, und zwar misst er dem Verhalten des letzteren die entscheidende Bedeutung bei, da er ,sein Vorhandensein und seine schnelle Zunahme zwischen den Rändern der Augenblase in den frühesten Stadien der Colobome direkt festgestellt habe". Meine Ansicht geht dahin, dass den Gefässen mindestens eine gleich wichtige Rolle zuzuschreiben ist wio dem zelligen Mesoderm, wozu mich namentlich auch der Umstand bestimmt, dass so ungemein viele Colobome mit Cystenbildung [ausser in den bereits aufgeführten noch in Fällen von Becker(54), van Duyse(36 u. 70), Ginsberg(3), Kundrat (28), Treacher Collins (71), Bernheimer(92) (hier war kein Optikus nachweisbar), Mayou (96), Mannhardt(13) u. A.] unmittelbar unterhalb des Optikus an der Grenze ron Stamm und Bulbus, also an einer Stelle liegen, wo zur Zeit des Schliessungsprozesses des fötalen Augenspaltes ein sehr wichtiges Gefäss, die Arteria hyaloidea, zwischen den Augenblasenrändern nach aussen in die Tiefe dringt. Dass es auch in dem Falle I von Bach den Anschein hat, als ob nur Gefässe das Verwachsen der Augenblasenränder verhindert hätten, habe ich bereits ausgesprochen. In dem Falle von Rindfleisch (10) dringen an dem von Netzhaut entblössten Colobombezirk ebenfalls Gefässchen und nur ganz spärliches junges Bindegewebe in das Auge hinein.

Doch sind dies Fragen von mehr nebensächlicher Bedeutung, deren Entscheidung erleichtert wird, sobald einmal unsere Kenntnisse 
von den Vorgängen beim normalen Schliessungsvorgang der Augenspalte auf einem noch festeren Boden stehen als jetzt.

Eine wichtigere Frage, welche auch aufgeworfen werden könnte, ist die, ob das Mesoderm und die Gefässe durch die vorwachsenden Augenblasenränder abgeschnürt werden, oder ob dem Vorwachsen der letzteren eine Resorption des Mesoderms vorausgeht.

Ich habe mich für die letatere Auffassung entschieden, und zwar erstens deswegen, weil ich (72) in einem menschlichen embryonalen. Auge, in welchem die fötale Augenspalte bereits teilweise geschlossen war, zwischen den noch nicht vereinigten Augenblasenrändern, namentlich in der Nähe des Augenbecherrandes, ausser den normalerweise vorhandenen Gefässverbindungen fast kein Mesoderm mehr angetroffen habe, und zweitens, weil sich im embryonalen Auge auch noch andere Rückbildungsvorgänge seitens des Mesoderms bzw. Gefässsystems abspielen - ich erinnere nur an das Verschwinden der Vasa hyaloidea propria, der Arteria hyaloidea, der Tunica vasculosa lentis, des fötalen Ligamentum pectinatum usw. - ohne dass eine Abschnürung dieser Gebilde durch ein andersartiges Gewebe in Frage kommt.

Ich glaube daraus den Analogieschluss ziehen zu dürfen, dass sich auch die Rückbildung des Mesoderms innerhalb der Augenspalte unabhängig von deren Rändern vollzieht. Um so verständlicher erscheint dann die Tatsache, dass schon eine abnorme Persistenz des Mesoderms allein genügt, um den normalen Schluss der Augenblasenränder zu stören.

Trotzdem somit unsere Ansicht über die Entstehung der typischen Colobome von der Elschnigs $\left.(1,2)^{1}\right)$ ganz erheblich abweicht, stehen wir doch dem prinzipiell sehr wichtigen Gedanken Elschnigs, dass die Ränder der Augeublase, ja dass ,jeder Teil

1) Der prinzipielle Unterschied zwischen meiner und Elschnigs Auffassung besteht, um ihn nochmals kurz festzulegen, darin, dass Elschnig ein primäres Sprossen der Augenblasenränder in abnormer Richtung annimmt und die mesodermale Einlagerung überhaupt nicht als mechanisehes Hindernis gelten lässt, während nach meiner Ansicht das zwisehen den Augenblasenrändem abnorm lange persistierende Mesoderm den ersten Anstoss zu dem Wachstum der Netzhaut in abnormer Richtung gibt.

Eine besondere Derbheit des Mesoderms im Augenspaltenbereiche ist dazu nicht erforderlich. Jedes abnorme Hindernis kann genügen, um die Netzhaut zum Ausweichen zu bestimmen und sie von ihrem richtigen Wege abzulenken, wobei schliesslich ein planloses und abundantes Wachstum in alnomer Richtung resultiert. 
der sekundären Augenblase - äusseres Blatt allein oder beide Blätter - während ihrer Entwicklung in abnormer Richtung proliferieren und so zur Bildung eines atypischen Coloboms führen können", durchaus nicht ablehnend gegentiber.

Gibt es doch eine Anzahl von Colobomen, in welchen vergeblich nach einem mesodermalen Hindernis gesucht worden ist, und wenn wir uns auch bei den typischen, d. h. den an typischer Stelle gelegenen, mit der wohlbegründeten Annahme einer nachträglichen Resorption des Mesoderms über alle Schwierigkeiten hinweghelfen können, so kann dieș doch nicht bei den atypischen geschehen. Betrachten wir z. B. nochmals meinen Fall I, ein sicher ausserbalb der fötalen Augenspalte im Bereiche des hinteren Augenpols gelegenes Colobom mit Cystenbildung, so finden wir nicht die Spur einer mesodermalen Leiste, sondern im Gegenteil eine Reihe von Anzeichen - Verdichtung und Verdickung der Sklera am Colobomrande -, welche den Gedanken aufzwingen, dass hier die Verhältnisse umgekehrt liegen, und dass hier das Mesoderm ein Hindernis fand, vor dem es ausweichen und sich in Falten legen musste. Nebenbei bemerkt, ist hier kein Mesoderm zur Bildung einer Leiste verbraucht worden, und doch stimmen Pigmentepithel- und Aderhautdefekt an Grösse fast vollkommen überein, genau wie bei den typischen Colobomen.

Für solche Fälle acceptieren wir die Elschnigsche Theorie sehr gerne, da sie nach unserem Dafürhalten die beste Erklärung für sonst äusserst schwer verständliche Befunde enthält. Sie hat vor allen Dingen viel mehr Wahrscheinlichkeit für sich als die Ginsbergsche (15) Hypothese, nach welcher ähnliche Veränderungen aus Abschnürungen von Teilen der Augenblase durch das Mesoderm hervorgehen sollen. Ein Abschnürungsvorgang setzt doch voraus, dass der abzuschnürende Teil von allen Seiten angreifbar ist, was in unserem Falle nur möglich ist, wenn eben Teile der Augenblase an umschriebener Stelle in das Mesoderm eingedrungen wären.

Dass die Entstehung eines solchen Coloboms auch nicht auf abnorme Spaltbildung an atypischen Stellen des Augenblasenrandes zurückgeführt werden kann [ran Duyse (88)], ergibt sich aus seiner Lage von selbst.

In neuester Zeit hat Keil (100) auf Grund ron anatomisehen Untersuchungen an Schweineembryonen für die alte längst aufgegebene Rotationstheorie von Vossius eine Lanze gebrochen und der Überzeugung Ausdruck gegeben, dass die fötale Augenspalte durch Störungen und $A b$ normitäten in dem angenommenen Drehungsmechanismus an atypische 
Stellen zu liegen kommen und dadurch die Eutstehung und der Sitz der sog. atypischen Colobome erklärt werden könne. -

Ganz abgesehen davon, dass selbst durch den einwandsfrei erbrachten Nachweis einer Rotation des embryonalen Schweineauges noch lange nicht bewiesen wäre, dass sich der gleiche Vorgang mit Konstanz auch in dem menschlichen Auge abspielen müsse, scheint mir die Beweislaraft der Keilschen Ausführungen hauptsächlich dureh den Umstand erschüttert zu sein, dass sie sich grösstenteils auf die anatomische Untersuchung und plastische Rekonstruktion eines Präparates stätzen, das nach des Autors eigenen Worten (St. 71) „sehr schlecht" fixiert gewesen ist. Wir sind wenigstens der Ansicht, dass die Feststellung von so hochkomplizierten. topographischen Verhältnissen nur an einem erstklassig fixierten Material ausgeführt werden kann.

Inwieweit die von Elschnig, Bach (9), Görlitz (35), van Duyse (41), Coats(110) u. A. beschriebenen taschenförmigen Einlagerungen von Netzhautgewebe zwischen Sklera und Sehnerv, oder in den Sehnerven, oder in die Duralscheide durch sekundäre Faltenbildungen analog denen beim typischen Colobom oder primäres Sprossen der Netzhaut in abnormer Richtung entstanden sind, wird von Fall zu Fall zu entscheiden sein. Ich würde unter allen Umständen die erstere Genese annehmen, sobald, wie in meinem Falle III, auch andere colobomatöse Veränderungen an typischer Stelle vorhanden sind. Auch spricht der Sitz unmittelbar unterhalb des Sehnerven, an einer für die Entstehung von Colobomen entschieden hervorragend prädisponierten Stelle, sehr für Störungen im Verschlusse der Augenspalte durch dazwischen gelagertes Mesoderm. Im übrigen verweise ich auf die Ausfihrungen E. v. Hippels im Arch.f. Ophth., Bd. LV, S. 539 bis 542 , welchen ich mich im wesentlichen vollkommen anschliesse.

$\mathrm{Zu}$ der Frage der taschenförmigen Einlagerungen von Netzhaut in die Aderhaut, welche von Elschnig in gleichem Sinne gedeutet worden sind, möchte ich bemerken, dass eine derartige Veränderung bereits in Jahre 1896 in einem Auge mit typischem Colobom von van Duyse(74) beschrieben und abgebuldet worden ist, und in Colobomangen vielleicht noch häufiger vorkommen dürfte, als es nach der Literatur den Anschein hat.

So finde ich sie 2. B. auch in exquisiter Weise im Falle I ron Bach (9), ferner, wenn auch weniger ausgesprochen, in meinem Falle III. (Vgl. Taf. XVII, Fig. 3.) Sie befindet sich in allen diesen Fällen an der Colobomgrenze. Die Netzhaut ist daselbst in meinem Falle leicht gefaltet, ein Zipfel der Falte springt spomartig gegen die Aderhant vor und ist mit dieser durch gliöses Gewebe verbunden. Im Falle Bach treffen wir die taschenförmige Einlagerung an der hinteren 
Pathol.-anat. Beiträge zur Kenntnis der angeborenen Colobome d. Auges. 333

Colobomgrenze ebenfalls unweit rom Sehnerven. Das Pigmentepithel und die Aderhaut hören hier, wie gewöhnlich, mit scharfem Rande auf, die Netzhaut, deren Struktur auch im Colobombereich noch ziemlich gut erhalten ist, sendet eine tiefe Falte zwischen Aderhaut und Sklera und setzt sich dann wieder in den Colobombereich hinein fort, in welchem sie mit ihrer mesodermalen Unterlage fest verbunden ist.

Es steht der Annahme nichts im Wege, diese Faltenbildungen mit den auch sonst in Colobomaugen gefundenen Duplikaturen der Netzhaut auf eine Stufe zu stellen. Die Annahme eines primären aktiven Wachstums erscheint, wenigstens für unsere Fälle, nicht unbedingt erforderlich.

Für die Entstehung gewisser Fälle von Mikrophthalmus hat vor kurzem Fleischer(75) eine Erklärung gegeben, welche sich mit unsern Anschauungen über die Genese der Colobome sehr gut vereinen lässt. Fleischer sieht „das wesentliche in der mehr oder weniger ausgedehnten Verwachsung der Retina mit dem das Colobom ausfíllenden Gewebe einerseits und der hinteren Linsenfläche anderseits, Adhäsionen, an denen sich auch der retinale Anteil der Iris beteiligt". Es ist mir nicht unwahrscheinlich, dass in meinem Falle IV seinerzeit zwischen Netzhaut, Linse und Colobomgewebe Verwachsungen bestanden haben, und dass dadurch die Entwicklung eines regelrechten Glaskörperraumes verhindert worden ist. Eine wesentliche Stütze findet die Fleischersche Theorie ausser den von ihm angeführten Fällen [Heine (90), Salffner] namentlich auch durch den Fall II von Bach (9), in welchem ebenfalls ausgedehnte Verwachsungen zwischen dem durch die Fötalspalte eindringenden. Mesoderm, der Linse und Retina zu konstatieren sind. Es versteht sich von selbst, dass die Retina unter solchen Umständen nicht in der Lage ist, eine für das Grössenwachstum des Auges sehr wichtige Funktion in normaler Weise auszuüben, welche wir ihr nach den Untersuchungen Rabls (76), Wolfrums (77) und anderer zuerkennen müssen, nämlich, Glaskörpergewebe zu produzieren.

Dass eine abnorme grosse Linse $[\mathrm{Bach}(9)]$ nur dazu beitragen kann, den Circulus vitiosus zu schliessen, liegt auf der Hand.

\section{Die Genese der typischen Iriscolobome.}

Zur Kenntnis der pathologischen Anatomie der Iriscolobome vermögen meine heutigen Untersuchungen leider nicht viel beizutragen ${ }^{1}$ ).

1) Siehe dagegen meinen unmittelbar vorausgehenden Aufsatz über Cyklopie. 
Im Falle II ist die horizontale Schnittrichtung fiur die Beurteilung dieser Verhältnisse ganz unvorteilhaft, und im Falle III sind die natürlichen Verhältnisse durch die perforierende Verletzung an der Stelle des Coloboms and die chronisch entzündlichen Veränderungen stark verwischt. Es lässt sich im letzteren Falle nur so viel sagen, dass die Iris im Colobomgebiet nicht ganz fehlt, sondern dass ein stummelartiger Rest von Trisstroma und Pigmentepithel vorhanden ist.

Ich benutze vor allem die heute sich bietende Gelegenheit, um auf einen Einwand einzugehen, welchen vor kurzem Brückner(78) in seiner sehr sorgfältigen Arbeit „über Persistenz von Resten der Tunica vasculosa lentis" gegen einige in der Arbeit von Wolfrum und mir (72) ibber die Entwicklung des Kammerwinkels usw. enthaltene Thesen erhoben hat.

Zum Verständnis des Folgenden sehe ich mich genötigt, die beanstandeten Sätze nochmals wörtlich anzuführen:

"Pupillarloch und Linse sind in jungen embryonalen Stadien im Verhältnis zu ihren späteren Ausmassen sehr klein, an Grösse sind sie einander ungefähr gleich. Beide vergrössern sich kontinuierlich bis zur Geburt und darïber hinaus. Das Wachstum beider Gebilde ist aber ein ungleiches, denn der Durchmesser der Linse nimmt schneller zu als der Durchmesser der Pupille. Das Wachstum der

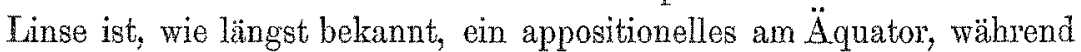
die Vergrösserung der Pupillarebene mit der Vergrösserung der Irisfläche verkntipft ist."

"Gewöhnlich pflegt man anzunehmen, dass die Tris auf der Linsenvorderfäche hinaufwächst. Überlegt man sich aber, dass die Grössenzunahme der Linse durch Apposition am Äquator zu stande kommt, und dass das Pupillarloch im Verhältnis zu jüngeren Stadien grösser geworden ist, so wird man zu der Annahme gezwungen, dass der Irisrand eine Rückwärtsbewegung vom vorderen Linsenpol nach der Peripherie macht und zwar in einer Grösse, die ungefähr der Vergrösserung des Pupillengebietes entspricht. Wir glauben also, dass man nicht annehmen kann, dass die Iris auf der Linse hinaufwächst und die Capsula vasculosa lentis in einen der Iris angehörenden und einen an der Linse verbleibenden Anteil spaltet."

Ohne sich unsern Äusserungen gegentuber ablehnend zu verhalten, spricht Briuckner doch die Ansicht aus, „dass es genauer zahlenmässiger Angaben der Grösse der Pupille und des Linsendurchmessers and zwar für alle Stadien der Entwicklung bedarf, um sicher zu erweisen, dass nicht wenigstens in einem gewissen $\mathrm{Ab}$ - 
Pathol.-anat. Beiträge zur Kenntnis der angeborenen Colobome d. Auges. 335

schnitte der Entwicklung auch ein Vorwachsen der Iris in dem bisher angenommenen Sinne stattfindet":

Die Berechtigung des Brücknerschen Einwandes erkennen wir rückhaltlos an.

Ich habe deshalb an meinem menschlichen embryonalen and fötalen Material, das inzwischen eine bedentende Bereicherung erfahren hat und beinahe lückenlos genannt werden kann, die entsprechenden Messungen ausgeführt und die Resultate in der folgenden Tabelle zusammengestellt.

Da ferner unsere Kenntnisse von dem Grössenwachstum des menschlichen Auges im embryonalen Leben noch sehr unvollkommen und, wie Nussbaum (79) bemerkt, grösstenteils an einem für Messungszwecke recht ungeeigneten Material gewonnen sind, hielt ich es für angezeigt, auch die Grösse der wichtigsten Durchmesser des Auges mit anzuführen.

Die zu den Messungen verwendeten Objekte sind, wie ich versichern kann, fast durchwegs lebensfrisch in Zenkerscher Lösung fixiert und mit grösster Vorsicht gehärtet worden. Die Messungen sind am gehärteten Präparat und, was bei der Art des Materials selbstverständlich ist, vielfach an Schnitten ausgeführt worden. Bei den jüngeren Stadien wurde das Okularmikrometer, bei den älteren Zirkel verwendet.

Ich verkenne aber nicht, dass trotz peinlicher Beobachtung aller Kautelen doch nicht jedes Mass als Ausdruck tatsächlicher Verhältnisse angesehen werden $\mathrm{k}$ ann, da verschiedene unvermeidliche Umstände die Form der Bulbi beeinflusst und verändert haben können, ehe diese in meine Hände gelangten.

Tabelle.

\begin{tabular}{|c|c|c|c|c|c|c|c|c|c|}
\hline $\mathrm{Nr}$. & Alter & Grösse & $\begin{array}{l}\text { Hori- } \\
\text { zontal. } \\
\text { Durch- } \\
\text { messer } \\
\text { des } \\
\text { Auges }\end{array}$ & $\begin{array}{l}\text { Durchm.d. } \\
\text { Auges vom } \\
\text { Scheitel d. } \\
\text { Cornea bis } \\
\text { zum Seh- } \\
\text { nerven- } \\
\text { eintritt }\end{array}$ & $\begin{array}{c}\text { Breite } \\
\text { der } \\
\text { Cornea }\end{array}$ & $\begin{array}{l}\text { Höhe } \\
\text { der } \\
\text { Cor- } \\
\text { nea }\end{array}$ & $\begin{array}{l}\text { Pupil- } \\
\text { len- } \\
\text { weite }\end{array}$ & $\begin{array}{l}\text { Iin- } \\
\text { sen- } \\
\text { durch- } \\
\text { messer }\end{array}$ & $\begin{array}{l}\text { Bemer- } \\
\text { kungen }\end{array}$ \\
\hline 1 & $\begin{array}{c}6 .-7 . \\
\text { Woche }\end{array}$ & $\frac{\mathrm{mm}}{19}$ & $\begin{array}{l}\mathrm{mm} \\
0,765\end{array}$ & $\underset{0,5}{\operatorname{mm}}$ & $\stackrel{\operatorname{mm}}{-}$ & mro & $\min _{0,345}$ & $\underset{0,25}{\mathrm{~mm}}$ & $\begin{array}{l}\text { Mesoderm } \\
\text { vor der } \\
\text { Linsenoch } \\
\text { nicht dif- } \\
\text { ferenziert. }\end{array}$ \\
\hline
\end{tabular}




\begin{tabular}{|c|c|c|c|c|c|c|c|c|c|}
\hline Nr. & Alter & Grösse & $\begin{array}{c}\text { Hori- } \\
\text { zontal. } \\
\text { Durch- } \\
\text { messer } \\
\text { des } \\
\text { Auges }\end{array}$ & $\begin{array}{l}\text { Durchm.d. } \\
\text { Auges vom } \\
\text { Scheitel d. } \\
\text { Comea bis } \\
\text { zum Seh- } \\
\text { nerven- } \\
\text { eintritt }\end{array}$ & $\mid \begin{array}{c}\text { Breite } \\
\text { der } \\
\text { Cornea }\end{array}$ & $\left|\begin{array}{c}\text { Höhe } \\
\text { der } \\
\text { Cor- } \\
\text { nea }\end{array}\right|$ & $\begin{array}{l}\text { Pupil- } \\
\text { len- } \\
\text { weite }\end{array}$ & \begin{tabular}{|c|} 
Lin- \\
sen- \\
durch- \\
messer
\end{tabular} & $\begin{array}{l}\text { Bemer- } \\
\text { kungen }\end{array}$ \\
\hline 2 & 8. Woche & $\begin{array}{c}\mathrm{mm} \\
20\end{array}$ & $\begin{array}{l}\mathrm{mm} \\
1,17\end{array}$ & $\mathrm{~mm}_{0,74}$ & $\mathrm{~mm}$ & $\stackrel{\mathrm{mm}}{-}$ & $\mathrm{mm}_{0,51}$ & $\operatorname{mm}_{0,45}$ & Wie bei 1 . \\
\hline 3 & $9 . \quad "$ & $\begin{array}{lr}21 & \text { Sch.-St. } \\
31,5 & \text { Sch.-S. }\end{array}$ & 1,8 & & 0,755 & - & 0,87 & 0,87 & \\
\hline 4 & 3. Mon. & unbekannt & 2,0 & 1,9 & 0,77 & - & 0,76 & 0,69 & \\
\hline $\begin{array}{l}5 \\
6\end{array}$ & $\begin{array}{ll}3 . & : 4 \\
3 & \end{array}$ & ${ }_{25} \mathrm{Sch}_{\mathrm{St}}$ & $\begin{array}{l}2,3 \\
30\end{array}$ & 2,0 & 0,9 & 一 & 0,86 & 0,75 & \\
\hline$b$ & 3. " " & $\begin{array}{l}35 \\
50 \\
50 \text { Sch.-S. }\end{array}$ & 3,0 & 2,5 & 1,2 & - & 1,12 & $1,0 b$ & \\
\hline 8 & 3. " & $\begin{array}{ll}40 & \text { Sch.-St. } \\
56 & \text { Sch.-S. }\end{array}$ & 2,4 & 1,99 & 1,27 & - & 1,26 & 1,035 & \\
\hline 8 & 3. " & $\left|\begin{array}{ll}45 & \text { Sch.-St. } \\
65 & \text { Sch.-S. }\end{array}\right|$ & 3,0 & 2,5 & 1,3 & - & 1,26 & 1,215 & \\
\hline 9 & 3. , & $\begin{array}{ll}54 & \text { Sch.-St. } \\
76 & \text { Seh.-S. }\end{array}$ & 3,5 & 3,0 & 1,5 & - & 1,41 & 1,35 & \\
\hline 10 & 3. " & $\begin{array}{ll}65 & \text { Sch.-St. } \\
88 & \text { Sch.-S. }\end{array}$ & 4,5 & 4,0 & 1,8 & - & 1,65 & 1,56 & \\
\hline 11 & 4. " & $\begin{array}{c}80 \text { Sch.-St. } \\
\mathrm{cm}\end{array}$ & 4,8 & 4,4 & 2,4 & - & 2,02 & 2,17 & \\
\hline 12 & 4. & 15,3 Sch.-S. & 5,6 & 4,9 & 2,55 & - & 2,13 & 2,32 & \\
\hline 13 & 4. " & & 6,7 & 6,3 & 3,3 & - & 2,55 & 2,7 & \\
\hline 14 & 4. " & $16 \quad "$ & 6,8 & 5,0 & 3,5 & - & 2,5 & 2,8 & \\
\hline 15 & 4. " " & $\left|\begin{array}{cc}10,3 & \text { Sch. }- \text { St. } \\
15,5 & \text { Sch. }-\mathrm{S} .\end{array}\right|$ & 7,1 & 6,0 & 3,3 & - & 2,55 & 2,55 & \\
\hline 16 & 4. , & $\left|\begin{array}{ll}11 & \text { Sch. }- \text { St. } \\
17,5 & \text { Sch.-S. }\end{array}\right|$ & 8,0 & 7,0 & 4,8 & 4,0 & 3,5 & - & $\begin{array}{l}\text { Ende 4. - } \\
\text { Anfang } \\
5 . \text { Monats. }\end{array}$ \\
\hline 17 & 5. " & unbekannt & 8,0 & 7,0 & 4,1 & - & 3,0 & 3,1 & \\
\hline 18 & 5. " " & $\begin{array}{ll}13 & \text { Sch,-St. } \\
21 & \text { Seh.-S. }\end{array}$ & 9,0 & 8,0 & 5,0 & 4,8 & 3,5 & 3,5 & \\
\hline 19 & 5. " & $24 \ldots$ & 9,3 & 8,0 & 5,0 & $=$ & 3,2 & 3,5 & \\
\hline 20 & 5. & $26,5, "$ & 11,0 & 10,0 & 5,9 & 5,5 & 4,3 & 4,5 & \\
\hline 21 & 5. " " & unbekannt & 11,0 & 10,0 & 6,0 & 5,3 & 4,2 & 4,3 & \\
\hline 22 & 5. " " & $"$ & 10,5 & 10,2 & 6,0 & 5,5 & 4,3 & 4,4 & \\
\hline $\begin{array}{l}23 \\
24\end{array}$ & 6. $\quad$, & $"$ & 11,0 & 11,0 & 6,0 & 5,1 & 4,9 & 4,5 & 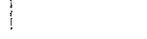 \\
\hline $\begin{array}{l}24 \\
25\end{array}$ & 6. " " & $"$ & 11,0 & 11,0 & 6,0 & 5,0 & 4,8 & 4,7 & \\
\hline 26 & & 28 S̈ch.-S. & $\begin{array}{l}11,0 \\
12,0\end{array}$ & $\begin{array}{l}11,2 \\
11.0\end{array}$ & $\begin{array}{l}6,0 \\
70\end{array}$ & $\begin{array}{l}5,1 \\
6,0\end{array}$ & 5 & $\overline{5,1}$ & \\
\hline 27 & $6 . "$, & unbekannt & 12,2 & & 6,3 & 5,5 & $\begin{array}{l}4,0 \\
4,2\end{array}$ & - & 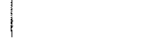 \\
\hline 28 & & & 13,0 & 12,5 & 6,5 & 6,0 & 4,5 & 5,0 & \\
\hline 29 & 7. " & 34,5 Sch.-S. & 14,0 & 13,0 & 7,0 & 6,2 & 5,3 & 5,3 & \\
\hline 30 & 8. & $40 \quad n$ & 14,1 & 13,5 & 8,0 & - & 4,5 & 5,5 & \\
\hline 31 & & 40 & 14,5 & 13,2 & 8,0 & - & 4,0 & 5,2 & \\
\hline 32 & 8. ", & 40 & 14,3 & 14, & 8,0 & 7,5 & 4,2 & 5,5 & \\
\hline 33 & & 40 & 14,2 & 13,7 & 8,0 & - & 4,1 & 5,4 & \\
\hline 34 & & 41 & 15,25 & 14,25 & 8,0 & 7,25 & 4,0 & 5,5 & \\
\hline 35 & 8. " & $"$ & 16,0 & 16,25 & 8,0 & 7,5 & 5,2 & 5,5 & \\
\hline 36 & $9 .$, & Sch.-St. & 17,0 & 16,5 & 9,0 & 7,8 & 4,0 & 5,5 & \\
\hline 37 & 9. Mon. & 42 Sch.-St. & 16,8 & 16,0 & 9,0 & - & 5,0 & 6,0 & \\
\hline 38 & $9 . \quad$, & 45 Sch.-St. & 15,5 & 14,8 & 9,0 & - & 4,0 & 5,7 & \\
\hline 39 & Neugeb. & - & 18,0 & 18,0 & 11,0 & - & 4,0 & 6,0 & \\
\hline 40 & $"$ & - & 18,3 & 18,0 & 10,1 & 9,5 & 4,0 & - & \\
\hline 41 & & - & 18,5 & 18,0 & 10,5 & - & 3,5 & $6, \overline{0}$ & \\
\hline
\end{tabular}


Pathol--anat. Beiträge zur Kenntnis der angeborenen Colobome d. Auges. 337

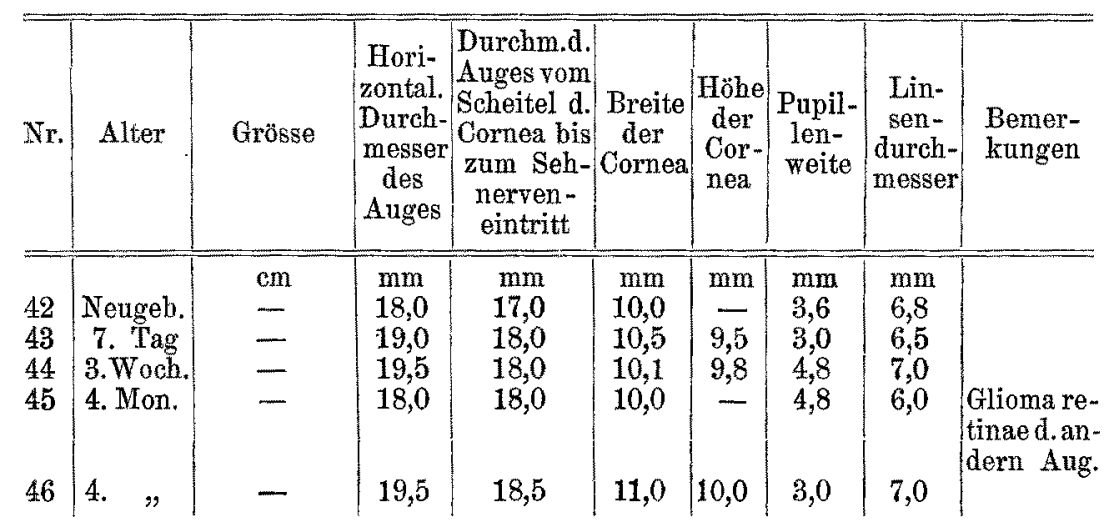

Anm.: Sch.-St. = Scheitel-Steisslänge. Sch.-S. = Scheitel-Sohlenlänge.

Aus der Tabelle geht, wie ich meine, in ganz unwiderleglicher Weise hervor, dass von der 6. Woche bis zum 8. Monate des fötalen Lebens kontinuierlich von Monat zu Monat eine Vergrösserung der Pupillenweite und eine etwas rascher vorwärtsschreitende Zunahmedes Linsendurchmessers stattfindet.

Wir finden bei einem etwa acht Wochen alten sehr gut konservierten Embryo eine Pupillenweite von $0,51 \mathrm{~mm}$, wogegen die durchschnittliche Pupillenweite einer Serie von Embryonen des dritten Monats bereits $0,99 \mathrm{~mm}$ beträgt. Eine ganz beträchtliche Zunahme erfährt sie aber im Laufe des vierten Monates (Durchschnittsmass 2,5 mm), erreicht im fünften Monat ein Durchschnittsmass von $3,75 \mathrm{~mm}$ und im sechsten Monat von $4,7 \mathrm{~mm}$. Die grösste $\mathrm{Pu}$ pillenweite zeigt ein Fötus des siebenten Monats mit $5,3 \mathrm{~mm}$.

Im achten Monat begegnen wir sehr erheblichen Schwankungen, welche auch schon makroskopisch in sehr auffälliger Weise in Erscheinung treten. So erhielt ich einmal gleichzeitig zwei Augenpaare von zwei gleichgrossen Föten des achten Monats. Das eine Augenpaar war in allen Dimensionen etwas kleiner als das andere. Dabei bestand cine ganz auffällige Differenz der Pupillenweiten von 4:5,2 mm.

Im neunten Monate erreicht die Pupille ungefähr die gleiche Weite wie beim Neugeborenen, doch kommen auch bei diesen noch ganz wesentliche Schwankungen vor (von 3,0 bis $4,5 \mathrm{~mm}$ ).

Wenn auch bei letzteren - wie ja auch bei Erwachsenen - gewiss individuelle Verhältnisse, z. B. auch Todesursache usw. eine Rolle spielen werden, so scheint mir doch der auffällige Umschlag im

จ. Graefe's Archiv für Ophthalmologie. LXVIII. 2. 
achten Monat nicht allein durch das Spiel des Zufalls ausreichend erklärt zu sein.

Was könnte aber die Ursache dieser piötzlichen Abnahme der Pupillenweite sein? Es wäre natürlich nicht angängig, ein plötzliches Verwachsen der Iris auf der Linse anzunehmen; stände doch ein so unverhältnismässig rasches Wachstum eines Teils der Augenanlage in einer so späten Entwicklungsperiode ohne Beispiel da.

Es liegt deshalb wohl nichts näher, als diesen Umschlag in der Pupillenweite mit einer um diese Zeit erstmalig einsetzenden Aktion des bis dahin anscheinend im Zustande der Untätigkeit verharrenden Sphinkters in Zusammenhang zu bringen, wodurch eine Entfaltung der bis dahin sehr schmalen Trisfläche und ein Engerwerden der Pupille erfolgen muss. Die Pupillenweite erlangt dadurch jenes Mass, das wir auch im späteren Leben als normal betrachten. Und es schien mir kein zufälliges Zusammentreffen zu sein, dass sich gerade zur selben Zeit die Rückbildung der Pupillarmembran vollzieht (O. Schultze), deren vollständiges Vorhandensein anscheinend jedem Pupillenspiel entgegenwirkt.

Durch die anatomische Untersuchung der beiden erwähnten Augenpaare ist mir diese schon vorher gehegte Vermutung fast zur Gewissheit geworden. In dem Augenpaare mit der engeren Pupille ist die Pupillarmembran bis auf rudimentäre Reste resorbiert, in dem mit der weiteren Pupille noch in ganzer Ausdehnung erhalten. Der Sphinkter des ersteren Augenpaares ist in Horizontalschnitten kurz und plump, der des andern Auges zeigt eine gestreckte und schlanke Form, welch letztere mehr dem Kontraktionszustande (Tonus) des Muskels entspricht.

Nach diesen Feststellungen haben wir selbstverständlich keine Veranlassung, etwas von unsern früheren Behauptungen zurückzunehmen.

Mit der Konstatierung dieser Tatsache müssen wir aber auch allen Theorien, welche die Entstehung der Iriscolobome auf Störungen in einem de facto wohl nie erfolgenden Verwachsen des Irisrandes auf der Linse zurückfübren wollen, endgültig ihre Berechtigung absprechen.

Diese fehlte schon von jeher all den Theorien, welche die Störung in dem Vorwachsen der Iris einer verspäteten Rückbildung der Gefässverbindungen zwischen Iris, Pupillarmembran und Tunica vasculosa zuschrieben, da diese Gefässverbindung normalerweise während des grössten Abschnittes der Entwicklungsperiode in unveränderter 
Pathol.-anat. Beiträge zur Kenntnis der angeborenen Colobome d. Anges. 339

Form nachweisbar ist und zu der Zeit, in welcher sie sich zurückbildet, unter keinen Umständen mehr zur Ursache für ein Iriscolobom werden kann.

Den gleichen Gedanken hat E. v. Hippel $(81,82)$ schon wiederholt ausgesprochen, später (112) allerdings etwas modifiziert.

An meinen Präparaten kann ich das Vorhandensein dieses gesamten Gefässsystems und zwar namentlich auch der um den $\mathrm{Pu}$ pillarrand herum nach hinten ziehenden Gefässe konstant bis in den siebenten Monat hinein nachweisen. Das Gleiche ist selbst noch bei einzelnen Föten des achten Monats der Fall, doch besitze ich auch Präparate von diesem Stadium, in welchen die Membrana capsularis und capsulo-pupillaris fast ganz zurückgebildet, dagegen die Membrana pupillaris noch vollständig erhalten ist. Die Rückbildung der letzteren vollzieht sich demnach offenbar unabhängig von dem übrigen Gefässsystem der Tunica vasculosa lentis. [Vgl. auch O. Schultze (80) und Wicherkiewicz, Arch. f. Ophth. Bd. XXXIV.]

Wenn ich demnach auch die von Bach (83) meines Wissens zuerst betonte frübzeitigere Rïckbildung der von der Tris nach hinten ziehenden Gefässe bestätigen kann, so kann ich doch nicht eine abnorme Persistenz dieses Gefässsystems als die mögliche geschweige denn regelmässige Ursache eines Triscoloboms gelten lassen, da durch die zu dieser Zeit weit vorgeschrittene Entwicklung der Iris die Entstehung eines Coloboms ausgeschlossen wird.

Wir müssen uns eben vor allem darüber klar sein, dass die Grundsteinlegung für ein Tris- und Aderhautcolobom zeitlich zusammenfällt, dass also die Entscheidung, ob ein Iriscolobom entsteht, bereits zur Zeit des Schliessungsprozesses der fötalen Augenspalte fallen muss.

Das Triscolobom ist ja doch nur der Ausdruck einer Störung im Verschlusse der fötalen Augenspalte am Becherrande und es ist die Folge des Ausfalls eines umschriebenen Gebietes der ersten Irisanlage.

Seine Grösse - ob inkomplettes oder totales Colobom - bängt von der Grösse des Abschnittes ab, der an der Vereinigung gehindert worden ist.

Seine mehr oder weniger spitz zulaufende Form, welche bekanntlich meist mit einer Birne verglichen wird, stimmt mit der Form des vordersten Abschnittes der Augenspalte überein, welche diese unmittel. bar vor dem Schlusse aufweist. [Vgl, meine Demonstrationen in Heidelberg (72), ferner die schönen Abbildungen A. v. Szilys (98).]

Die Tatsache, dass isolierte Iriscolobome ohne Beteiligung des 
Ciliarkörpers und der Aderhaut vorkommen, erfährt durch den Nachweis, dass sich der zur Bildung der Iris bestimmte Abschnitt der fötalen Augenspalte zuletzt ${ }^{1}$ ) schliesst, eine ausreichende Erklärung. Brückencolobome können, wie schon Manz(53) erwähnt, möglicherweise dadurch entstehen, dass es den Augenblasenrändern an einer Stelle gelingt, unter Umgehung des Hindernisses die Spalte zu überbrücken $\left.{ }^{2}\right)$. Dies scheint, wie leicht verständlich, meist an der schmalsten Stelle des Spaltes, in der Nähe des Ciliarkörpers stattzufinden.

Vorausgesetzt ist natürlich, dass das Pigmentepithel im Bereiche der Brücke vorhanden ist.

Als primäre Ursachen für das Ausbleiben des Verschlusses der Augenspalte am Augenbecherrande werden die gleichen Momente anzuschuldigen sein, welche wir als die Ursachen der Colobome überhaupt kennen gelernt haben, und es sind auch von verschiedenen Forschern [Salffiner (85), Hess, v. Hippel (112), Cosmettatos (113), de Vries (84)] gefässhaltige Stränge gefunden wurden, welche an der Stelle des Triscoloboms in den Bulbus eindrangen. Es liegt auf der Hand, dass ihr Effekt an dieser Stelle ein ähnlicher sein wird, wie im sonstigen Bereiche der fötalen Augenspalte.

Es handelt sich aber, wie nochmals betont sei, immer nur um die mechanische Behinderung der Anbildung einer Organanlage und nicht um die Behinderung des Vorwachsens eines angelegten Organs.

Eine wichtige Rolle als solche mechanische Hindernisse werden meines Erachtens auch die an dieser Stelle besonders mächtigen Gefässverbindungen spielen, welche von der Ringarterie durch die Becherspalte in das Auge eintreten.

Persistenz der Arteria hyaloidea und ihrer gliösen Hülle.

Endlich sei mir noch gestattet, kurz eine Veränderung zu besprechen, welche in zahlreichen, zumeist klinischen Abhandlungen geschildert worden ist und eine recht mannigfache, vielfach sicher nicht zutreffende Deutung erfahren hat.

Ich meine die von der Papille entspringenden und in der Richtung des hinteren Linsenpols verlaufenden ange-

1) Noch später schliesst sich die Augenspalte an der Grenze von Optikusstamm und Bulbus.

2) Das Gleiche gilt natürlich für die Brückencolobome der Aderhaut, deren Kasuistik jüngst von Herford (103) um einen schönen Fall bereichert worden ist. 
Pathol.-anat. Beiträge zur Kenntnis der angeborenen Colobome d. Auges. 341

borenen strang-, schlauch- oder zeltdachartigen Gebilde, welche die Papille manchmal ganz verdecken und zuerst als Persistenz des Cloquetschen Kanales bezeichnet wurden.

Ich kann von einer eingehenden klinischen Beschreibung dieser Veränderung ganz absehen und brauche in dieser Hinsicht nur auf die vor kurzem erschienene Arbeit von Reis(86) zu verweisen, in welcher auch die Literatur auf das sorgfältigste zusammengestellt und berücksichtigt ist. Von Interesse dürfte vielleicht die Mitteilung einer sehr seltenen Beobachtung sein, welche ich vor einigen Jahren an unserer Klinik gemeinsam mit mehreren Kollegen machen konnte, nämlich die eines vollständig erhaltenen blutfiuhrenden Gefässnetzes der Arteria hyaloidea und, wenn ich mich recht entsinne, auch der Vasa hyaloidea propria in dem Glaskörperraume eines erwachsenen Menschen. Leider habe ich mir damals über den hochinteressanten Fall, dessen eigenartiges Bild mir noch auf das lebhafteste vor Augen steht, keine genaueren Notizen gemacht, weshalb ich mich auf diese kurze Mitteilung beschränken muss.

Mir kommt es heute hauptsächlich darauf an, auf die anatomische Grundlage des die Hyaloidea schlauch- oder mantelartig umgebenden Gewebes einzugehen. Die bisherigen anatomischen Mitteilungen darüber sind spärlich genug:

Vassaux(109) hat einen Fall von persistierender Pupillarmembran und persistierender Arteria hyaloidea anatomisch untersucht und beschrieben, in welchem die Arteria hyaloidea in ihrem ganzen Verlaufe von der Papille bis zur Linse erhalten und von einer aus zwei Zellschichten und feinen wellig verlaufenden Fibrillen zusammengesetzten Scheide umgeben war. Zwischen der Arterie und Scheide bestand ein Zwischenraum, welcher von koagulierter Flüssigkeit und Leukocyten eingenommen war. Die Scheidenwand setzte sich entlang der Arterie bis in den Sehnerven hinein fort (zentraler Gliamantel Krückmann!); vorne ging sie in eine der hinteren Linsenfläche aufgelagerte und aus spindelförmigen in mehreren parallelen Reihen angeordneten Zellen gebildete Gewebsschicht über, welche mit Fasern in Verbindung stand, die von den Ciliarfortsätzen ausgingen.

Vassaux betrachtet die Umbüllung der Arteria hyaloidea als eine Lymphscheide; über ihren histologischen Charakter spricht er sich nicht weiter aus. Der Fall war wegen Verdachts auf Gliom zur Enucleation gelangt. -

Die nächste mir bekannte Mitteilung stammt von Hess (52): 
Um eine in dem Auge eines 3 Wochen alten Kindes yom Optikuseintritt zur hinteren Linsenfäche verlaufende sehr mächtige Arteria hyaloidea "legt sich ein Mantel eines ziemlich lockeren Gewebes an, das besonders charakterisiert ist durch den nicht unbeträchtlichen Gehalt an mittelgrossen kreisrunden, stark tingierten Kernen neben spärlichen spindelförmigen Elementen; der Mantel hat eine konische Gestalt, indem er nach vorne zu bis zur Mitte des Glaskörpers an Mächtigkeit abnimmt and hier bis auf einen ganz schmalen Saum verschwindet, unmittelbar nach vorn von dieser Stelle wird er wieder mächtiger, erscheint aber hier gebildet von grossen, gleichmässig langgestreckten Kernen mit fibrillärer Zwischensubstanz". "Aus diesem vorderen Teil des Mantels entwickelt sich nun nach vorn eine dicke Membran, die zunächst einen grösseren Teil der hinteren Linsenkapsel äberzieht, mit welcher sie in innigstem Zusammenhang steht."

Eine Fortsetzung dieses Stranges nach unten tritt durch die Lücke eines Iriscoloboms in die vordere Kammer und spaltet sich in zwei Schenkel, deren einer als gefässhaltige Membran auf die vordere Kapsel, und deren anderer am Fontanaschen Raum ganz kontinuierlich in Sklera und Chorioidea übergeht.

Über die histologischen Verhältnisse der Ansatzstelle dieses Mantels am Optikus, dessen Stärke er etwa gleichkam, habe ich keine genauen Angäben finden können.

Eine anscheinend ganz analoge mantelartige Umhüllung einer persistierenden Arteria hyaloidea in dem rechten Auge eines zehnmonatlichen Kindes beschreibt de Vries(84):

„Die Arteria hyaloidea, welche eine dentliche Wand mit längs- und querverlaufenden Kernen besitzt, ist überall von einem Mantel eingehüll, welcher der Arterie nur lose anliegt; dieser Mantel, aus Bindegewebe mit längsovalen Kernen bestehend, ist nur eine Zelle dick und erweitert sich trichterförmig an der Papille Nervi optici und gleichfalls, aber in geringerem Grade, an der Stelle, wo sie in den Bindegewebskegel eintritt. Sobald sie jedoch in den Kegel eingetreten ist, wird dieser Mantel viel dicker und begleitet die Arterie noch eine Strecke in den Kegel hinein" usw.

Schon vorher hat Salffner (85) in dem missgebildeten linken Auge eines zehn Monate alten Kindes einen von der Papille zur Linse verlaufenden Strang gefunden und beschrieben, der zum grössten Teil aus netzförmig angeordnetem feinstem Faserwerk besteht und in dessen obersten Teile die Hyaloidea verläuft.

Das Stranggewebe setzt sich in diesem Falle ebenfalls auf die hintere Linsenfläche fort, hüllt diese grossenteils ein und verbreitet sich schliesslich in der vorderen Kammer im Bereiche des Iriscoloboms. 
Pathol.-anat. Beiträge zur Kenntnis der angeborenen Colobome d. Auges. 343

Das Stranggewebe in Salffners Falle unterschied sich bei van Gieson-Färbung durch eine strohgelbe Farbe deutlich von dem mesodermalen Gewebe und wird auf Grund dieses Verhaltens von Salffner meines Erachtens mit vollem Rechte als gliöses Gewebe erklärt.

Um so verwunderlicher muss es erscheinen, dass de Vries, dem allerdings die Salffnersche Mitteilung entgangen zu sein scheint, trotzdem in seinem Falle diese Verhältnisse wesentlich einfacher liegen und auch, wie nach der Beschreibung angenommen werden muss, ganz richtig gesehen worden sind, von einem Bindegewebsmantel spricht und diesen als Lymphscheidenwand der Arterie anzusprechen geneigt ist.

Es unterliegt nämlich keinem Zweifel, dass der Mantel der Hyaloidea in dem Falle de Vries ebenfalls aus Glia besteht, also ektodermaler Herkunft ist, und zwar geht dies einerseits aus der sehr klaren Zeichnung, anderseits aus der Mitteilung von de Vries hervor, dass der Mantel im Niveau der Papille mit der Limitans interna retinae verschmilzt.

Über die Natur des Mantelgewebes in dem Falle von Hess erlaube ich mir kein Urteil auszusprechen, da über. seine Verbindung mit der Papille, welche ron ausschlaggebender Bedeutung ist, keine genauere Schilderung vorliegt. Die konische Form des Mantels spräche ja, wie ich noch ausführen werde, sehr für die gliöse Natur des Gewebes, wogegen sein direkter Übergang in das Mesoderm des vorderen Augenabschnittes auf eine mesodermale Herkunft schliessen lässt.

Die Entwicklung dieser gliösen Einscheidung der Arteria hyaloidea lässt sich aber auf eine viel einfachere Weise erklären, als es Salffner getan hat.

Ich behalte mir vor, diese Verhältnisse, über welche ich eingehende Studien angestellt habe, in einer Arbeit über die Entwicklung der Sehnerveneintrittsstelle ausführlich zu schildern und beschränke mich heute darauf, nur das zum Verständnisse der pathologischen Veränderungen Notwendige anzugeben.

Die Bildung eines Gliamantels um die Arteria hyaloidea ist, wie wir bereits durch die Mitteilungen Jakobys und Krückmanns wissen, ein physiologischer Vorgang.

Ich kann noch hinzufügen, dass sie sehr frühzeitig beginnt und dass die ersten Anfänge bereits nach Schluss der Optikusrinne nàchweisbar sind, sobald der Sehnerv in einen soliden Stiel umgewandelt worden ist. 
Der Mantel geht aus den Gliazellen des Sehnerven selbst hervor und entwickelt sich entlang dem Stamme der Arteria hyaloidea, welche er als eine lockere, aus zwei bis drei Zellagen und faserigem Gewebe bestehende Hïlle umgibt. Er ist stets von der Gefässwand deutlich abzugrenzen und regelmässig durch einen ganz schmalen Spaltraum davon getrennt.

Er sitzt auf der Papille mit breiter Basis auf, verjüngt sich nach vorne zu und ahmt dadurch die Form eines Kegels nach. An seiner Ursprungsstelle geht er unvermittelt in das gliöse Gewebe der Papille über; sein anderes Ende, welches normalerweise nie weiter als bis zur Mitte des Glaskörperraumes reicht, zeigt eine ganz geringfügige Verdickung und leichte Abrundung.

Mit der Arteria hyaloidea verschwindet auch der gliöse Mantel, bleiben aber von ersterer Reste bestehen, so sind sie gewöbnlich auch ron einem Gliamantel umgeben.

Wenn wir auf diesen einwandsfrei feststehenden Tatsachen weiterbauen, dann hält es nicht schwer, für eine ganze Reihe abnormer klinischer Befunde eine durchaus zuverlässige Erklärung zu finden.

So gut wir uns vorstellen können, dass die Arteria hyaloidea und ihr Gliamantel unter pathologischen Verhältnissen persistieren können, so leicht begreiflich ist es, dass die gliöse Hülle $\mathrm{zu}$ jeder Zeit anfangen kann, ihre physiologischen Wachstumsgrenzen zu überschreiten, bis zur hinteren Linsenfäche vorzudringen und diese selbst noch teilweise einzuhüllen. Dass sie dann bei längerem Bestehen ihre natürliche Zartheit verlieren und zu einem dichten Mantel werden könne, versteht sich bei der bedeutenden Wucherungsfähigkeit der Glia von selbst. Und es braucht nur zu einer Vergrösserung des Raumes zwischen Hyaloidea und Gliamantel zu kommen, um aus einem strangförmigen ein schlauchartiges Gebilde entstehen zu lassen. Reicht aber der Gliamantel nicht bis zur hinteren Linsenfläche, dann wird selbstverständlich das klinische Bild entsprechende Modifikationen erfahren, wir werden zeltdachähnliche oder blasenförmige Gebilde wahrnehmen, aus welchen, wie z. B. im Falle 2 von Reis, Äste der Hyaloidea hervorgehen können.

Es wird nicht immer möglich sein, klinisch eine sichere Entscheidung iiber die anatomische Grundlage dieser Veränderungen zu treffen. Ich möchte aber betonen, dass die schlauchartigen und verwandten Formen, welche mit breiter Basis von der $\mathrm{Pa}$ pille entspringen und diese ganz verdecken können, mit einer an Sicherheit grenzenden Wahrscheinlichkeit auch 
Pathol.-anat. Beiträge zur Kenntnis der angeborenen Colobome d. Auges. 345

schon klinisch als Abkömmlinge des die fötale Glaskörperschlagader umgebenden Gliage webes gedeutet werdenkönnen. Das bekannte weisslich glänzende und grünlich reflektierende Aussehen dieser Gebilde spricht ebenfalls mehr für eine gliöse Herkunft (Gliareflexe) derselben und pflegt mesodermalen Gewebssträngen nicht eigentïmlich zu sein.

Meine in den vorstehenden Ausfiihrungen ausgesprochenen Anschauungen fasse ich in folgenden Sätzen zusammen:

1. Die typischen Colobome und die mit ihnen auf das engste verwandten Colobome mit Cystenbildung entstehen infolge von Störungen des Verschlusses der fötalen Augenspalte durch abnorm lange persistierendes Mesoderm.

2. Bei der Zusammensetzung des den Schluss störenden Mesoderms dïrften die durch die Augenspalte ein- bzw. austretenden Gefässe mindestens eine gleich wichtige Rolle spielen wie das zellige (Bindegewebe bildende) Mesoderm.

3. Die Tatsache der Verhinderung des normalen Verschlusses findet einen besonders deutlichen Ausdruck in der Duplikaturenbildung der Netzhaut vor der mesodermalen Leiste, sowie auch an entfernteren Stellen.

4. Die abnormen Faltungen des Epithels der Pars plana corporis ciliaris, sowie die abnorme Grösse von Ciliarfortsätzen in Colobomaugen entstehen aus der gleichen Ursache wie die Faltungen der Netzhaut und sind mit diesen auf eine Stufe zu stellen.

5. Da eine Vereinigung der Netzhautfalten auch ohne Schwund des mesodermalen'Hindernisses jederzeit erfolgen kann, beweist das Fehlen eines Netzhautdefektes nichts gegen die angenommene Genese der Colobome.

6. Zur Entstehung eines klinisch als total imponierenden Coloboms ist das Vorhandensein einer kontinuierlichen Mesodermleiste wahrscheinlich nicht erforderlich. Es werden auch mehrere diskontinuierlich angeordnete Hindernisse den regelrechten Verschluss der Augenspalte in ganzer Ausdehnung stören können.

7. Die typischen Iriscolobome entstehen in gleicher Weise wie alle typischen Colobombildungen durch das Ausbleiben des Verschlusses der sekundären Augenblase und zwar ihres periphersten am Augenbecherrande gelegenen Abschnittes. 
8. Ein Vorwachsen des Augenblasenrandes auf der vorderen Linsenfläche findet in keiner Zeit des fötalen Lebens statt. Der Durchmesser der Pupille nimmt bis in den achten Monat hinein kontinuierlich zu. Die in dieser Zeit ziemlich regelmässig eintretende rasche Verkleinerung der Pupille ist wahrscheinlich auf eine nach Resorption der Pupillarmembran eintretende Aktion des Sphinkters zurückzuführen.

9. Die strangförmigen und schlauchartigen weisslich glänzenden und grünlich schillernden Gebilde, welche von der Papille in der Richtung nach dem hinteren Linsenpol verlaufen und die Arteria hyaloidea ganz oder teilweise mantelartig umgeben, werden meist als die Folge einer abnormen Persistenz der die fötale Glaskörperschlagader begleitenden Gliahülle anzusehen sein.

10. Für einen Teil der atypischen Colobome, welche nicht mit Spaltbildungen in Zusammenhang gebracht werden können, gibt die Theorie Elschnigs, dass jeder Teil der sekundären Augenblase im embryonalen Leben in abnormer Richtung sprossen könne, nach unserm Dafürhalten zurzeit die beste Erklärung.

11. Die primäre Ursache des gänzlichen Fehlens einer Papille, welches zuweilen in hochgradig missbildeten, sowie häufiger in den Augen von hirnlosen Missgeburten beobachtet worden ist, beruht in dem Ausbleiben einer Entwicklung der Sehnervenfasern, wodurch eine abnorme Annäherung und glatte Vereinigung der beiden Blätter der sekundären Augenblase an der Grenze von Bulbus- und Optikusanlage ermöglicht wird.

Einer angenehmen Pflicht entledige ich mich noch, indem ich meinem hochverehrten Lehrer, Herrn Geheimrat Sattler, auch an dieser Stelle für die liebenswürdige Überlassung des seltenen Materials und für das wohlwollende und fördernde Interesse an meinen Untersuchungen meinen wärmsten Dank ausspreche.

Nach Abschluss der vorliegenden Arbeit erschien eine Mitteilung A. v. Szilys (89) über ein atypisches, nicht mit der Fotalspalte zusammenhängendes Colobom bei einem vier Wochen alten menschlichen Embryo, welche zusammen mit dem gleichartigen Falle von van Duyse(88) geeignet ist, auf die Entstehung der atypischen Colobome des vorderen Augenabschnittes ein klares Licht zu werfen. 
Pathol.-anat. Beiträge zur Kenntnis der angeborenen Colobome d. Auges. 347

v. Szily fand in den beiden Augenanlagen dieser Embryos neben der typischen vor dem Verschlusse stehenden Augenspalte noch eine zweite nach unten und innen gerichtete Einkerbung des vorderen Augenblasen- bzw. Pupillarrandes, welche er auf eine daselbst nachweisbare Gefässverbindung zwischen dem Ringgefäss und den inneren Augengefässen zurückführt. Durch das Gefässchen ist nach der Ansicht A. v. Szilys das Verwachsen des vorderen Becherrandes an der betreffenden Stelle verhindert worden. Die Befunde A. von Szilys und van Duyses sind von grosser prinzipieller Bedeutung, da sie zeigen, dass an jeder Stelle des Augenblasenrandes Einkerbungen zu stande kommen können, deren Nichtbeseitigung wahrscheinlich Spaltbildungen von seiten der Iris und event. auch noch des Ciliarkörpers zur Folge haben kann. Ob die Einkerbung, wie v. Szily annimmt, durch die Gefässverbindung verursacht ist, oder ob sich das Gefäss erst sekundär im Bereiche der Einkerbung entwickelt hat, wird sich wohl nicht mit Sicherheit entscheiden lassen.

Im übrigen stimme ich mit den Schlussfolgerungen, welche A. v. Szily aus seinen Befunden zieht, vollständig überein und zwar ganz besonders auch mit der Bemerkung, dass sie zur Erklärung der makularen Colobome und verwandter Veränderungen nicht herangezogen werden können. Ich habe mich iuber diese Frage, sowie über die Rolle, welche das Mesoderm bei deren Zustandekommen spielen dürfte, an anderer ${ }^{1}$ ) Stelle eingehender ausgesprochen.

Eine erfreuliche Übereinstimmung zwischen A. v. Szily und mir besteht ferner in der Würdigung des Einflusses der durch die Becherspalte ziehenden Gefässe auf die Genese der typischen Colobome.

Die wichtige Tatsache, dass sich die Becherspalte zuerst in dem mittleren Augenabschnitt schliesst, und dass, was auch von Keil(100) nach Untersuchungen an Schweinsembryonen bestätigt wird, ibr Verschluss normaler Weise in einem kurzen Abschnitte des embryonalen Lebens an ihren beiden Enden durch einen gefässfübrenden Mesodermfortsatz gehindert ist, erfährt durch v. Szily eine neue gewichtige Stiitze.

1) In der vorausgehenden Arbeit über Cyklopie. 


\section{Literaturverzeichnis ${ }^{1}$.}

1) Elschnig, Das Colobom am Sehnerveneintritt und der Conus nach unten. Arch. f. Ophth. Bd. LI. 1900.

2) - Weitere Mitteilung über das Colobom am Sehnerveneintritt und den Conus nach unten. Arch. f. Ophth. Bd. LVI. 1903.

3) Ginsberg, Beitrag zur Kenntnis der Mikrophthalmie mit Cystenbildung. Arch. f. Ophth. Bd. XLYI. 1897.

4) v. Hippel, Anatomische Untersuchungen über angeborene Katarakt, zugleich ein Beitrag zur Kenntnis einer newen Missbildung dex Linse. Arch. f. Ophth. Bd. LX. 1905 .

5) Krückmann, Über die Pigmentierung und Wucherung der Netzhantneuroglia. Arch. f. Ophth. Bd. LX. 1905.

6) - Ophthalmoskopisches und Klinisches über die Neuroglia des Augenhintergrundes. 32. Heidelberger Ber. 1905.

7) Levinsohn, Kurzer Beitrag zur Histologie angeborener Augenanomalien. Arch. f. Ophth. Bd. LVII. 1908.

8) Hess, Pathologisoh-anatomische Studien uber einige seltene angeborene Missbildungen des Auges. (Lenticonus posterior usw.) Arch. f. Ophth. Bd. XLTI. 1896.

9) Bach, Pathologisch-anatomische Studien über verschiedene Missbildungen des Auges. Arch. f. Ophth. Bd. XLV. 1898.

10) Rindfleisch, Beitrag zur Entstehungsgeschichte der angeborenen Missbildungen des Auges. Areh. f. Ophth. Bd. XXXVII, 3. 1892.

11) E. v. Hippel, Embryologische Untersuchungen über die Entstehungsweise der typischen angeborenen Spaltbildungen. Arch. f. Ophth. Bd. LV. 1903.

12) - Embryologische Untersuchungen über die Entstehung usw. 30. Heidelberger Ber: 1902.

13) Mannhardt, Weitere Untersuchungen über das Coloboma sclero-chorioideae. Arch. f. Ophth. Bd. LX. 1905,

14) Parse, Anatomischer Befund bei einem Colobom der Iris und Chorioidea. Arch. f. Ophth. Bd. XXIV, 2. 1878.

15) Ginsberg, Utber embryonale Keimverlagerung in Retina und Zentralnervensystem. Arch. f. Ophth. Bd. XLVIII. 1899.

16) - Uber die epithelialen Gliomeinschlusse und diesen ahnliche Gebilde in missbildeten Augen. Zeitschr. f. Augenheilk. Bd. V. 1901.

17) Pichler, Zur Pathologie und Pathogenese des Mikrophthalmus. Zeitschr. f. Augenheilk. Bd. III. Erg.-Heft. 1900.

18) Körber, Über Glioma und Pseudoglioma retinae. Zeitschr. f. Augenheilk. Bd. VIII. 1902.

19) Welhrli, Über der Makro- und Mikrogyrie analoge Entwicklungsstörungen der Retina; mit Besprechung der Epithelrosetten und der Pathogenese des Glioms. Areh. f. Ophth. Bd. LX. 1905.

20) E. v. Hippel, Uber das normale Auge des Neugeborenen. Arch: f. Ophth. Bd. XLV, 2. 1898.

21) Chievitz, Über die Area und Fovea centralis. Arch. f. Anat. u. Entwicklungsgesch, 1890.

22) Gilbert, Beiträge zur Kenntnis der pathologischen Anatomie der angebor. Colobome des Augapfels mit besonderer Berücksichtigung des Sehnerven. Arch. f. Ophth. Bd. LXV. 1907.

23) Parsons, Pathology of the Eye. Vol. III.

24) Jakoby, Über die Neuroglia des Sehnerven. Klin. Monatsbl. f. Augenheilk. 43. Jahre. 1905.

25) Bock, Die angeborenen Colobome des Augapfels. Wien 1893.

1) Es ist nur die in Texte citierte Literatur angeführt worden. Vollständige Literaturzusammenstellungen finden sich in den Werken von $\vee$. Hippel, van Duyse und Parsons: Über die Missbildungen des Auges. 
Pathol.-anat. Beiträge zur Kenntnis der angeborenen Colobome d. Auges. 349

26) Elschnig u, Lauber, Über die sogenannten Klumpenzellen der Iris. Arch. f. Ophth. Bd. LXV. 1907.

27) E. v. Hippel, Ist das Zusammenvorkommen ron Gliom und Mikrophthalmus congenitus im gleichen Auge sicher erwiesen. Arch. f. Ophth. Bd. LXI. 1906.

28) Kundrat, Über die angeborenen Cysten im unteren Augenlide usw. Wien. med. Presse Nr. 51. 1886.

29) Natanson, Mikrophthalmie und Bulbuscysten. 31. Heidelberger Bericht 1903.

30) Charles May u. Ward A. Holden, Ein Fall von MikrophthaImus mit Oberlidcyste. Arch. f. Augenheilk. Bd. LVIII.

31) Dor, Revue générale d'opht. 1882, cit. bei Rindfle isch (10).

32) Helfreich, Beitrag zur Lehre vom Glioma retinae. Arch. f. Ophth. Bd. XXI. 1875.

33) Schnaudigl, Die kavernöse Sehnervenentartung. Arch. f. Ophth. Bd. LIX. 1904.

34) Deutschmann, Zur pathologischen Anatomie des hämorrhagischen Glaukoms. Arch. f. Ophth. Bd. XXV, 3, 1879.

35) van Duyse, Aplasie du nerf optique et colobomes maculaires dans un oeil de Cyelope. Arch. d'opht. XIX. 1899.

36) - Pathogénie de la Cyclopie. Arch. d'opht. XVIII. 1898.

37) Doetseh, Anatomische Untersuchung eines Falles von Mikrophthalmus congenitus bilateralis. Arch. f. Ophth. Bd. XLVIII. 1899.

38) Manz, Das Auge der hirnlosen Missgeburten. Virchows Arch. Bd. LI.

39) Rosenbaum, Beiträge zur Aplasie des Nervus opticus. Zeitschr. f. Augenheillk. Bd. VII. 1907.

40) Sachsalber, Über das Auge der Anen- und Hemicephalen. Zeitschr. f. Augenheilk, Bd. IX. 1903.

41) van Duyse, Encyclopédie française d'ophtalmologie. Embryologie - Tératologie. 1905 .

42) v. Hippe1, Weitere Beiträge zur Kenntnis seltener Missbildungen. Arch. f. Ophth. Bd. LXIII.

43) Hanke, Zwei seltene Missbildungen des Bulbus. Arch.f. Ophth. Bd. LVII.

44) H. Fuchs, Zur Entwicklungsgeschichte des Wirbeltierauges. I. Über die Entwickling der Augengefässe des Kaninchens. Anat. Hefte. MerkelBonnet. Bd. XXVIIL. 1905.

45) $\mathrm{Ba}$ ch, Weitere Beiträge zur Kenntnis der angeborenen Anomalien des Auges mit besonderer Berücksichtigung der Genese der Korektopie. Zeitschr. f. Augenheilk. Bd. VI. 1901.

46) Salffner, Angeborene Anomalien der Cornea und Sklera, sowie andere Missbildungen zweier Pferdebulbi. Arch. f. Augenheilk. Bd. XLV. 1902.

47) Hess, Öber fötale Rupturen der hinteren Linsenkapsel und über Lenticonus posterior. Zeitschr. f., Augenheilk. Bd. I. 1899.

48) Kitamura, Über Mikrophthalmus congenitus und Lidbulbuscysten nach Untersuchungen am Schweinsauge. Klin. Monatsbl. f. Augenheilk. Beilageheft. 44. Jahrg, 1906.

49) Cruise, Transact. of the Ophthalm. Soc. of the United Kingdom. Bd. XXV. 1905.

50) Treacher-Collins, Transact. of the Ophth. Soc. etc. Bd. XIII. 1893.

51) Hess, Über angeborene Bulbusunterlideysten und ihre Entstehung. Arch. f. Augenheilk. Bd. XLI. 1900.

52) - Zur Pathogenese des Mikrophthalmus. Arch. f. Ophth. Bब. XXXIV, 3. 1888.

53) Manz, Die Missbildungen des menschlichen Auges. Graefe-Saemisch, Handb. d. ges. Augenheilk. I. Aufl. 1874.

54) Becker, Mikrophthalmus und Orbitopalpebralcyste. Arch. f. Angenheilk. Bd. XXVIII.

55) - Ein Fall von Mikrophthalmus congenitus bilateralis, nebst einigen Bemerkungen über die vermutliche Ätiologie und Entwicklungsgeschichte derselben. Arch. f. Ophth. Bd. XXXIV, 3. 1888. 
56) Leber u. Addario, Angeborene Panophthalmitis mit Bacillenbefund bei einer Ziege nebst Bemerkungen usw. Arch. f. Ophth. Bd. XLVIII. 1899.

57) E. v. Hippel, Über experimentelle Erzengung von angeborenem Star bei Kaninchen usw. Arch. f. Ophth. Bd. LXV. 1905.

58) Hoppe. Partielles Oberlideolobom bei einem missbildeten Fotus. Arch. $f$. Ophth. Bd. XXXIX, 3. 1893.

59) yan Duyse, Bride dermoide oculo-palpébrale et colobome partiel de la paupière avec remarques sur la genèse de ces anomalies. Ref.

60) Bernheimer, Angeborenes totales Hornhautstaphylom mit Dermoidbildung. Arch. f. Augenheilk. Bd. XVIII.

61) Wiegels, Mikrophthalmus congenitus mit Fett im Glaskörper. Arch. f. Ophth. Bd. L. 1900.

62) Lange, Zur Anatomie und Pathogenese des Mikrophthalmus congenitus unilateralis. Arch. f. Ophth. Bd. XLIV. 1897.

b3) Hess, Beiträge zur Kenntnis der pathologischen Anatomie der angeborenen Missbildungen des Anges. Arch. f. Ophth. Bd. XXXVIII, 3. 1892.

64) Haab, Beiträge zu den angeborenen Fehlern des Auges. Arch. f. Ophth. Bd. XXIV, 1. 1878 .

65) Seefelder u. Wolfrum, Zur Entwicklung der vorderen Kammer und des Kammerwinkels beim Menschen nebst Bemerkungen über ihre Entstehung bei Tieren, Arch. f. Ophth. Bd. LXIII. 1906.

66) Mannhardt, Das Colobom der Aderhaut und seine Folgen. Arch. f. Ophth. Bd. XLIII. 1897.

67) Falchi, Über die Histogenese der Retina und des Nervus opticus. Arch. f. Ophth. Bd. XXXIV. 1888.

68) Rogman, Kyste orbitaire et mikrophthalmie. Annal. d'ocul. Tom. CXXXI. 1904.

69) Bednarski, Über die von dem fơtalen Bulbus ausgehenden Cysten des Unterlids und der Augenhöhle. Ref. Zeitschr. f. Augenheilk. Okt. 1906. St. 369 .

70) van Duyse, Pathogénie des kystes colobomateux rétro-palpébraux. Arch. d'opht. Bd. XX. 1900.

71) Treacher-Collins, Transact. of the Ophthalm, etc. Bd. XVII. (Cit. bei Parsons.)

72) Seefelder, Demonstration von mikroskopischen Präparaten embryonalex menschlicher Augen. 34. Heidelberger Ber. 1907.

73) Görlitz, Anatomische Untersuchung eines sogenannten Coloboma nervi optici. Arch. f. Augenheilk. Bd. XXXV.

74) van Duyse, Contribution à l'étude des colobomes de l'oeil. Arch. d'opht. Bd. XVI.

75) Fleischer, Über Mikrophthalmus. 33. Heidelberger Ber. 1906.

76) Rabl, Über den Bau und die Entwicklung der Linse. III. Teil. Die Linse der Säugetiere usw. Zeitschr. f. wissenseh. Zoologie. Bd. XLVIII.

77) Wolfrum, Zur Entwicklung und normalen Struktur des Glaskorpers, Arch. f. Ophth. Bd. LXV. 1907.

78) Brückner, Über Persistenz von Resten der Tunica vasculosa lentis. Arch. f. Angenheilk. Bd. LVI. Erg.-Heft.

79) Nussbaum, Die Entwicklungsgeschichte des menschlichen Auges. GraefeSaem isch, Handb. d. ges. Augenheilk. II. Aufl.

80) Schultze, Zur Entwicklungsgeschichte des Gefässsystems im Săugetierauge. Leipzig 1892.

81) E. v. Hippel, Die Missbildungen und angeborenen Fehler des Auges. Graefe-Saemisch, Handb. d. ges, Augenheilk. II. Aufl. 1900.

82) - Anatomische Untersuchung über angeborene Korektopie mit LinsenIuxation. Arch. f. Ophth. Bd. Li. 1900.

83) Bach, Weitere Beiträge zur Kenntnis der angeborenen Anomalien des Auges mit besonderer Berücksichtigung der Genese der Korektopie. Zeitschr. f. Augenheilk. Bd. VI. 1901.

84) de Vries, Uber eine Missbildung des menschlichen Auges. (Colob. iridis, 
Pathol.-anat. Beiträge zur Kenntnis der angeborenen Colobome d. Auges. 351

Katarakt, Stränge und Gefässe im Glaskörper.) Arch. f. Ophth. Bd. LVII. 1904.

85) Salffner, Bulbus septatus. Arch.f. Ophth. Bd. LIV. 1902.

86) Reis, Beiträge zur Kenntnis der angeborenen Bindegewebsbildungen im Glaskörper. Klin. Monatsbl. f. Augenheilk. Bd. XLI. 1903.

87) Schmidt-Rimpler, Zu weiterer Kenntnis einiger:Missbildungen des Auges. Arch. f. Ophth. Bd. XXIII. 1877.

88) ran Duyse, La double fente foetale et la colobome atypique de l'oeil. Arch. d'opht. Bd. XXI. 1901.

89) A. v. Szily, Ein nach unten und innen gerichtetes, nicht mit der Fötalspalte zusammenhängendes Colobom der beiden Augenbecher bei einem etwa 4 Wochen alten menschlichen Embryo. Klin. Monatsbl. f. Augenheilk. Beilageheft 1908. 45. Jahrg.

90) Heine, Klinisches und Anatomisches über eine bisher unbekannte Missbildung des Auges. Angeborene Cystenretina. Arch. f. Ophth. Bd. LVIII. 1905.

91) Matys, Eine Missbildung des menschlichen Anges durch ein amniotisches Band. Żeitschr. f. Augenheilk. Bd. XIII. 1905.

92) Bernheimer, Ein Beitrag zur Kenntnis der Missbildungen des Auges. Arch. f. Augenheilk. Bd. XXVIII. 1894.

93) Vossiu s, Ein Fall von Mikrophthalmus congenitus. 25. Heidelberger Ber, 1896.

94) v. Hippel, Pathologisch-anatomische Befunde am Auge des Neugeborenen. Arch. f. Ophth. Bd. XLV. 1898.

95) Hoeltzke, Mikrophthalmus und Colobom von einem Kaninchen. Arch. f. Augenheilk. Bd. XII. 1883.

96) May ou, Mikrophthalmus. Ref. Jahresber. f. Ophth. 1904.

97) - The condition of the retina and optic nerve in anencephaly. Ref. Jahresber. f, Ophth. 1904.

98) Golovine, Cambios de los ojos observados en la anencefalia. Ref. Jahresber. f. Ophth. 1904.

99) Marchand, Missbildungen. Realencykl, von Eulenburg. 1898.

100) Keil, Beitrag zur Entwicklung des Auges rom Schwein mit besonderer Berücksichtigung der fötalen Augenspalte. Anat. Hefte. Bd. XXXII. 1906.

101) Keibel, Die Entwicklungsgeschichte des Wirbeltierauges. Klin. Monatsbl. f. Augenheilk. Bd. XLIV. 1906.

102) G. Stanculeano et $V$. Costin, Deux observations de colobome des paupières. Annal. d'ocul. Tom. CXXXI. 1904.

103) Herford, Ein Brückencolobom der Regenbogen- und Aderhaut. Zeitschr. f. Augenheilk. Bd. IX. 1903.

104) Natanson, Ubber Mikrophthalmus und Anophthalmus congenitus mit serösen Orbitopalpebralcysten. Arch. f. Ophth. Bd. LXXVII. 1908.

105) Brière, Absence des papilles, cecité. Annal. d'ocul. Tom. LXXVIII. 1877.

106) Hertel, Experimentelles über die Verengerung der Pupille auf Lichtreize. 33. Heidelberger Ber. 1906.

107) - Experimenteller Beitrag zur Kenntnis der Pupillenverengerung auf Lichtreize. Arch. f. Ophth. Bd. LXV. 1906.

108) Salzmann, Zur Anatomie der angeborenen Sichel nach innen unten. Arch. f. Ophth. Bd. XXXIX. 1898.

109) Vassaux, Persistance de l'artère hyaloidienne et de la membrane pupillaire, ayant déterminé des altérations intra-oculaires, simulant cliniquement un néoplasme. Arch. d'opht. III. 1883.

110) George Coats, The Pathology of coloboma of the Nerve Entrance. The Royal London ophthalmic hosp. reports. Januar 1908.

111) Best, Demonstration yon Präparaten von Mikrophthalmus. Versammlung deutscher Naturf. u. Ärzte. Dresden 1907.

112) v. Hüppel, Über Mikrophthalmus congenitus, Colobom; "Rosetten" der Netzhaut, Aniridin und Korektopie. Zi eglers Beiträge zur pathol. Anat. u. allgem. Pathol. 7. Suppl. Festschr. f. Arnold. 1905.

113) Gosmettatos, Trois cas de microphthalmie. Ann. d'ocul. Tom. CXXXIX. 1908. 


\section{Erklärung der Abbildungen - Mikrophotogramme - auf Taf. XVI-XVII, Fig. 1-}

Fig. 1 (Zeiss, Proj. Okular, Obj. AA.) zeigt dje Verhältnisse des atypischen Coloboms an seiner breitesten Stelle.

Die Verdichtung und das Ausbiegen der Sklerallamellen nach aussen am Colobomrande ist deutlich erkennbar. Die dunklen Stellen entsprechen den Blutpigmentschollen. Die Netzhaut kleidet in stark degeneriertem Zustande den Skleraldefekt aus und dringt eine Strecke weit in die Skleralcyste hinein. Die Grenze des Pigmentepitheldefektes ist rechts sichtbar. Links reicht sie uber den abgebildeten Bezirk hinaus. Die feine Punktierung innerhalb des skleralen Defektes ist durch Farbstoffniederschläge verursacht.

Fig. 2 (Z eiss-Planar 1,45) ist nach einem van Gies on-Hämalaunpräparat aufgenommen worden. Die hellen - im Präparate gelb gefarbten - Gewebspartien sind ektodermaler Herkunft (Netzhaut), die dunklen - rot gefärbten Gewebspartien - sind mesodermaler Abstammung.

Der Schnitt liegt etwas nasal und zeigt vor allem die unterhalb und nasal von der Papille gelegene Ausstïlpung des Ektoderms (Netzbaut) in die Sklera und dessen Vermengung mit mesodermalem Gewebe, Die Fortsetzung dieses Gemenges in die untere Papillenhalfte hinein tritt dentlich zutage. Eine Lamina cribrosa und eine normale Papillenbildung findet sich nur in der oberen. Sehnervenhälfte. Die vorhandene Lamina cribrosa und das Septengewebe des Sehnerven sind stark verbreitert. Man beachte aber den grossen Unterschied zwischen oberer und unterer Sehnervenhalfte. Der Scheidenraum ist nur oben nachweisbar. -

Fig. 3 (gleiche Vergrösserung) lässt die Verhältnisse im Bereiche des peripheren Sehnervenendes noch besser erkennen. Der Optikusstamm verhält sich im wesentlichen gleich. Die Zentralarterie ist in ziemilicher Ausdehnung getroffen. Sie verläuft nach oben und bildet die Grenze zwischen dem normalen oberen Sehnervenabschnitt und dem Colobomgewebe an der Stelle der unteren Sehnervenhälfte, mit dem sie durch eine ziemlich breite Brücke verbunden ist. Der mesodermale Balken, mit dem sie verbunden ist, ragt in andern Schnitten zapfenförmig gegen den Glaskörper vor. Die Ansdehnung des Colobomgewebes nach hinten wird deutlich veranschaulicht.

Oben sehen wir ein sogenanntes Colobom am Sehnerveneintritt abgebildet im Gegensatz zu dem wirklichen Colobom in der unteren Sehnervenhälfte. Wir finden hier einen flachen Defekt der inneren Skleralschichten, totales Fehlen der Aderhaut und des Pigmentepithels, Faltung der Netzhaut an der Colobomgrenze, gliöse Verwachsung der Falten nit Cystenbildung usw.

Fig. 4 - gleiche Vergrösserung - stellt ein Übersichtsbild des hinteren Augenabschnittes von Fall IV dar,

Das Präparat war nach Heidenhain - van Gieson gefärbt, der Unterschied zwisehen Glia und Mesoderm kommt deshalb in der Photographie leider nicht so deutlich zum Ausdruck wie in Fig. 2 u. 3.

Das Augeninnere ist, soweit es in dem Präparate vorhanden ist, mit Ausnahme des von dem Skleralzapfen $(Z)$ zur hinteren Fläche des Linsenrudiments (l) verlaufenden und von Gefässen und feinen Fibrillen eingenommenen Raumes, welcher dem Reste des ehemaligen Glaskörpers $(c . v$.$) entspricht, von gewucherter$ Glia $(g l)$ ausgefüllt. In benachbarten Schnitten wird der hier vorhandene Glaskörperrest ganz von dem mit der hinteren Linsenflache verwachsenen Strange eingenommen.

Die dunklen Stellen $(e)$ entsprechen eystischen, von Fibrin, Blutliörperchen und Blutfarbstoff ausgefüllten Hohlräumen. Die sehr verdickte Sklera ist auf der rechten Seite von GliainseIn $(g l, i$ ) durchsetzt. 
Pathol.-anat. Beiträge zur Kenntnis der angeborenen Colobome d. Auges. 353

Im hintersten Abschnitt des Präparates ist der Sehnerv (o.) getroffen.

In den benachbarten Schnitten nimmt die Masse der die Sklera durchsetzenden Glia erheblich zu und überwiegt streckenweise sogar über das Mesoderm. Der Sehnitt warde gewählt, weil er von allem Wesentlichen wenigstens etwas enthält.

In Fig. 5 ist ein Abschnitt der orbitalen Glia und ihrer mesodermalen Hülle bei gleicher Vergrösserung dargestellt. Schon diese gestattet eine Vorstellung von der enormen Verdickung der Gefässwände und der hochgradigen Verengerung der Gefässlumina, welche in dem Gefässe, das die Mitte des Bildes einnimmt, zu einer vollständigen Obliteration geführt hat.

Die beiden Veränderungen erreichen bei den Gefässen der Glia innerhalb des Auges bei weitem nicht einen so hohen Grad.

Fig. 6 (Z eiss, Proj. Okular, Obj. AA) zeigt die Gefässe in dem obersten mittleren Abschnitte der Fig. 5 mit ihrer nächsten Umgebung bei stärkerer Vergrösserung.

In Fig. 7 (Zeiss, Proj. Okular, Obj. DD) sind bei noch stärkerer Vergrösserung die Anordnung und Struktur des Gliagewebes, sowie namentlich die Beziehungen desselben zu den sowohl in Längs- als Querschnitten getroffenen Gefässen dargestellt. 
v. Graefe's Archiv. Bd. LXVIII.

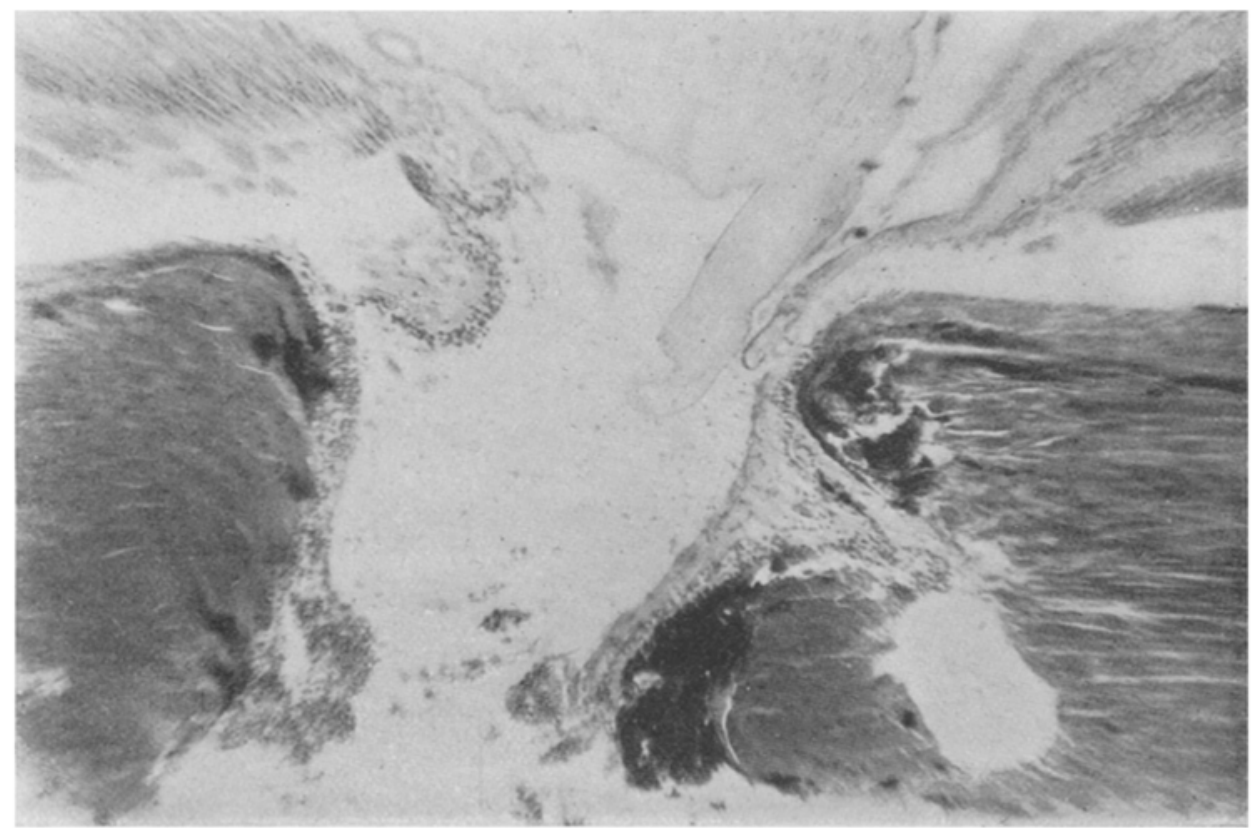

Fig. 1.

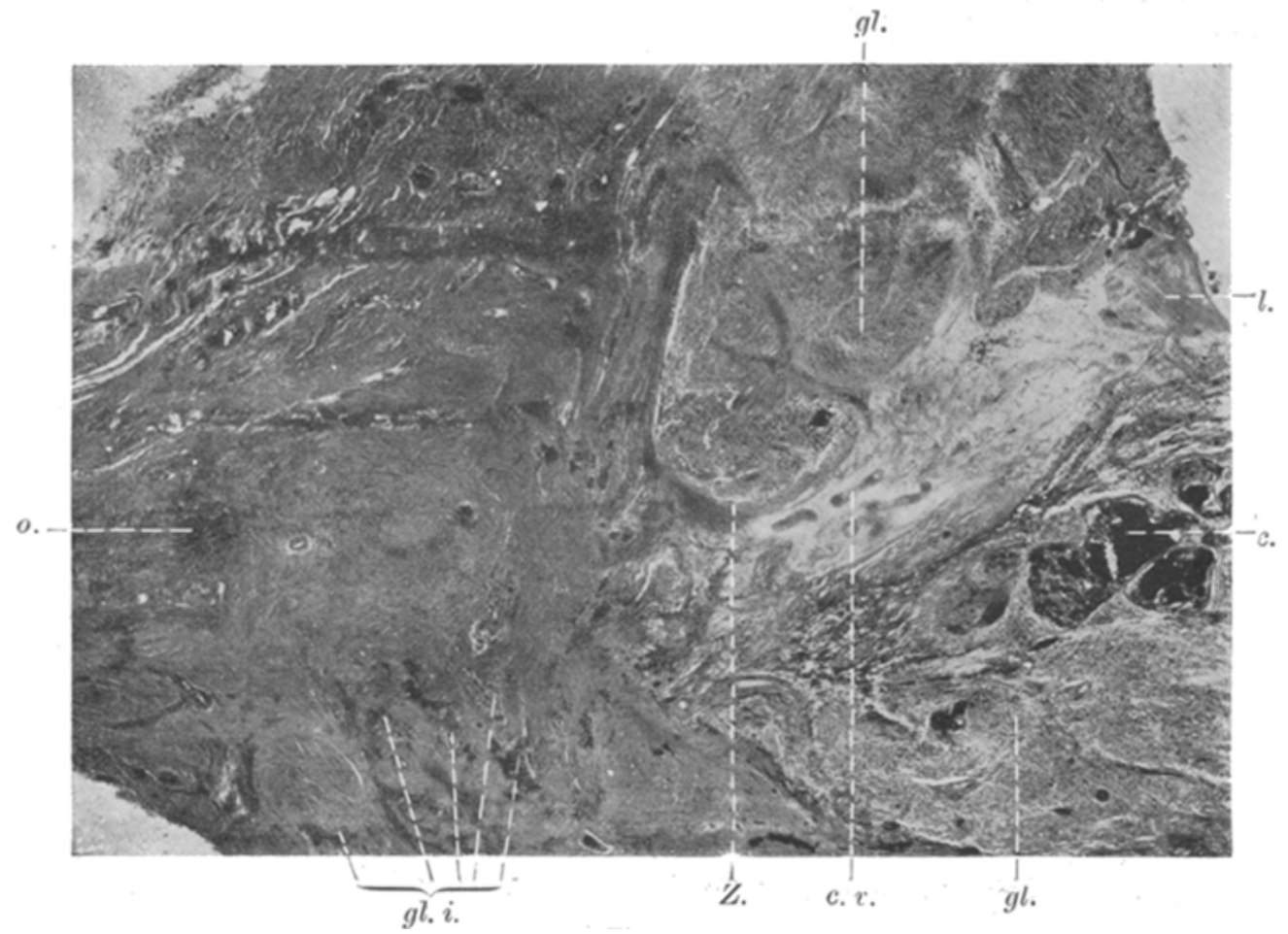

Fig. 4. 


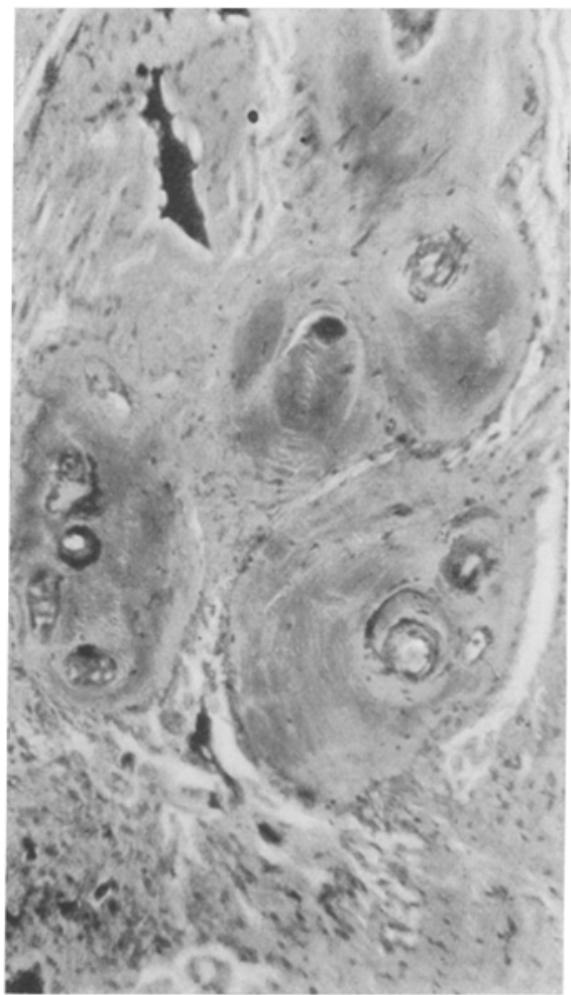

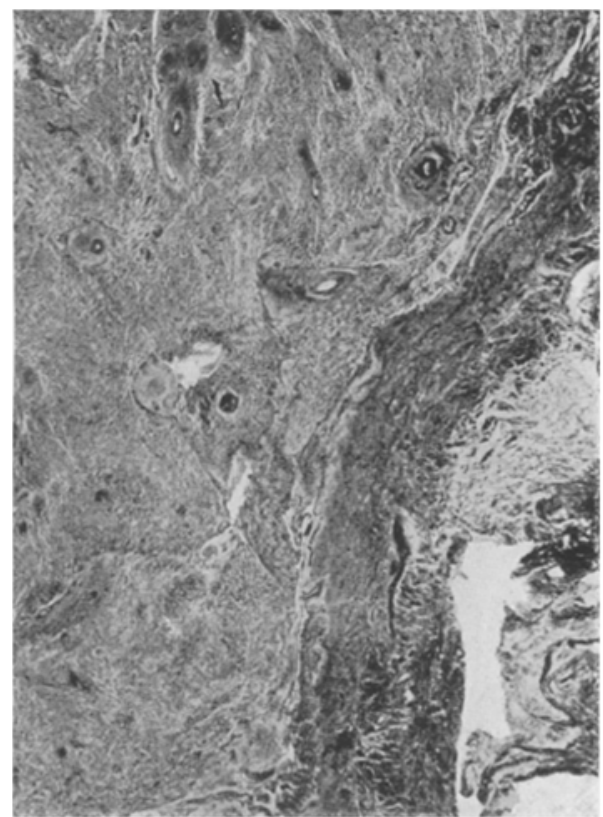

Fig. 5.

Fig. 6.

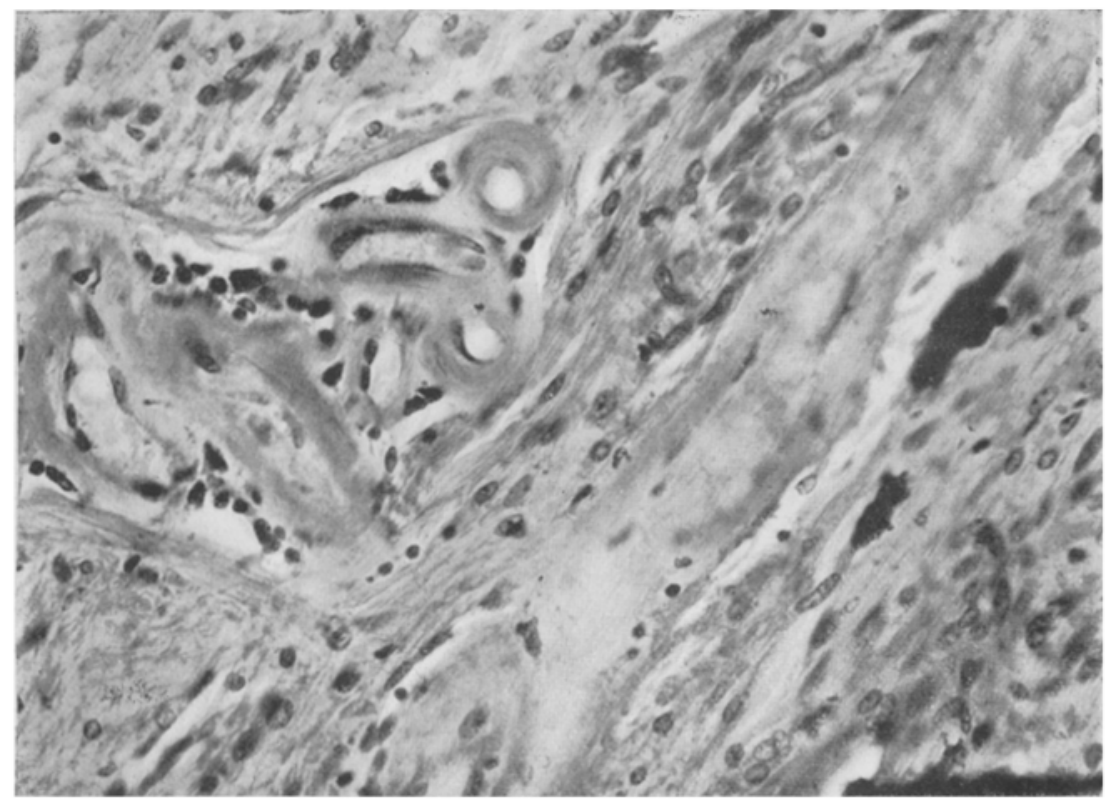

Fig. 7. 
5
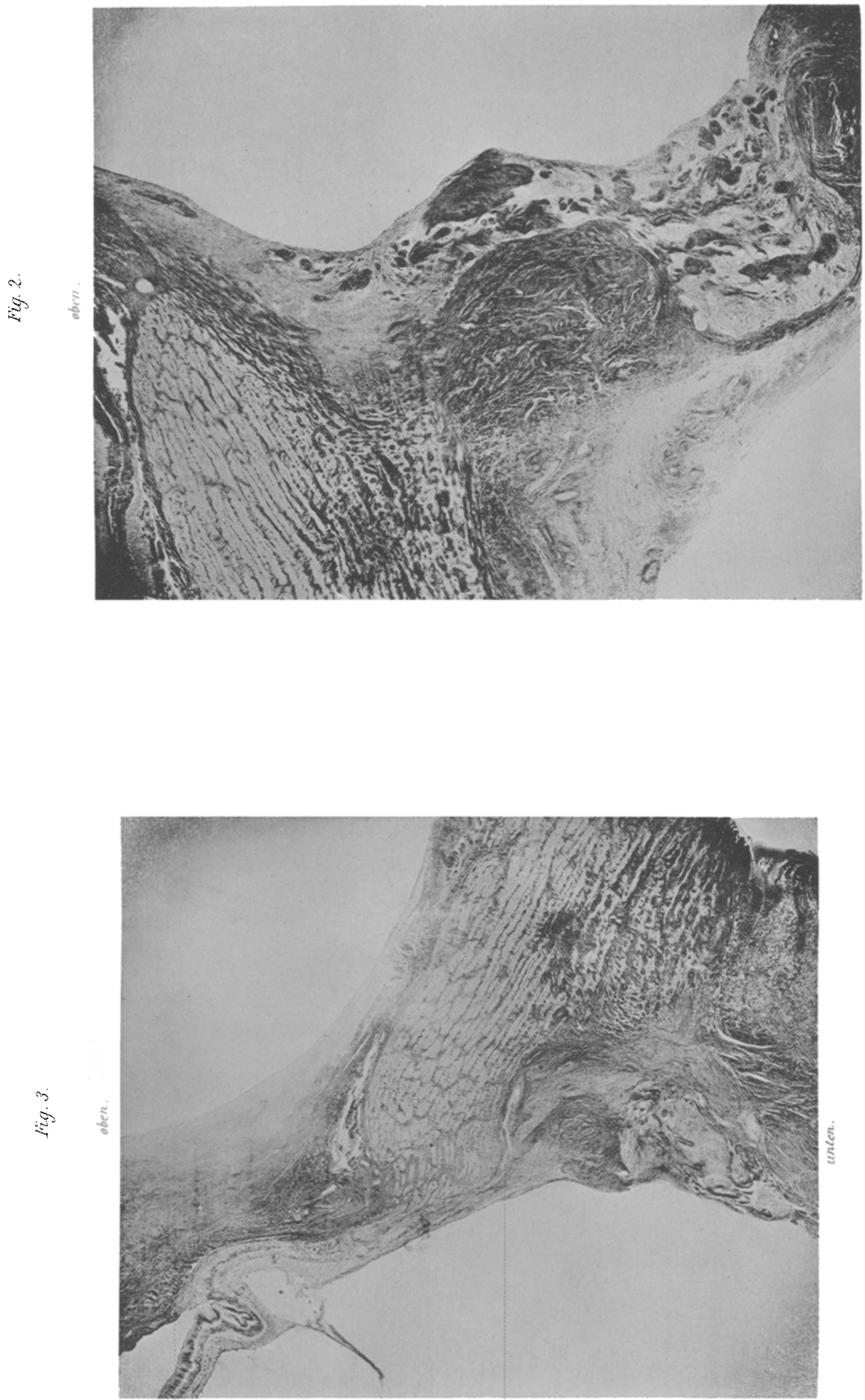